\title{
Metallacyclic Assembly of Interlocked Superstructures
}

Sheng-Li Huang, ${ }^{a}$ T. S. Andy. Hor, ${ }^{b}$ Guo-Xin Jin ${ }^{a^{*}}$ 


\begin{abstract}
:
Interlocked molecules are a type of supramolecules whose sub-components are held together not by covalent bonds but non-covalent interactions. Examples include rotaxanes, catenanes, Solomon links, ring-in-ring complexes, molecular Borromean rings, molecular knots and interlocked cages. The design and manufacture of these architectures is mainly based on self-assembly and templatedirected methodologies. Inspired by the successful utilization of coordination-driven assembly in metallasupramolecular systems, the metallacyclic assembly of interlocked superstructures is developing rapidly and as such makes a fascinating topic for reviewing. In this review we will focus on the metal-directed synthesis of the different types of interlocked superstructures, as well as their functional applications.
\end{abstract}

\title{
Keywords:
}

Interlocked

Metallasupramolecules

Coordination-driven assembly

Supramolecular chemistry 


\section{Introduction}

Interlocked structures, also referred to interpenetrating frameworks, are molecules that are connected as a consequence of their topology, in keeping with Aristotle's maxim that 'Nature abhors a vacuum' [1-8]. Although the interpenetration of polymeric structures is common in the crystalline state [6-8], interlocked superstructures still remain a synthetic challenge to chemists. Such topologically non-trivial structures form despite the absence of chemical bonds between the interpenetrated sub-frameworks, and cannot be separated without breaking the loop. These molecular architectures have been attracting continued attention due to their unique architectures and potential application in the development of molecular devices [9-11].

What interlocked superstructures have in common is that they contain macrocyclic components. Unfortunately, due to the thermodynamically favourable but kinetically unfavourable nature of macrocyclization processes, the formation of closed structures is often hindered by formation of polymeric side-products [12-14]. There is an intricate balance between discrete and polymeric products that is determined by the kinetic stability of the last cyclization step. Commonly, the use of non-reversible covalent bonding (ca. 60-120 kcal/mol) leads to kinetically controlled cyclization processes and results in equilibrium mixtures with low yields of the oligomers. To circumvent this problem, reversible forms of bonding (e.g. hydrogen bonds [15-17], dynamic covalent bonds [1823] and coordination bonds [24-30]) in the final ring-closing step are utilised, and therefore the product distribution will be dominated by the thermodynamically-favoured discrete aggregates. Coordination bonds are usually of moderate bonding energy (15-50 kcal/mol), which facilitates kinetic transformations (bond making and breaking ability) between the reactants, intermeditaes and products in the synthetic process. This behaviour helps in modulating the kinetically-formed intermediates (self-repairing capability) and making good use of thermodynamically-controlled molecular recognition processes. Another important feature of coordination species is that the highly directional and predictable nature of metal-ligand interactions will facilitate the rational design and synthesis of predictable architectures [24-30].

In the synthesis of metal-containing interlocked molecular aggregates, metal ions often serve two roles: as templates and as directing units. In the former methodology, metal ions are mainly used to guide the interlocking process by pre-organizing the precursors of the subcomponents. The metal ions are not the basic ingredients for the construction of interlocked superstructures, and the interlocked architectures are maintained upon demetalation [31-34]. In the latter methodology, metal ions modulate the assembly of building blocks and lead to the desired interlocking systems through metal-ligand interactions. The metal ions are incorporated as constitutive elements and are essential parts of the aggregates [1-5]. With suitable choice of metal ions and rational ligand design, 
interlocked superstructures were always unexpectedly observed in the self-assembly of metallasupramolecules. This one-pot formation of interlocked superstructures is a fascinating process, and many questions about the process remain, ranging from the nature of the driving force to the formation mechanism. Examples of metal-template interpenetrating systems have been documented previously in short sections of reviews focused on supramolecular assemblies in general [31-34]. In this review, we focus on the metal-directed assembly of these fascinating interlocked superstructures, and some of the architectures incorporating dual functional metal centers are also discussed.

The past two decades have seen a tremendous proliferation of new metallasupramolecules from metal-directed assembly. Three main strategies (the metal-corner approach, the ligand-corner approach and the symmetry interaction approach) were developed for synthesizing these superstructures. Meanwhile, the good choice of building blocks, the modularity and the versatility of these design strategies have lent themselves to the efficient construction of interlocked molecules. For example, Fujita's catenanes are accessible using a $\mathrm{Pd}^{\mathrm{II}}$-driven multicomponent assembly process [35-37]. The key feature of these interlocked species is that they are comprised of metallacycle components, and the metal-ligand interactions are applied as the final locking link. This synthetic methodology is termed metallacyclic assembly. In sharp contrast to the numerous known non-interpenetrating metallasupramolecular systems, metallacyclic-assembled interlocked superstructures are still limited, and most are unintentionally produced in the synthesis of metallasupramolecules [28-30]. Although some documents have concluded the interpenetrating system [1-3], especially the metal-directed synthetic strategies [4-5], the comprehensive review of the metallacyclic assembly of interlocked superstructures is still rare. Thus, an overview of these aggregates is given herein with a focus on better understanding interlocked systems.

Each different type of interlocked molecule [1-5], is discussed in a separate section, including rotaxanes, catenanes, Solomon links, ring-in-ring complexes, molecular Borromean rings, molecular knots and interlocked cages. X-ray crystallography often plays a crucial role in the structural characterization of interlocked superstructures and, hence, crystal structures are shown wherever possible to provide the direct visual impression that is not always apparent from line drawings of chemical structures. All of the crystal data shown in this review are obtained from the Cambridge Structural Database (CSD) [38].

\section{Rotaxanes}

Rotaxanes are interlocked superstructures assembled from the threading of a ring and a dumbbell-shaped molecule [39]. Most of the ring components applied in rotaxanes are covalently bonded macrocycles, such as crown ethers, cucurbituril, cyclodextrins and cyclophanes. Incorporating 
metallacycles into rotaxanes is difficult due to the lack of notable interactions to drive the interpenetration between the metallacycle and the thread. Until 2000, the only reported metallacycle-based rotaxanes 1-Os ${ }^{\mathbf{I V}}$ were those prepared by Jeong and co-workers [40]. The mononuclear metallacycles were built from semi-cyclic units $\mathrm{L}_{1}$ and cis-Os ${ }^{\mathrm{IV}}$ corner units, and form the rotaxanes in the presence of an amide thread, driven by the ring-thread $\mathrm{NH} \cdots \mathrm{O}$ hydrogen bonds. Later, other similar rotaxanes 1-Re ${ }^{\mathbf{I}}, \mathbf{1 - P t ^ { I I }}$ and 1-Pd ${ }^{\text {II }}$ were also synthesized by the use of different metal-corner units (Fig. 1) [42]. The rotaxane 1-Os ${ }^{\mathbf{I V}}, \mathbf{1 - P t ^ { \mathbf { I I } }}$ and $\mathbf{1 - P d ^ { \mathbf { I I } }}$ are kinetically labile, and all of them exist in equilibrium with their free components in solution. Only the rotaxanes $\mathbf{1}-\mathbf{R e}^{\mathbf{I}}$ was kinetically stable enough to be isolated (in $62 \%$ yield). In contrast, using a binuclear $\mathrm{Os}^{\mathrm{IV}}$ macrocycle as the ring component, both [2]- and [3] rotaxanes were observed [41]. A [2] rotaxane molecular shuttle was also observed by using a thread with multiple recognition sites [43].

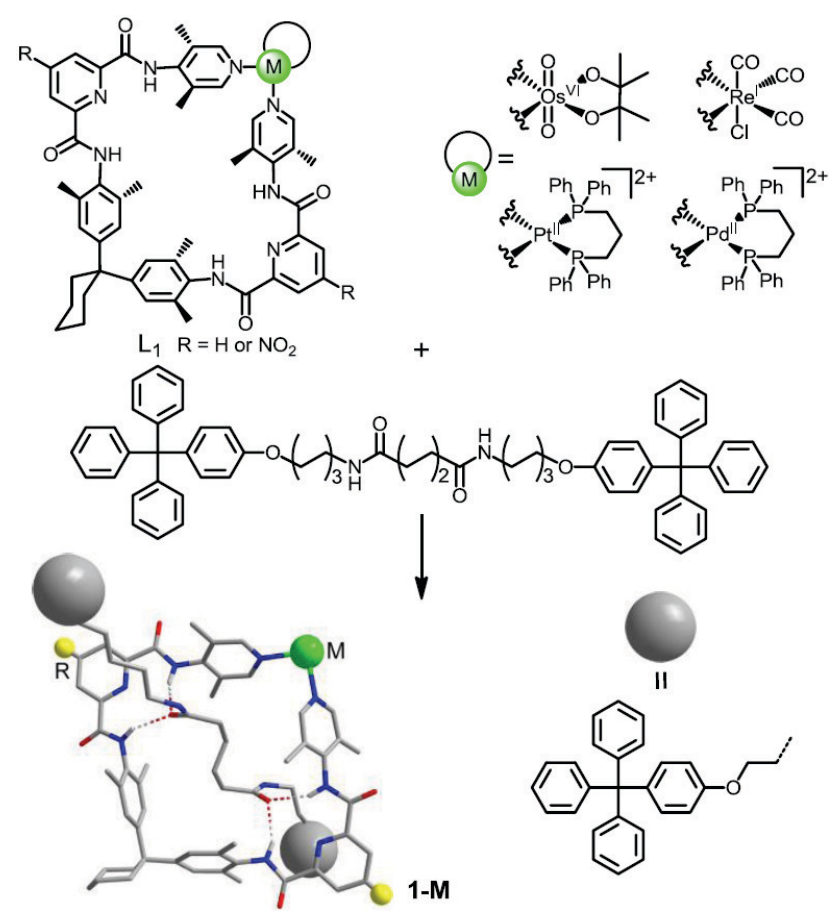

Fig. 1. The [2] rotaxanes 1-M synthesized from mono-nuclear metallacycles [42].

In Hunter's group, the axial coordination between pyridine units and Zn-porphyrins was utilized to assemble macrocycles suitable for rotaxane formation. With the aid of amide-amide hydrogen

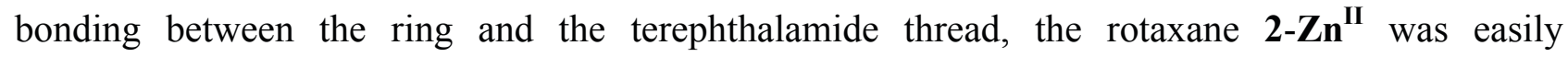
constructed (Fig. 2a) [44]. A crown ether incorporating a ferrocene moiety was designed by Osakada and co-workers. Similar to other polyethers, it can be easily threaded onto dialkylammonium derivatives due to the well-known hydrogen bonding interactions between these groups. The incorporation of ferrocene groups impart interesting photochemical and electrochemical properties on the resulting rotaxanes 3-Fe ${ }^{\text {II }}$ (Fig. 2b) [45]. 
(a)

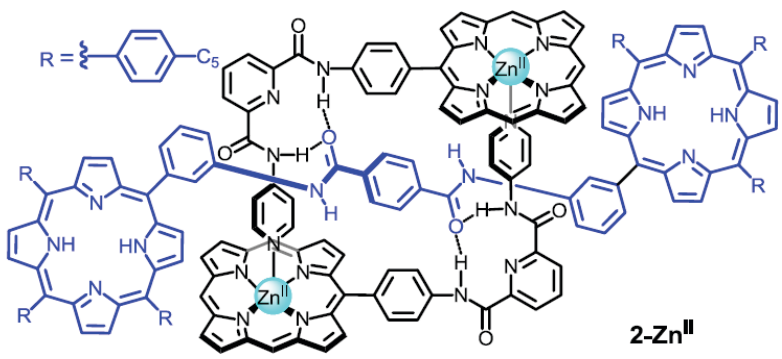

(b)

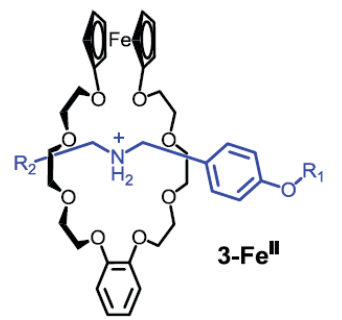

Fig. 2. (a) [2] rotaxanes $\mathbf{2}-\mathbf{Z n}^{\mathrm{II}}$ assembled from $\mathrm{Zn}^{\mathrm{II}}$-porphyrin-based macrocycles [44] and (b) $\mathbf{3}-\mathbf{F} \mathrm{e}^{\mathrm{II}}$ comprising a ferrocence-based polyether [45].

In contrast to the macrocycle-based rotaxanes, by using the banana-shaped ligand $\mathrm{L}_{2}$, Shionoya and Clever described a pseudorotaxane $\left(\mathbf{4}-\mathbf{M}^{\mathrm{II}}, \mathbf{M}=\mathrm{Pd}\right.$ or $\left.\mathrm{Pt}\right)$ derived from the $\left[\mathrm{M}_{2}\left(\mathrm{~L}_{2}\right)_{4}\right]^{4+}$ metallacage (Fig. 3) [46]. Although the coordinatively-saturated metal ions of metallacages can not directly bond with the bis-sulfonate thread, they provide positive charges for attracting the negatively charged thread. The Coulombic interactions between the metallacage and bis-anionic guests determined the formation of the rotaxanes, as indicated by the dethreading and rethreading process upon addition of $\mathrm{HBF}_{4}$ and tributylamine, respectively.

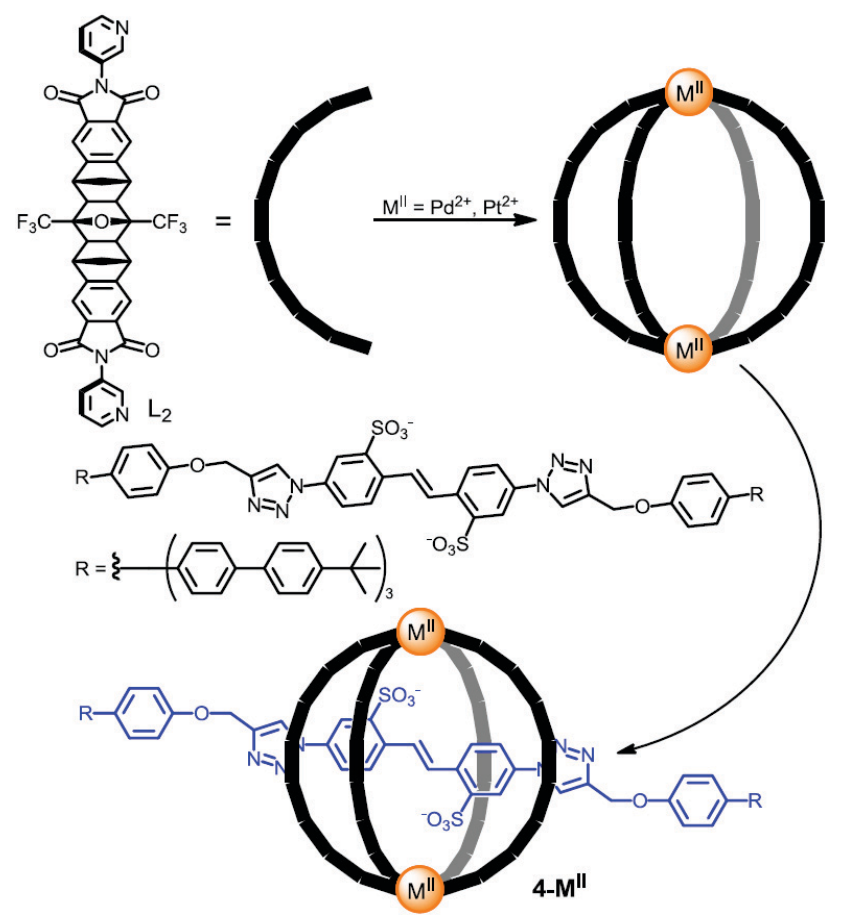

Fig. 3. The large pseudo[2]rotaxanes 4-MII synthesized from a metallacage of the form $\left[\mathrm{M}_{2}\left(\mathrm{~L}_{2}\right)_{4}\right]^{4+}[46]$.

One type of eight-membered heterometallic ring, consisting of seven $\mathrm{Cr}^{\mathrm{III}}$ cations and a single divalent $\mathrm{M}^{\mathrm{II}}(\mathrm{M}=\mathrm{Co}, \mathrm{Ni}, \mathrm{Fe}, \mathrm{Mn}, \mathrm{Zn}, \mathrm{Cu}, \mathrm{Cd})$ cation bridged by alkylcarboxylate and fluoride 
anions, was applied in the synthesis of rotaxanes $\mathbf{5}-\mathbf{C r}{ }^{\mathbf{I I I}}{ }_{7} \mathbf{M}^{\mathrm{II}}$ [47-49]. These are neutral molecules as the single charge remaining on the macrocycles is balanced by the positive charge on the protonated aminoalkane thread. By using more stable stopper groups and additives to direct the ring assembly, 5-Cr ${ }_{7}^{\mathrm{III}} \mathbf{M}^{\mathrm{II}}$ could be formed in up to $92 \%$ yield (Fig. 4a). Changing the number of spaced ammonium sites from one to two, the [2] rotaxane molecular shuttle $6-\mathbf{C r}^{\mathrm{III}}{ }_{7} \mathbf{C o}^{\mathrm{II}}$ was synthesized (Fig. 4b).
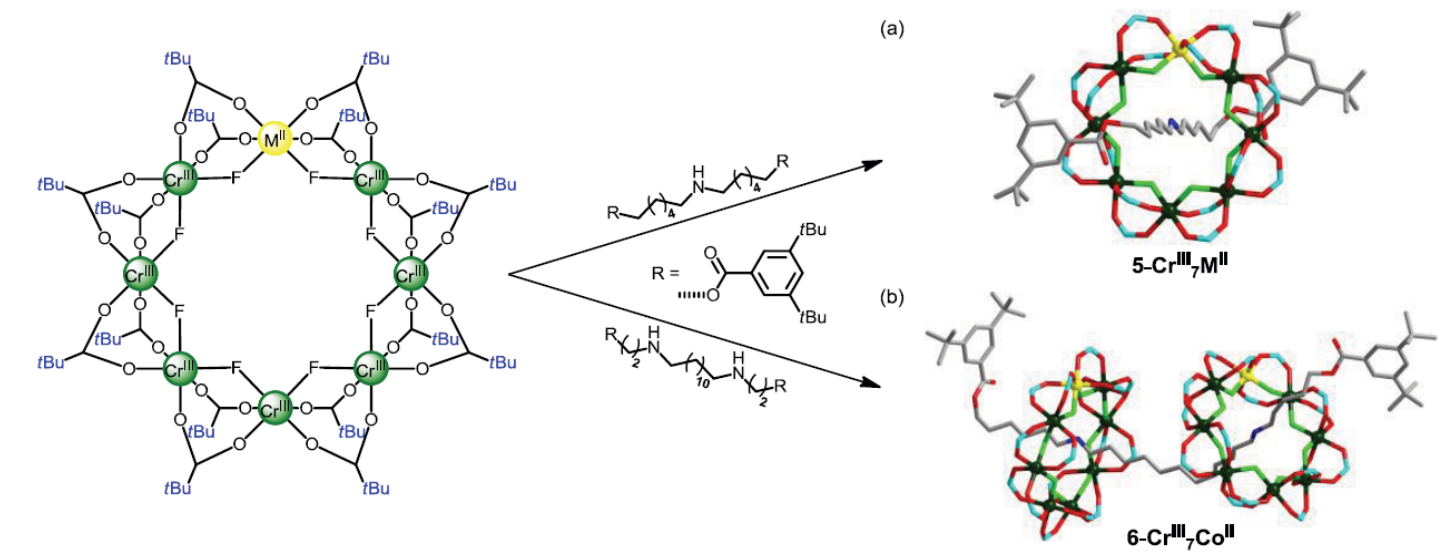

Fig. 4. The rotaxanes 5-CriI ${ }_{7} \mathbf{M}^{\mathrm{II}}$ and the molecular shuttle $6-\mathbf{C r}^{\mathrm{III}}{ }_{7} \mathbf{C o}^{\mathrm{II}}$ based on the heterometallic rings [47-49].

\section{Catenanes}

\subsection{Homo-catenanes}

By far the most well-explored and well-understood area of interlocked superstructures is the family of structures known as catenanes [35-37, 50]. These assemblies are molecular ensembles containing two or more interlocked rings, which are not linked chemically but cannot be separated from each other without breakage of the rings. A large number of synthetic strategies based on statistical methods [51], metal templation [31-34], donor-acceptor interactions [52], anion templation [53], and hydrogen bonding [15-17] have been developed. All these methods involve threading a linear molecule through a ring, followed by ring closure. In sharp contrast, coordination-driven self-assembly of catenanes is more simple and highly efficient [35-37]. Herein, these structures are classified into three groups: 1) one-pot self-assembled catenanes; 2) heterometallic catenanes incorporating more functional metal centers; and 3) hybrid catenanes with both organic and inorganic macrocycles.

The first organometallic catenane 7-Mg ${ }^{\text {II }}$, published in 1993 by Bickelhaupt et al., consisted of interpenetrating crown ether and diarylalkyl rings surrounding a $\mathrm{Mg}^{\mathrm{II}}$ ion, and were prepared by $\mathrm{Mg}-\mathrm{C}$ bond dissociation, threading and ring closure [54]. A large family of fascinating catenanes containing $\mathrm{M}^{\mathrm{II}}-\mathrm{N}(\mathrm{M}=\mathrm{Pd}, \mathrm{Pt})$ linkages was pioneered by Fujita and co-workers. In 1995, their first catenane 8-Pd ${ }^{\text {II }}$ was achieved by combining $\mathrm{Pd}(\mathrm{en})\left(\mathrm{NO}_{3}\right)_{2}$ and the bipyridyl linker $\mathrm{L}_{3}$ (Fig. 5a) [5556]. Due to the dynamic nature of the $\mathrm{Pd}^{\mathrm{II}}-\mathrm{N}$ bond, an equilibrium between the dimeric and 
monomeric products was observed, and more catenanes could be obtained at high concentrations or by using more polar solvents. The driving force for spontaneous generation of catenanes was proposed to be the close interaction between two rings. Therefore, another type of molecular rectangles with large cavities were designed using the bridging ligand $\mathrm{L}_{4}$ containing only one flexible methylene group [57]. Surprisingly, only the catenated dimer 9-Pd ${ }^{\text {II }}$ could be observed, irrespective of the change of concentration or polarity of media. The expanded linker $\mathrm{L}_{5}$ could also

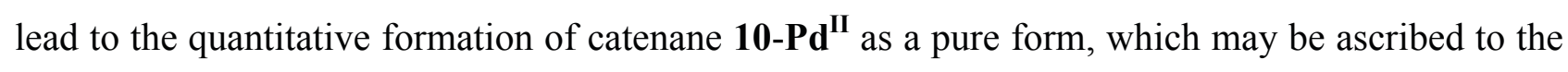
greater thermodynamic stability of the catenated structure than that of mono-counterpart (Fig. 5b). This feature was further confirmed by the observation of sole catenaned products 11-Pd ${ }^{\text {II }}$ via threecomponent $\left[\mathrm{Pd}(\mathrm{en})\left(\mathrm{NO}_{3}\right)_{2}, \mathrm{~L}_{6}, \mathrm{~L}_{7}\right]$ coordination assembly, which overcame the combination problem arising from the multi-component system. The use of expanded ligands $\left(\mathrm{L}_{8}\right.$ and $\left.\mathrm{L}_{9}\right)$ resulted in the quantitative formation of catenane 12-Pd ${ }^{\text {II }}$ as deduced from an ESI-MS study (Fig. $5 c)$.

(a)

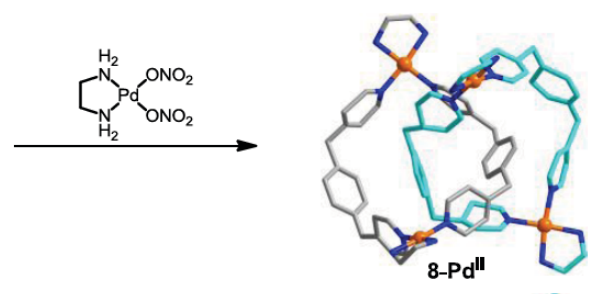

(b)
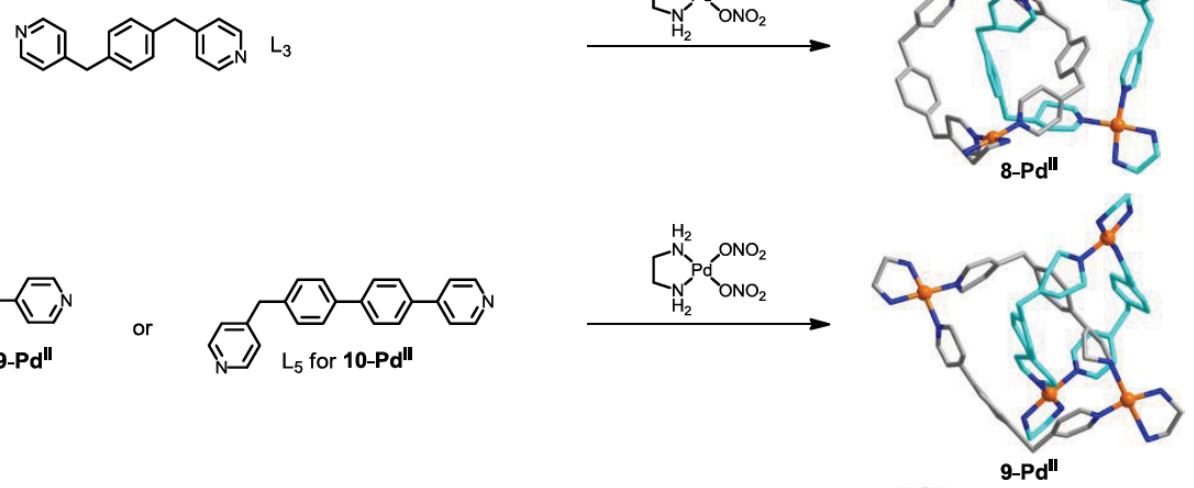

(c)
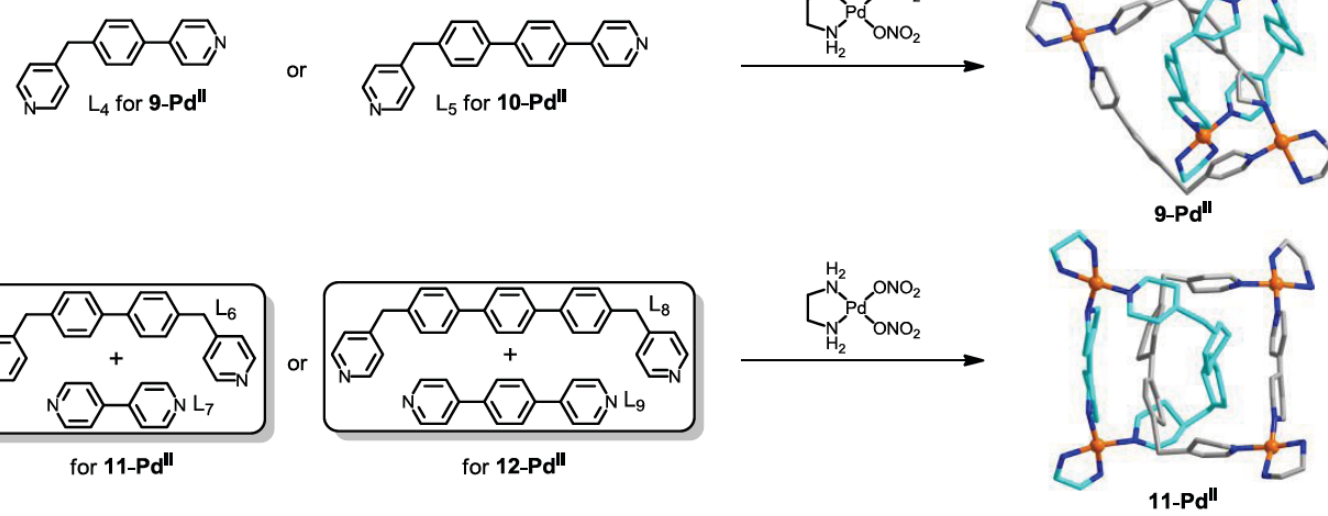

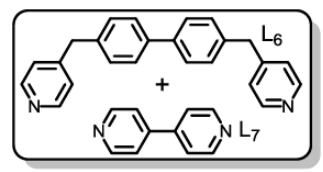

for 11-Pd"

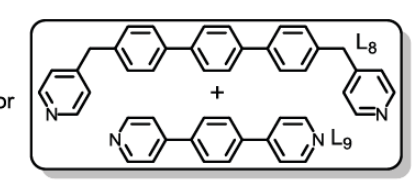

for 12-Pd"

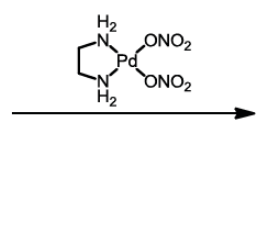

Fig. 5. [2]catenanes based on $\mathrm{Pd}^{\mathrm{II}}$-pyridine interactions [55-57].

Similar to the synthesis of catenane 11-Pd ${ }^{\text {II }}$, changing $\mathrm{L}_{6}$ to another flexible ligand also led to the formation of [2] catenane 13-Pd ${ }^{\text {II }}$ with the equilibrating macrocycle $\mathbf{1 3}^{\mathbf{}}-\mathbf{P} \mathbf{d}^{\text {II }}$. The equilibrium is concentration dependent, lower concentrations gave the macrocycle as the major product, whereas at higher concentrations the equilibrium shifted in favor of the corresponding [2]catenane. The addition of $\mathrm{CH}_{3} \mathrm{CN}$ to the reaction system can preclude the formation of interlocked species [58]. The ligands $\mathrm{L}_{10}$ incorporated with flexible oligopeptides endows them special structural complexity, upon $\mathrm{Ag}^{\mathrm{I}}$ complexation, they are fold into the $\left[\mathrm{Ag}_{3}\left(\mathrm{~L}_{10}\right)_{3}\right] \Omega$-loops while concomitantly self-

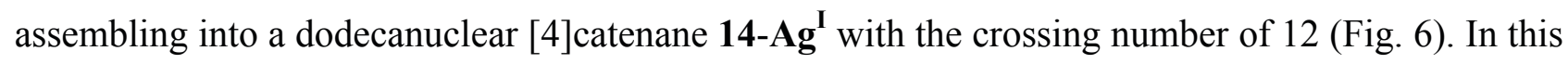


[4]catenane structure, four macrocycles are interlocked in such a way that every ring is threaded by the other three, and the $\mathrm{O} \cdots \mathrm{Ag}$ interaction may favour the formation of this interlocked structures. Interestingly, the size of one attached rings influenced the formation of interlocked superstructures [59].

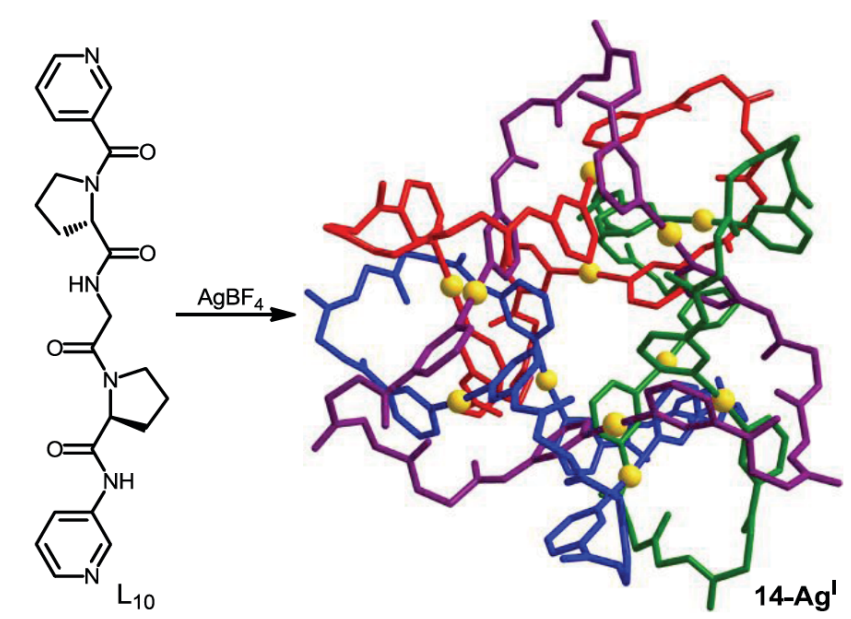

Fig. 6. The self-assembly of 12-crossing [4]catenane 14-Ag ${ }^{\mathrm{I}}$ (all carbon atoms of five-member rings are omitted for clarity) [59].

Fujita and co-workers designed a pentakis(m-phenylene) ligand $\mathrm{L}_{11}$ containing pyridine units at both ends of the strand. The reaction of $\mathrm{L}_{11}$ with $\mathrm{Pd}(\mathrm{en})\left(\mathrm{NO}_{3}\right)_{2}$ conveniently afforded the [2] catenanes 15a-Pd ${ }^{\text {II }}$. If chiral units were used at the cis-Pd ${ }^{\text {II }}$ corner, the chiral catenanes $\mathbf{1 5 b}-\mathbf{P d}^{\text {II }}$ were obtained (Fig. 7a) [60]. Although examples of thermodynamically-controlled assembly of catenanes are numerous, those of kinetically self-assembled compounds are rare. The homocatenation of $\mathbf{1 6}-\mathbf{P d}^{\mathbf{I I}}$ is kinetically unfavorable because of the steric demand of the alkoxy side chains. Via a kinetic method, the cross-catenane 17-Pd ${ }^{\text {II }}$ was generated from the reaction of two different $\mathrm{Pd}^{\mathrm{II}}$-clipped ring precursors (Fig. 7b) [61]. By replacing the capping ligand with a bifunctional ligand, the long acyclic complex $\mathbf{1 8}^{\prime}-\mathbf{P d}^{\mathbf{I I}}$ was obtained with macrocyclic units at both ends. Upon addition of water, complex $\mathbf{1 8}^{\prime}-\mathbf{P d}^{\mathbf{I I}}$ selectively catenated into ultramacrocyclic dimer 18-Pd ${ }^{\text {II }}$, which contains over 200 non-hydrogen atoms in its backbone [62]. In the transformation, no other products were formed, as indicated by ${ }^{1} \mathrm{H}$ NMR spectroscopy and CSI-MS studies (Fig. 7c). Compared with the labile $\mathrm{Pd}^{\mathrm{II}}-\mathrm{N}$ bond, the $\mathrm{Pt}^{\mathrm{II}}-\mathrm{N}$ bond is more inert and becomes labile at high temperature or under light irradiation. A photo-switchable molecular lock phenomenon was also observed in Fujita's lab. Namely, upon UV irradiation, the $\mathrm{Pt}^{\mathrm{II}}$-linked ring 19'-Pt $^{\mathrm{II}}$ is rapidly catenated to give 19-Pt ${ }^{\mathrm{II}}$ in an aqueous solution [63]. The conversion was very rapid and highly efficient. The calculated energy of an electronic transition indicated that an adsorption band around $305 \mathrm{~nm}$ was caused by the HOMO-LUMO transition, suggesting that excitation with a UV light could weaken the $\mathrm{Pt}^{\mathrm{II}}-\mathrm{N}$ coordination bonds (Fig. 7d). 

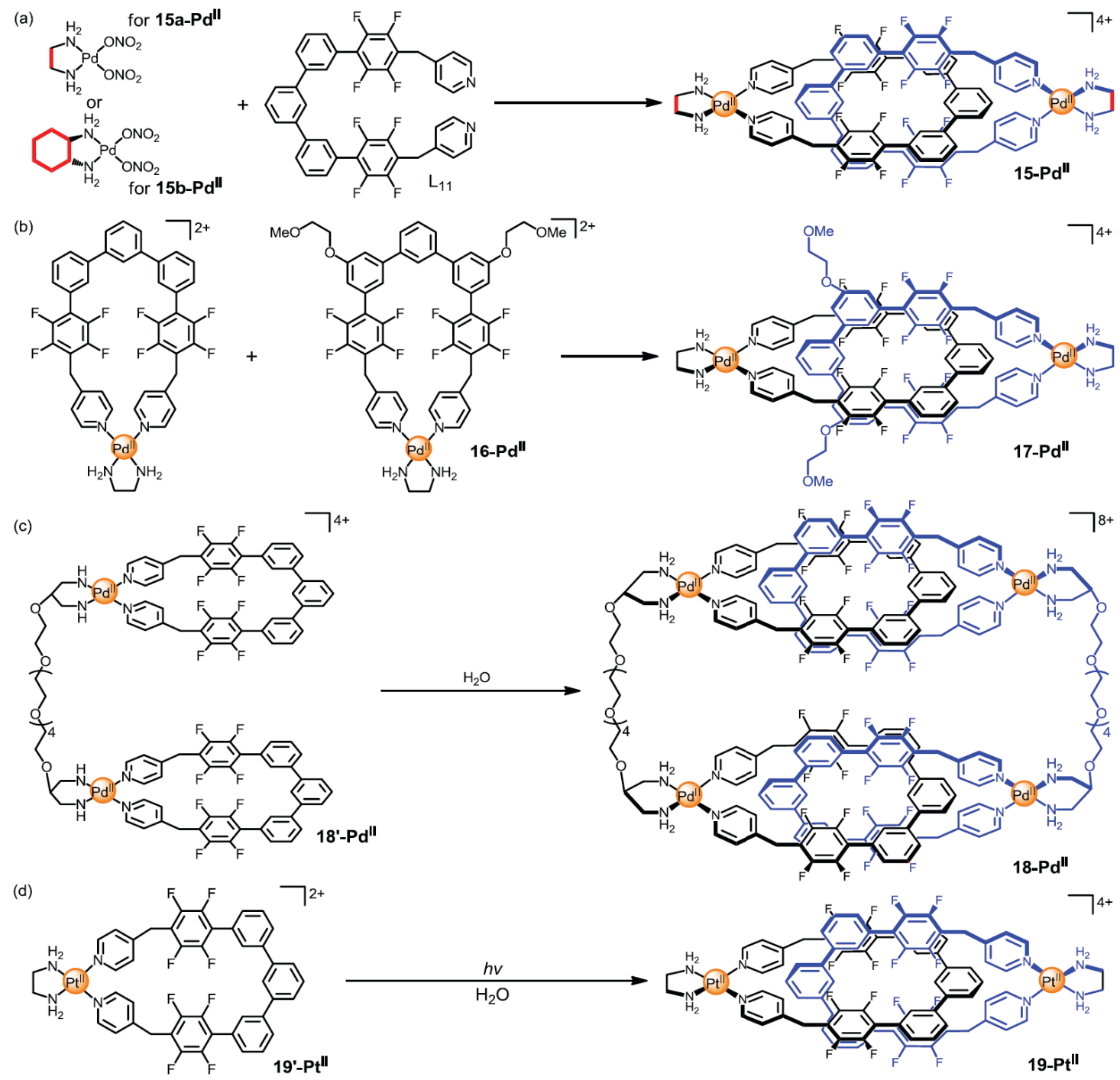

Fig. 7. [2]catenanes derived from semi-cyclic bipyridyl ligands [60-63].

In 1995, Mingos and co-workers reported the first $\mathrm{Au}^{\mathrm{I}}$-acetylide-based [2]catenanes 20-A $\mathbf{u}^{\mathbf{I}}$ from the reaction of $\left[\mathrm{Au}\left(\mathrm{NH}_{3}\right)_{2}\right] \mathrm{BF}_{4}$ with $\mathrm{tBuC} \equiv \mathrm{CH}$ in a yield of $65 \%$ [64]. Taking a different synthetic strategy, a digold-diacetylide-diphosphane based an organometallic [2]catenane system was developed by Puddephatt and co-workers. The combination of digold-diacetylide precursors X(4$\left.\mathrm{C}_{6} \mathrm{H}_{4} \mathrm{OCH}_{2} \mathrm{C} \equiv \mathrm{CAu}\right)_{2}$ and diphosphane ligands $\mathrm{Ph}_{2} \mathrm{PZPPh}_{2}\left[\mathrm{Z}=\left(\mathrm{CH}_{2}\right)_{\mathrm{n}}\right]$ simply afforded macrocyclic complexes with the general formula $\left[\mathrm{X}\left(4-\mathrm{C}_{6} \mathrm{H}_{4} \mathrm{OCH}_{2} \mathrm{C} \equiv \mathrm{CAu}\right)_{2}\left(\mu-\mathrm{Ph}_{2} \mathrm{PZPPh}_{2}\right)\right]_{y}[65-$ 75]. Systematic investigation indicated that the ring size, degree of catenation and ultimate outcome of the catenated products depended solely on the hinge group $\mathrm{X}$ of the diacetylide precursors and the length of the spacer groups in diphosphane ligands (Fig. 8). Of these two key factors, the careful choice of diacetylide ligands is an essential prerequisite determining if a [2]catenane can be formed. The orientation of the aryl units of $\mathrm{X}\left(\mathrm{C}_{6} \mathrm{H}_{4} \mathrm{O}\right)_{2}$ groups (termed the aryl twist angle, $\theta$, mainly depended on the hinge group $\mathrm{X}$ ) is a subtle factor that executes the determination. The formation of [2] catenane 21- $\mathbf{A} \mathbf{u}^{\mathbf{I}}$ is favored when $\theta=45-90^{\circ}$ but not when $\theta \approx 0^{\circ}$, since the in-plane aryl group can block the cavity and then prevents the interpenetration. Cases with $\theta=45-90^{\circ}$ are found when $\mathrm{X}$ 
$=\mathrm{CH}_{2}, \mathrm{CHR}, \mathrm{CR}_{2}(\mathrm{R}=$ alkyl, aryl or pyridyl $), \mathrm{SO}_{2}$ or $\mathrm{C}(\mathrm{OR})_{2}$. When $\mathrm{X}=\mathrm{O}, \mathrm{S}, \mathrm{C}=\mathrm{O}$, the hinge groups $\mathrm{X}$ can $\pi$-bond to the aryl groups, leading to nearly $0^{\circ} \theta$ values and formation of the single ring complex 22-Au' ${ }^{\mathbf{I}}$. When $\mathrm{X}=\mathrm{C}_{6} \mathrm{H}_{10}$ (cyclohexylidene), the $\theta$ value is about $90^{\circ}$ and the Solomon link complex 63-Au' ${ }^{\mathrm{I}}$ was surprisingly observed with the $\mathrm{Ph}_{2} \mathrm{P}\left(\mathrm{CH}_{2}\right)_{4} \mathrm{PPh}_{2}$ linker. Besides choosing the suitable diacetylide ligand $\mathrm{X}$, the spacer group of diphosphane ligand is also important in determining the catenane formation. For shorter spacer groups $\mathrm{Z}=\mathrm{C} \equiv \mathrm{C}$, trans- $\mathrm{HC}=\mathrm{CH}$, or $\left(\mathrm{CH}_{2}\right)_{2}$, the mono-ring complexes are formed because the 23-membered rings are too small to allow interpenetration to give [2] catenanes. Longer spacer groups, such as where $\mathrm{Z}=\left(\mathrm{CH}_{2}\right)_{5}$, also disfavor the formation of [2]catenanes. Over-large ring sizes can loosen the inter-ring contacts, therefore providing insufficient binding energy to overcome the entropy reduction of catenane formation.
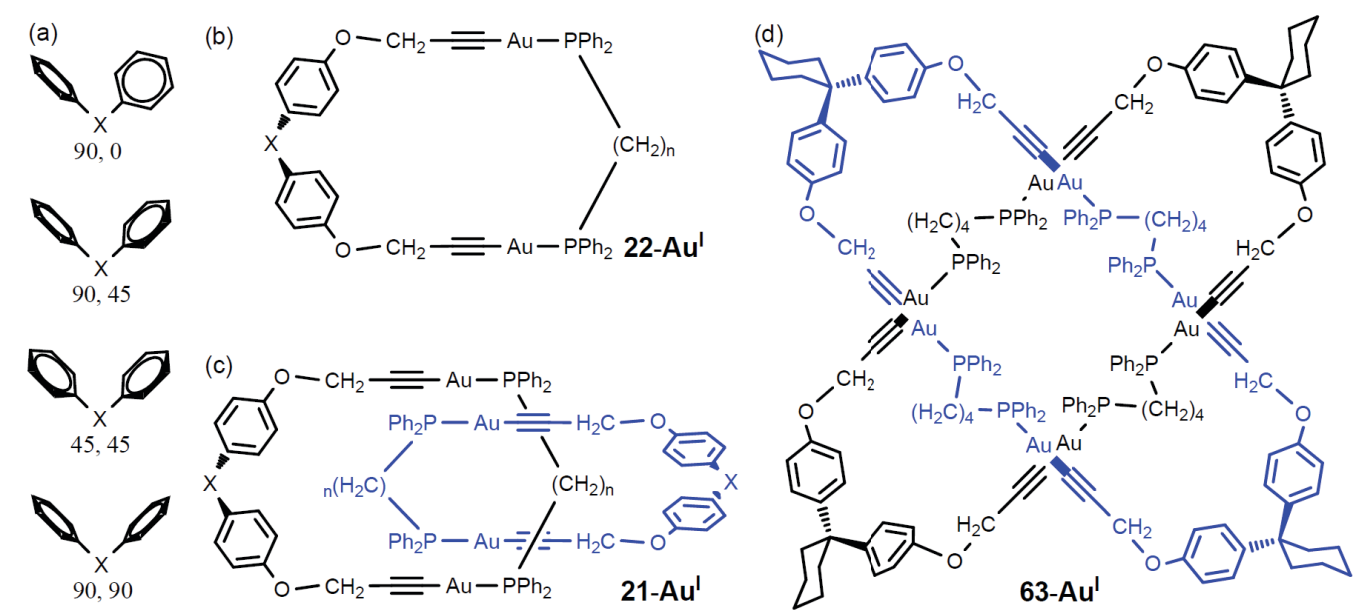

Fig. 8. (a) Conformations of $\mathrm{X}\left(\mathrm{C}_{6} \mathrm{H}_{4} \mathrm{O}\right)_{2}$ groups and (b-d) Different digold-diacetylide-diphosphane-based complexes [65-75].

Rees and co-workers designed the multidentate ligand 2,2,28,28-tetramethyl-3,5,25,27-tetraoxo6,9,12,15,18,21,24-heptaoxanonacosane $\mathrm{L}_{12}$, which consists of a hexaethylene glycol central segment and two terminal $\beta$-ketoester functionalities. By treating it with a slurry of $\mathrm{Ba}\left(\mathrm{NH}_{2}\right)_{2}$ in toluene, the charge-neutral [2]catenane 23-Ba ${ }^{\text {II }}$ was obtained (Fig. 9) [76]. As evidenced from its Xray structure, each nine-coordinate $\mathrm{Ba}^{\mathrm{II}}$ cation is bound by two ketoester groups of one ligand, and additionally encapsulated by a "crown ether" pocket from the second ligand. The terminal ketoester groups of each ligand are linked together by the $\mathrm{Ba}^{\mathrm{II}}$ ion, leading to a closed ring. Two rings are perpendicularly interlocked with each other due to the template effect of the $\mathrm{Ba}^{\mathrm{II}}$ ion.

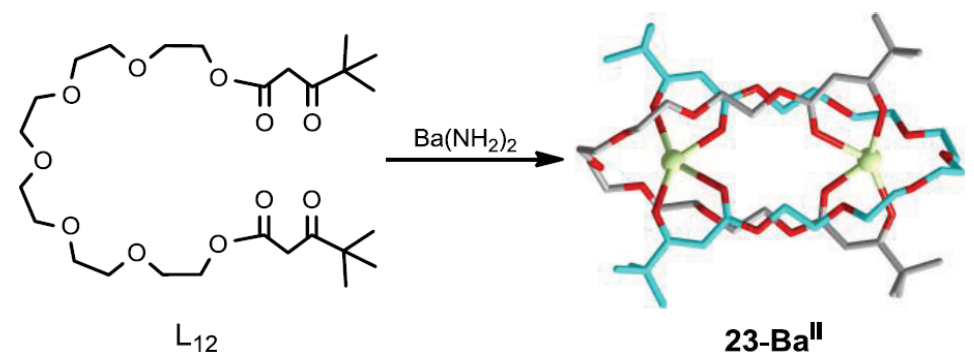


Fig. 9. Synthetic route leading to the [2]catenane 21-Ba ${ }^{\text {II }}[76]$.

The reaction of oxalic-dihydrazide-based polydentate ligands $\mathrm{L}_{13}$ with $\mathrm{Co}\left(\mathrm{NO}_{3}\right)_{2} \cdot 6 \mathrm{H}_{2} \mathrm{O}$ in air gave the [2 $\mathrm{x}$ 2] molecular square 24-Co ${ }^{\text {II }}$, involving both cis and trans conformations in the organic

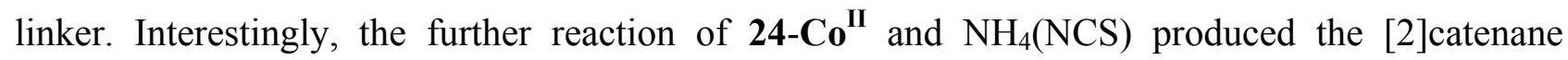
complex 25-Co ${ }^{\text {II }} \mathbf{C o}^{\text {III }}$ (Fig. 10). Since the catenane was formed from a molecular square precursor, the dissociation-association of the metal-ligand interaction must be taking place. The presence of the $\mathrm{NCS}^{-}$ion is presumably responsible for the negation of the strong coordination of tridentate $\mathrm{L}_{13}$, as evidenced from the observed $\left[\mathrm{Co}(\mathrm{NCS})_{4}\right]^{2-}$ anion. It is known that addition of salt can promote the formation of catenanes [77]. Hence, the participation of $\mathrm{NCS}^{-}$can also explain why the catenane was not directly self-assembled from the starting materials but alternatively formed from the square precursor.

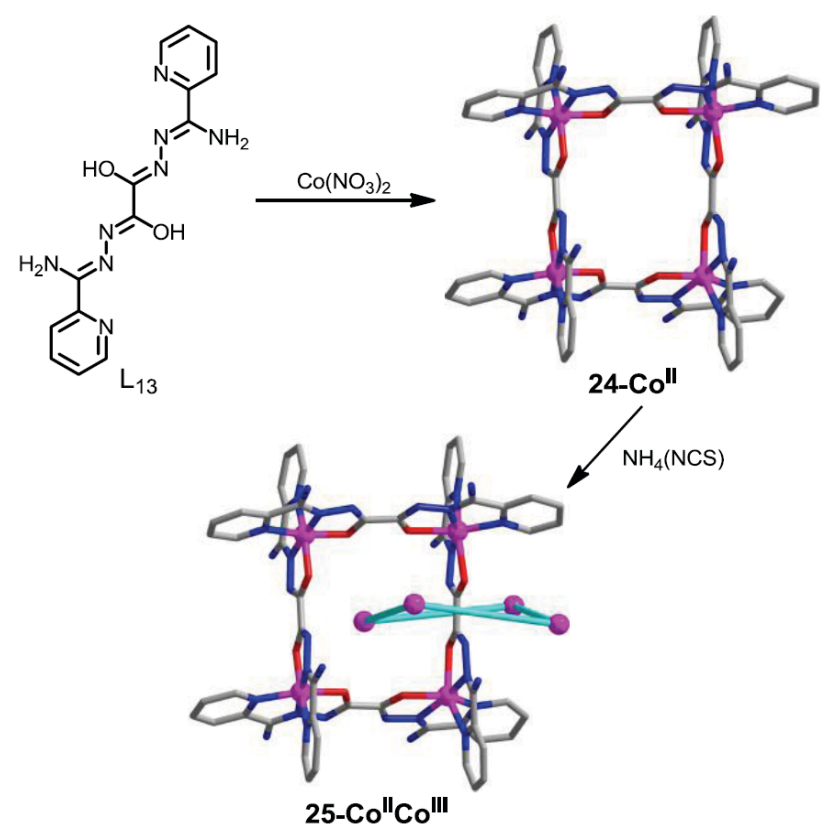

Fig. 10. Step-wise synthesis of the [2] catenane $25-\mathbf{C o}^{\text {II }} \mathbf{C o}^{\text {III }}$ [77].

Interlocked $\pi$-conjugated oligothiophene macrocycles included both electronic benefits and topology-based properties. In contrast to relatively flexible intertwined molecules, the preparation of defect-free conjugated molecules remains a synthetic challenge due to the use of more rigid structural elements. Through a step-wise synthetic method, the interlocked $\pi$-conjugated macrocycle 26 was synthesized by Bäuerle and co-workers. Under thermodynamic control, the $\mathrm{Cu}^{\mathrm{I}}$-templated cross link and $c i s-\mathrm{Pt}^{\mathrm{II}}$-templated ring closure provided access to the interlocked trimetallated $\mathrm{Pt}^{\mathrm{II}}$ $\mathrm{Cu}^{\mathrm{I}}-\mathrm{Pt}^{\mathrm{II}}$ catenate 26-C $\mathbf{u}^{\mathrm{I}} \mathbf{P t}^{\mathrm{II}}$. Subsequent reaction with $\mathrm{I}_{2}$ led to 1,1-reductive elimination of the $\mathrm{Pt}$ corners and simultaneous $\mathrm{C}-\mathrm{C}$ bond formation to generate $\mathrm{Cu}{ }^{\mathrm{I}}$ catenate $\mathbf{2 6 -} \mathbf{C} \mathbf{u}^{\mathrm{I}}$. By reaction with $\mathrm{KCN}$, decomplexation of the $\mathrm{Cu}^{\mathrm{I}}$ center was achieved, and metal-free conjugated-catenane 26 was

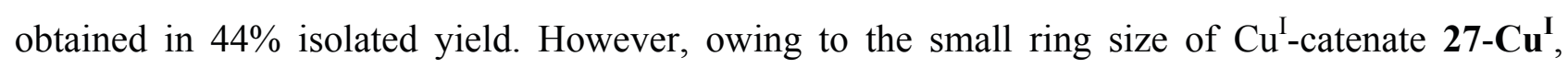
removal of the $\mathrm{Cu}^{\mathrm{I}}$ template failed (Fig. 11) [78]. The optical and redox properties of simple ring 
26' and catenane 26 were investigated and clearly showed a mutual interaction between the two rings in 26. Although both complexes showed similar broad bands in absorption spectra, the molar extinction coefficient of catenane $\mathbf{2 6}$ is doubled that of simple ring $\mathbf{2 6}$ ', thus indicating an additive contribution of both rings in the interlocked system [79].

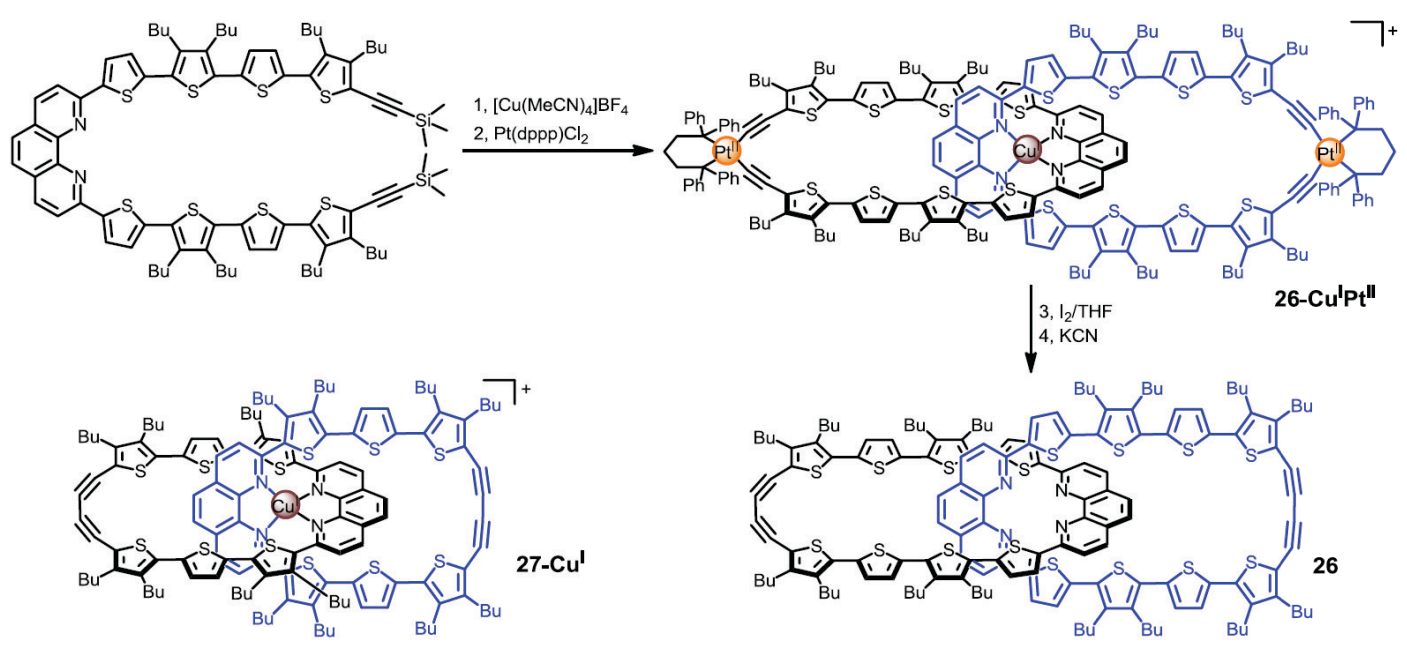

Fig. 11. The step-wise synthesis of conjugated-catenane 26 [78-79].

The semi-cyclic pyridyl ligand $\mathrm{L}_{14}$ was synthesized by Wisner and co-workers, and the reaction of $\mathrm{L}_{14}$ and $\mathrm{Pd}(\mathrm{PhCN})_{2} \mathrm{Cl}_{2}$ in a solvent mixture of 3:1 $\mathrm{CHCl}_{3} / \mathrm{MeCN}$ afforded the [2] catenane 28-Pd (Fig. 12). This [2]catenane architecture depends on the same $\mathrm{Pd}^{\mathrm{II}}$ center for both the macrocyclization and templation of its self-assembly. The driving force for catenane formation rested mainly on the $\mathrm{NH} \cdots \mathrm{Cl}$ hydrogen bonds derived from the amide groups and $\mathrm{Cl}$ atoms. The topology of the product was dependent on solvent polarity, and the utilization of highly polar solvent DMSO resulted in the mono-ring complex $\mathbf{2 8}$ '-Pd $\mathbf{P d}^{\mathbf{I I}}$ being observed and the re-formation of 28-Pd ${ }^{\text {II }}$ could be realized substantially upon replacing the polar DMSO with less-polar solvents $[80]$.

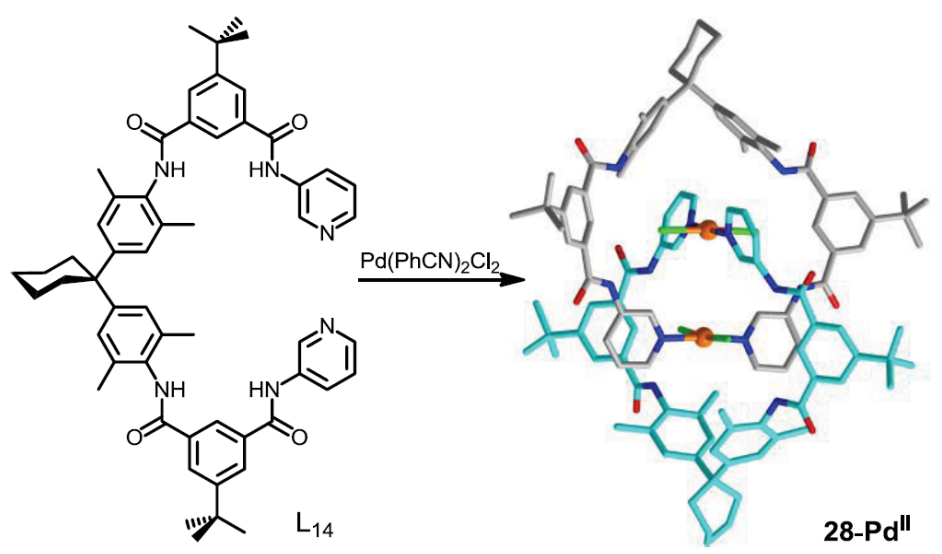

Fig. 12. Synthesis of [2]catenane 28-Pd ${ }^{\mathrm{II}}[80]$.

Batten and co-workers synthesized two ditopic ligands that were composed of 4-(4pyridyl)pyrazolyl arms and alkyl connecting-groups. Upon its combination with cis-protected 
[(dppp)Pd(OTf $\left.)_{2}\right]$, the propane-bridged $\mathrm{L}_{16}$ forms $\mathrm{M}_{2}\left(\mathrm{~L}_{16}\right)_{2}$ metallocycles 29-Pd ${ }^{\mathrm{II}}$, while ethanebridged $\mathrm{L}_{15}$ affords [2] catenane 30-Pd ${ }^{\mathrm{II}}$ (Fig. 13) [81]. The formation of the catenane is dependent upon the length of the bridging ditopic ligand, and the over-large cavity can no longer act as a good host for another identical ligand, hence the formation of a catenated complex does not occur. Single-crystal X-ray analysis clearly showed the close interactions of two rings in catenane 30-Pd ${ }^{\text {II }}$. Along its longest dimension, a continuous array of face-to-face $\pi$ interactions were observed with eight aromatic groups.

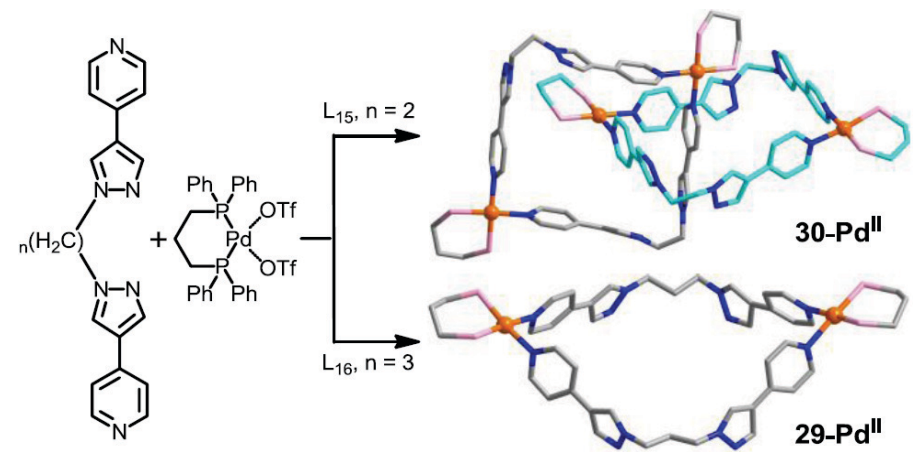

Fig. 13. Formation of the metallacycle 29-Pd ${ }^{\text {II }}$ and catenane $\mathbf{3 0 - P d ^ { I I }}$ (the $\mathrm{Ph}$ rings are omitted for clarity in the molecular structure) [81].

In Puddephatt's group, the chiral [2]catenanes 31-Pd ${ }^{\text {II }}$ were prepared by self-assembly of chiral bis(amidopyridyl)binaphthyl ligands $\mathrm{L}_{17}$ and trans-PdX $(\mathrm{X}=\mathrm{Cl}$ or $\mathrm{Br})$ (Fig. 14a). Although each macrocycle component is meso (RS) and thus achiral, with $\mathrm{C}_{2 \mathrm{~h}}$ symmetry, the [2]catenane is dissymmetric with $\mathrm{C}_{2}$ symmetry as a result of the catenation step [82]. In Lützen's group, through the combination of enantiomerically pure ligand $\mathrm{L}_{18}$ and cis-protected $\left[(\mathrm{dppp}) \mathrm{Pd}(\mathrm{OTf})_{2}\right]$, the first example of homochiral tetranuclear catenane $\left[(\mathrm{dppp})_{4} \mathrm{Pd}_{4}\left\{(\mathrm{R})-\mathrm{L}_{18}\right\}_{4}\right](\mathrm{OTf})_{8}\left(\mathbf{3 2}-\mathbf{P d}^{\mathbf{I I}}\right)$ was observed in addition to dinuclear metallosupramolecular aggregates in an equilibrated mixture (Fig. 14b). Viewed from the single-crystal structure of $\mathbf{3 2}-\mathbf{P d}^{\mathbf{I I}}$, the size and shape of spirobifluorene moiety nicely fits the cavity of the dinuclear rhombus, suggesting that the formation of catenane 32-Pd ${ }^{\text {II }}$ should be favored by the close contact of two rings. The addition of a sterically-blocking methyl group in $\mathrm{L}_{19}$ produced the non-interlocked dinuclear complexes 33-Pd ${ }^{\text {II }}$ as expected, further proving that the efficient contact of two rings is a key factor influencing the formation of interlocked superstructures [83]. 


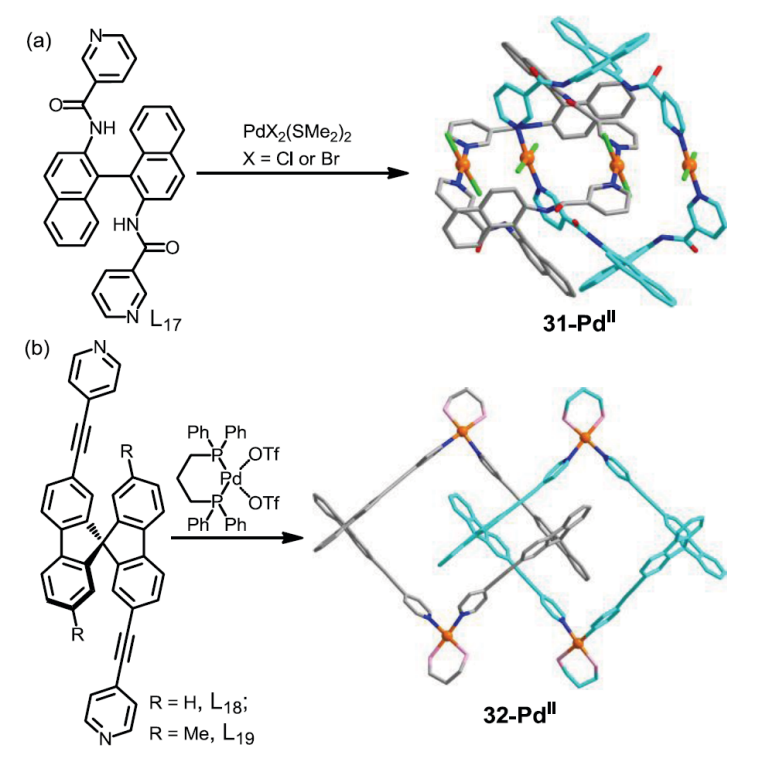

Fig. 14. The assembly of chiral [2]catenanes 31-Pd ${ }^{\text {II }}$ (a) [82] and 32-Pd ${ }^{\text {II }}$ (b) [83].

The combination of cis-Ru, bifunctional pyridyl ligands and bis-chelating linkers often gave

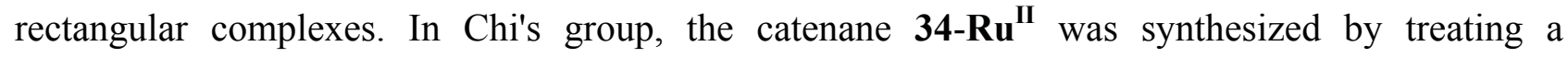
tetracene-based arene- $\mathrm{Ru}^{\mathrm{II}}$ acceptor $\left(\mathrm{L}_{20}\right)$ with an anthracene-based donor $\left(\mathrm{L}_{21}\right)$ in methanol, whereas the same building blocks assembled in nitromethane to give mono-rectangular complex 34'-Ru' ${ }^{\text {II }}$. Both the solvent used and the concentration play a key role in determining the selective self-assembly. In nitromethane, when the concentration of mono-ring $\mathbf{3 4}^{\prime}-\mathbf{R u}^{\text {II }}$ was $\leq 2 \mathrm{mM}$, no interlocked complex was observed. Upon increasing the concentration of mono-ring $\mathbf{3 4} \mathbf{A}^{\mathbf{2}}-\mathbf{R} \mathbf{u}^{\mathbf{I I}}$ to $>2$ $\mathrm{mM}$, the catenane 34-Ru${ }^{\text {II }}$ was formed as verified by ${ }^{1} \mathrm{H}$ NMR analysis. The presence of $\pi$-bondrich pyrene guest molecules can inhibit the intermolecular $\pi-\pi$ interactions between the rings, resulting in the formation of non-interlocked complex $\mathbf{3 5 - R \mathbf { u } ^ { \text { II } }}$ with two guest molecules (Fig. 15). The guest template, solvent, and concentration effects allow the reversible fine-tuning of the formation of this interlocked species [84].

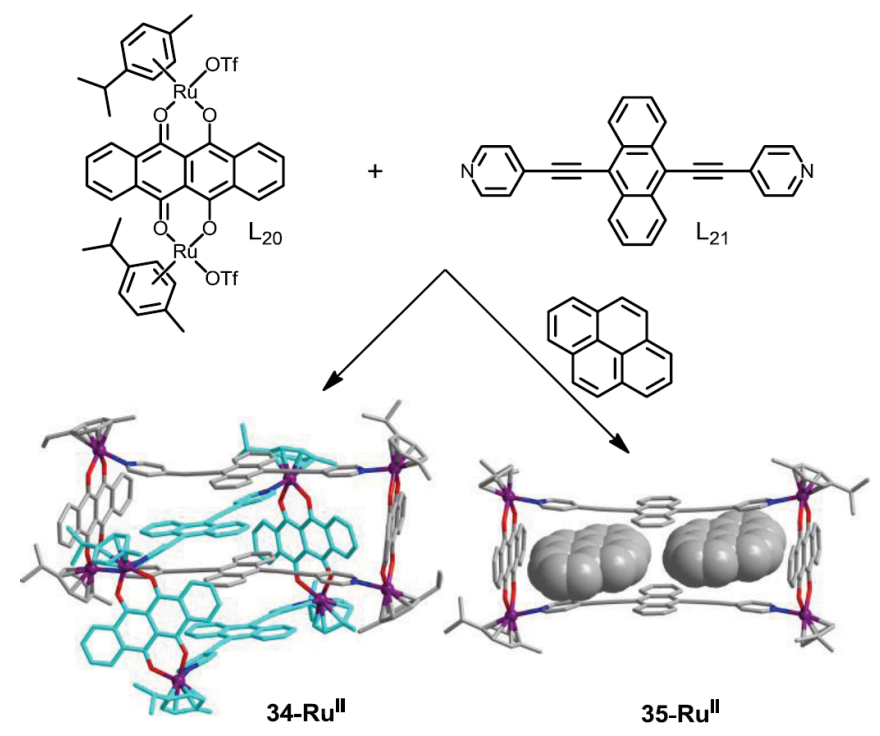

Fig. 15. Formation of [2] catenane $34-\mathbf{R} \mathbf{u}^{\text {II }}$ and pyrene-encapsulating rectangle $35-\mathbf{R} \mathbf{u}^{\text {II }}$ [84]. 


\subsection{Heterometallic Catenanes}

Heterometallic catenanes (also known as "heterocatenanes") are interesting family of structures, as the different metal ions can play different roles in their formation, such as the combined use of metal-template and metal-directed effects. As the donating groups to metal centers, the rational design of segmental ligands with different binding units is important for the construction of programmed heterometallic catenanes. Using the ligand $\mathrm{L}_{22}$, composed of the bidentate unit $2,2^{\prime}-$ bipyridine and the alkali-metal-ion-recognizing group 15-crown-5, Beer and co-workers successfully synthesized the novel hetero [2] catenane $36-\mathbf{C} \mathbf{u}^{\mathbf{I}} \mathbf{K}^{\mathbf{I}}$ by a two-step reaction (Fig. 16a) [85]. The initial combination of ligand $\mathrm{L}_{22}$ with $\mathrm{Cu}(\mathrm{MeCN})_{4} \mathrm{PF}_{6}$ afforded the air-stable complex 36$\mathbf{C} \mathbf{u}^{\mathbf{I}}$, and further reaction of $\mathbf{3 6}-\mathbf{C u}^{\mathrm{I}}$ with an excess of $\mathrm{KPF}_{6}$ gave the catenane $36-\mathbf{C} \mathbf{u}^{\mathrm{I}} \mathbf{K}^{\mathbf{I}}$. In contrast to $\mathrm{K}^{\mathrm{I}}$, no canenane was observed when $\mathrm{Na}^{\mathrm{I}}$ was used, which may be ascribed to the smaller ionic radius of $\mathrm{Na}^{\mathrm{I}}$, which can not hold 15-crown-5 groups together intramolecularly to form the required sandwich lock. One efficient way to synthesize heterometallic catenanes is to form a "cross catenane" of different metal-containing rings. For example, based on the different kinetic nature of $\mathrm{Pd}^{\mathrm{II}}-\mathrm{N}$ and $\mathrm{Pt}^{\mathrm{II}}-\mathrm{N}$ bonds, the $\mathrm{Pd}^{\mathrm{II}}-\mathrm{Pt}^{\mathrm{II}}$-catenane $37-\mathbf{P d}^{\mathrm{II}} \mathbf{P t}^{\mathrm{II}}$ can be produced by the cross catenation of $\mathrm{Pd}^{\mathrm{II}}$ - and $\mathrm{Pt}^{\mathrm{II}}$-linked rings (Fig. 16b). By adding $\mathrm{H}_{2} \mathrm{O}$ to a DMF solution of $\mathrm{Pd}^{\mathrm{II}}-$ linked and $\mathrm{Pt}^{\mathrm{II}}-$ linked rings, the heterometallic canenane $\mathbf{3 7 -}-\mathbf{P d}^{\mathrm{II}} \mathbf{P t}^{\mathrm{II}}$ was selectively formed, as confirmed by both ${ }^{1} \mathrm{H}$ NMR and CSI-MS analysis [86].

(a)
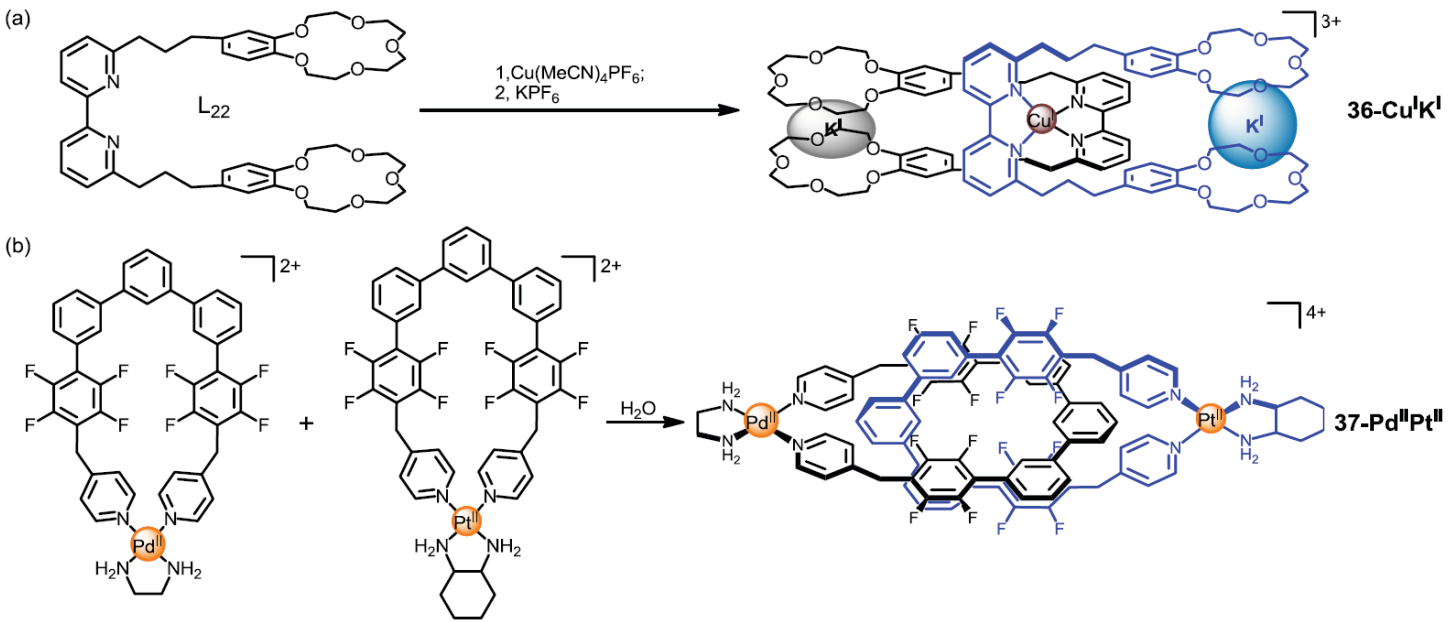

Fig. 16. The formation of heterometallic catenenes $36-\mathbf{C} \mathbf{u}^{\mathbf{I}} \mathbf{K}^{\mathbf{I}}$ (a) [85] and $\mathbf{3 7 -}-\mathbf{P d}^{\mathrm{II}} \mathbf{P} \mathbf{t}^{\mathrm{II}}$ (b) [86].

Most of the known hetero catenanes are constructed by stepwise reactions, and examples obtained from one-pot reaction are rare, because it is difficult to control the matching of binding sites with metal centers. Hence, a deep understanding of the coordination nature of different metal ions, and the rational design of ligands with selective binding units and enough flexibility, play a key role in the multi-component synthesis of hetero catenanes. In Piguet's group, one $\mathrm{Fe}^{\mathrm{II}}-\mathrm{Ag}^{\mathrm{I}}-$ hetero [2] catenane $\mathbf{3 8}-\mathbf{F e}^{\mathbf{I I}} \mathbf{A g}^{\mathbf{I}}$ was generated in the reaction of ligand $\mathrm{L}_{23}$ with mixed-metal 
acceptors $\mathrm{Fe}^{\mathrm{II}}$ and $\mathrm{Ag}^{\mathrm{I}}$, where the $\mathrm{Fe}^{\mathrm{II}}$ ion can be functionalized as a template center and $\mathrm{Ag}^{\mathrm{I}}$ acts as a lock center (Fig. 17) [87-88]. Because the two ions accommodate different numbers of coordinating groups, the $\mathrm{Fe}^{\mathrm{II}}$ center was pseudooctahedrally coordinated by the two tridentate units from two strands, while each $\mathrm{Ag}^{\mathrm{I}}$ ion was pseudotetrahedrally bound to two bidentate units of one ligand.

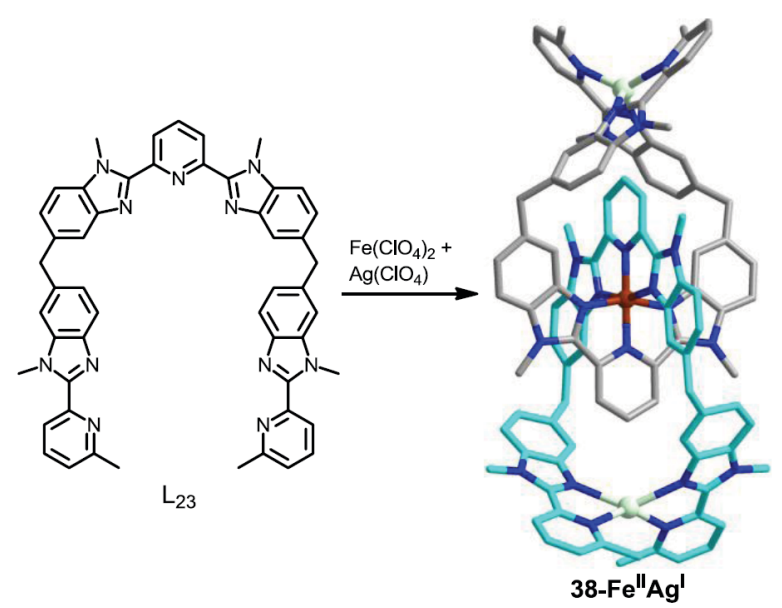

Fig. 17. The one-pot synthesis of heterometallic catenane $\mathbf{3 8 - F} \mathbf{F}^{\mathbf{I I}} \mathbf{A g}^{\mathbf{I}}$ [87-88].

The stepwise construction of heterometallic species by employing multiple identical coordinating fragments is a significant challenge because of the loss of metal ion recognition. However, with a deep understanding of the different coordinating properties and kinetic stabilities of $\mathrm{Cu}^{\mathrm{I}}, \mathrm{Ru}^{\mathrm{II}}$ and $\mathrm{M}^{\mathrm{II}}(\mathrm{M}=\mathrm{Cu}, \mathrm{Co}, \mathrm{Fe}, \mathrm{Zn})$, the heterotrimetallic [2]catenanes 39-Ru $\mathbf{u}^{\mathrm{II}} \mathbf{C} \mathbf{u}^{\mathrm{I}} \mathbf{M}^{\mathrm{II}}$ were synthesized in three steps including $\mathrm{Ru}^{\mathrm{II}}$-directed macrocycle formation, a $\mathrm{Cu}^{\mathrm{I}}$-templated threading process and $\mathrm{M}^{\mathrm{II}}$-directed ring closure [89]. The $\mathrm{Cu}^{\mathrm{I}}$ cation has tetrahedral coordination geometry and has been extensively used as a templating metal centre in the preparation of complex interlocking or knotted topologies. $\mathrm{Pd}^{\mathrm{II}}$ has square planar coordination geometry and has been used frequently in the synthesis of metallasupramolecules. By combining $\mathrm{Cu}^{\mathrm{I}}$-templation and $\mathrm{Pd}^{\mathrm{II}}$-directed closure in the same assembly, Sauvage and his colleagues successfully synthesized a series of heterometallic catenanes (40-Cu $\mathbf{u}^{\mathbf{I}} \mathbf{P d}^{\mathbf{I I}}$ ) [90-91]. The reaction of $\mathrm{L}_{24}\left(\right.$ or $\left.\mathrm{L}_{25}\right)$ and $\mathrm{Cu}(\mathrm{MeCN})_{4} \mathrm{PF}_{6}$ in mixed $\mathrm{MeCN}-$ DMF solution, immediately afforded the precursor 40-Cu $\mathbf{u}^{\mathbf{I}}$. Upon subsequent treatment with $\mathrm{Pd}(\mathrm{en})\left(\mathrm{NO}_{3}\right)_{2}$ for the ring-closure step, catenane 40-C $\mathbf{u}^{\mathbf{I}} \mathbf{P} \mathbf{d}^{\mathrm{II}}$ was obtained quantitatively (Fig. 18a). Both ${ }^{1} \mathrm{H}$ NMR and CSI-MS supported the formation of catenane 40-Cu $\mathbf{u}^{\mathbf{I}} \mathbf{P d} \mathbf{d}^{\text {II }}$. In sharp contrast with the labile $\mathrm{Pd}^{\mathrm{II}}$ center, $\mathrm{Ru}^{\mathrm{II}}$ is more substitutionally inert. Due to the presence of easily-substituted MeCN ligands in cis-Ru(phen $)_{2}(\mathrm{MeCN})_{2}\left(\mathrm{PF}_{6}\right)_{2}$, the $\mathrm{Ru}^{\mathrm{II}}$ analogues of $\mathrm{Pd}^{\mathrm{II}}$-catenanes were also targetted. The combination of ligand $\mathrm{L}_{24}$ and the $\mathrm{Ru}^{\mathrm{II}}$-corner successfully produced macrocycle $\mathbf{4 1}^{\prime}$ $\mathbf{R} \mathbf{u}^{\text {II }} . \mathrm{L}_{24}$ was threaded inside the macrocycle $\mathbf{4 1}-\mathbf{R} \mathbf{u}^{\text {II }}$ with the aid of the $\mathrm{Cu}^{\mathrm{I}}$-template. The cyclization step between the dangling pyridine donors and the $\mathrm{Ru}^{\mathrm{II}}$-corners finally led to the hetero [2]catenane 41-Ru ${ }^{\text {II }} \mathbf{C u}^{\text {I }}$ (Fig. 18b) [92]. Using a similar synthetic strategy, but exchanging the ring- 
closing units with strands composed of $\mathrm{Zn}$-porphyrins linked by aromatic spacers, the apical coordination of the uncoordinated pyridines to the $\mathrm{Zn}$-porphyrin units afforded the [2] catenane 42 $\mathrm{Cu}^{\mathrm{I}} \mathbf{Z n}^{\text {II }}$ [93].
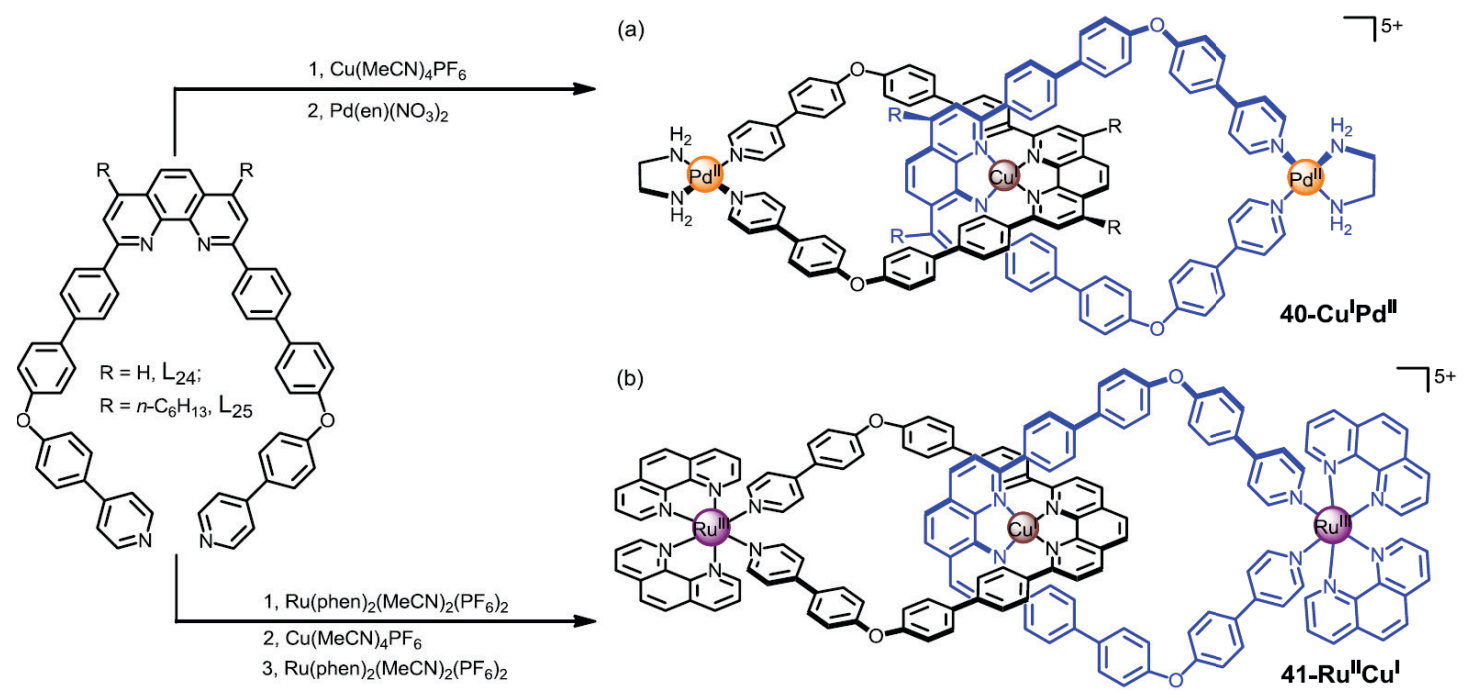

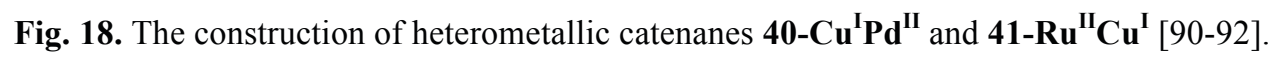

Based on the selective reaction of the multi-functional ligand with different metal sources, Sauvage and co-workers developed a new method for the preparation of metal-containing catenanes. By taking advantage of the differential stereoelectronic requirements of transition metals, different types of metal ions were applied, respectively acting as assembling and templating species. One ligand $\left(\mathrm{L}_{26}\right)$ containing two terpyridine (terpy) units and one diphenylphenanthroline (dpp) unit was prepared. In accordance with the preferred tetrahedral coordination of the $\left[\mathrm{Cu}(\mathrm{dpp})_{2}\right]^{+}$moiety, the polyfunctional ligand $\mathrm{L}_{26}$ and the dpp-containing macrocycle $\mathrm{L}_{27}$ were bound together through a $\mathrm{Cu}^{\mathrm{I}}$ template, resulting in a highly stable intertwined structure presenting two free terpy moieties. In this process, no competition of the terpy units take place. Upon subsequent treatment with $\mathrm{Ru}^{\mathrm{II}}$ ions, the two terpy units are linked together, achieving the ring closure and giving $\mathrm{Cu}^{\mathrm{I}}-\mathrm{Ru}^{\mathrm{II}}$-canenane 43$\mathbf{C u}^{\mathrm{I}} \mathbf{R} \mathbf{u}^{\text {II }}$ (Fig. 19). The high stability of the Ru(terpy) ${ }_{2}{ }^{2+}$ center allows for the selective removal of the $\mathrm{Cu}^{\mathrm{I}}$ template, leading to the formation of template-free $\mathrm{Ru}^{\mathrm{II}}$-catenane $\mathbf{4 3}-\mathbf{R} \mathbf{u}^{\mathrm{II}}$. By adding $\mathrm{Ag}^{\mathrm{I}}$ or $\mathrm{Zn}^{\mathrm{II}}$ ions to the solution of the $\mathrm{Ru}^{\mathrm{II}}$-catenane, the two dpp units can again be bound together, resulting in the formation of $\mathrm{Ag}^{\mathrm{I}}-\mathrm{Ru}^{\mathrm{II}}$-canenane $\mathbf{4 3}-\mathbf{A g}{ }^{\mathrm{I}} \mathbf{R} \mathbf{u}^{\mathrm{II}}$ or $\mathrm{Zn}^{\mathrm{II}}-\mathrm{Ru}^{\mathrm{II}}$-canenane $\mathbf{4 3 -} \mathbf{Z n}^{\mathrm{II}} \mathbf{R} \mathbf{u}^{\mathrm{II}}$. The different choice of the metal ion incorporated in the $\left[\mathrm{M}(\mathrm{phen})_{2}\right]^{\mathrm{n}+}$ center has a large influence on the energy- and/or electron-transfer between the moieties of $\left[\mathrm{M}(\mathrm{phen})_{2}\right]^{\mathrm{n}+}$ and $\mathrm{Ru}(\text { terpy })_{2}{ }^{2+}$, induced by photoinduced excited-state intercomponent interactions [94-95]. 


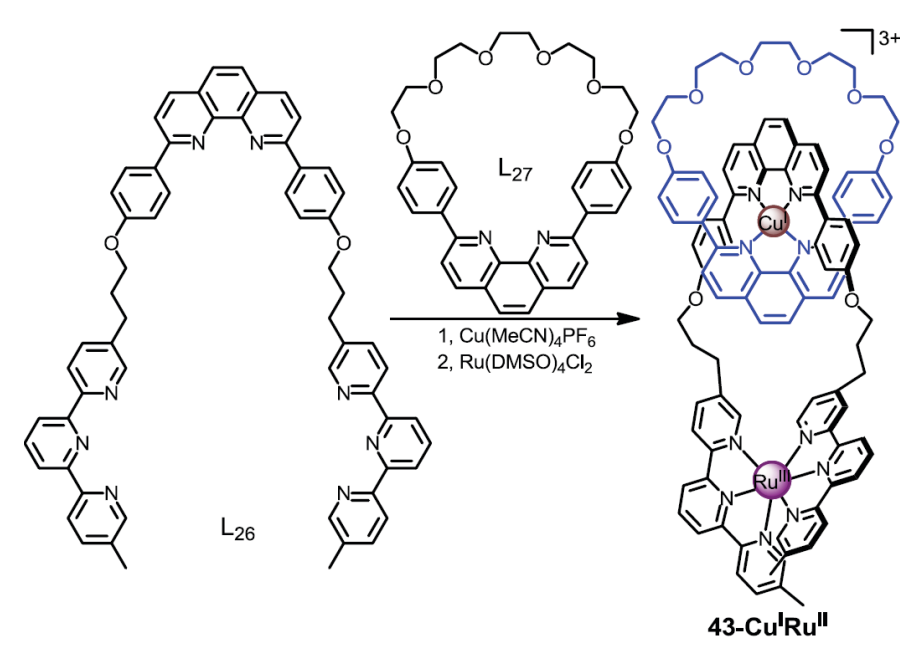

Fig. 19. The construction of heterometallic catenanes $43-\mathbf{C} \mathbf{u}^{\mathrm{I}} \mathbf{R} \mathbf{u}^{\mathrm{II}}[94-95]$.

The incorporation of redox-active metal-ligand moieties into metallasupramolecules not only endows them with the ability to act as electrochemical sensors, but also provides an opportunity for altering the inertness of coordination bonds through a controlled redox reaction. By the selective oxidation of pre-synthesized $\mathrm{Cu}^{\mathrm{II}}$ dithiocarbamate macrocycles, the mixed-valence $\mathrm{Cu}^{\mathrm{II}} / \mathrm{Cu}^{\mathrm{III}}$ [2] catenanes 44-Cu $\mathbf{u}^{\text {II }} \mathbf{C u}^{\text {III }}$ were serendipitously observed in Beer's group. The sequential addition of $\mathrm{FeCl}_{3}$ and $\mathrm{NaReO}_{4}$ to the solution of naphthyl-spaced macrocycles $44^{\prime}-\mathbf{C u}^{\text {II }}$ afforded the [2]catenanes 44-Cu${ }^{\text {II }} \mathbf{C u}^{\text {III }}$ (Fig. 20) [96]. As evidenced from the single-crystal X-ray analysis, all four independent $\mathrm{Cu}$ atoms have square-planar coordination spheres made up of the $\mathrm{S}$ atoms from two dithiocarbamate (dtc) ligands. In addition to the equatorial metal-ligand interactions, these $\mathrm{Cu}$ atoms also form either axial intra- or intermolecular contacts to $\mathrm{S}$ atoms in adjacent thiocarbamate ligands. The electrochemical properties of $\mathbf{4 4}^{\prime}-\mathbf{C u}^{\text {II }}$ and [2] catenane 44-Cu${ }^{\text {II }} \mathbf{C u}^{\text {III }}$ were investigated using cyclic and square-wave voltammetry. Compared with the single broad quasi-reversible oxidation wave $(0.19 \mathrm{~V})$ of mono-ring $\mathbf{4 4}^{\prime}-\mathbf{C u}^{\mathbf{I I}}$, the catenanes exhibit two quasi-reversible oxidation waves at 0.07 and $0.25 \mathrm{~V}$. The first oxidation of catenane occurs at a significantly less anodic potential than that of the mono-ring $\mathbf{4 4}^{\prime}-\mathbf{C u}^{\mathbf{I I}}$, suggesting that the topological rearrangement from mono-ring to [2] catenane stabilizes the $\mathrm{Cu}^{\mathrm{III}}$ oxidation state. The oxidation of $\mathrm{Cu}^{\mathrm{II}}-\mathrm{dtc}$ is responsible for the occurrence of interpenetrating process, because the kinetic lability of $\mathrm{Cu}^{\mathrm{III}}$-dtc enables the dissociation of preformed macrocycles, providing the kinetic possibility for catenane formation. The electron-deficient nature of the positively charged $\mathrm{Cu}^{\text {III }}$-dtc unit leads to a unique affinity for the electron-rich $\mathrm{Cu}^{\mathrm{II}}$-dtc moieties, providing a direct driving force for catenane formation. 


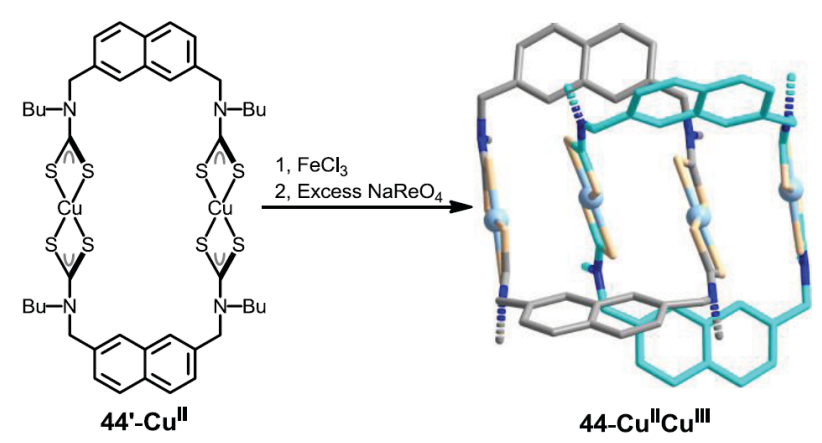

Fig. 20. Synthesis of [2]catenane 44-Cu $\mathbf{u}^{\text {II }} \mathbf{C} \mathbf{u}^{\text {III }}$ [96].

Similar to $\mathrm{Cu}^{\mathrm{III}}$-dtc, $\mathrm{Au}^{\mathrm{III}}$-dtc shows remarkable kinetic lability and electron-deficiency, hence the $\mathrm{Au}^{\mathrm{III}}$-dtc macrocyclic analogue was employed to test the above hypothesis. Treatment of macrocyclic precursor $\mathbf{4 4}^{\prime}-\mathrm{Cu}^{\mathrm{II}}$ with $\mathrm{NaAuCl}_{4}$ afforded the corresponding heterometallic complexes 45-Cu ${ }^{\text {II }} \mathbf{A} \mathbf{u}^{\text {III }}$ in yields of 60-80\% (Fig. 21) [97]. The catenane formation and the metal and ligand exchange were all detected by ESI-MS analysis. Interestingly, only the participation of Aunaphthalene-spaced macrocycles led to the formation of heterometallic [2]catenane $\mathbf{4 5 -} \mathbf{C u}^{\text {II }} \mathbf{A} \mathbf{u}^{\text {III }}$ with a single metal and spacer in each ring. In contrast, the reaction of $\mathrm{Cu}$-naphthalene-spaced macrocycles with other Au-macrocycles afforded only the Au-based mixed-ligand mono-ring, suggesting that the donor-acceptor-donor $\mathrm{Cu}^{\mathrm{II}}-\mathrm{Au}^{\mathrm{III}}-\mathrm{Cu}^{\mathrm{II}}$ dtc electrostatic interactions are the crucial driving force to favour and stabilise catenane formation. Due to the short length of m-xylyl arm, participation of m-xylyl-spaced macrocycles afforded only the $\mathrm{Cu}$-Au-based mono-ring product. The combination of other macrocycles generated only the mixed-ligand-based gold mono-ring. These competing ligand exchange and transmetallation reactions highlight the lability of transition metal-dtc coordination bonds. However, only one [2]catenane containing a naphthalene spacer was successfully isolated, all other [2]catenanes transformed to the mixed-ligand or mixed-metal macrocycles over a longer time scale, which suggests that these catenanes are kinetic products.

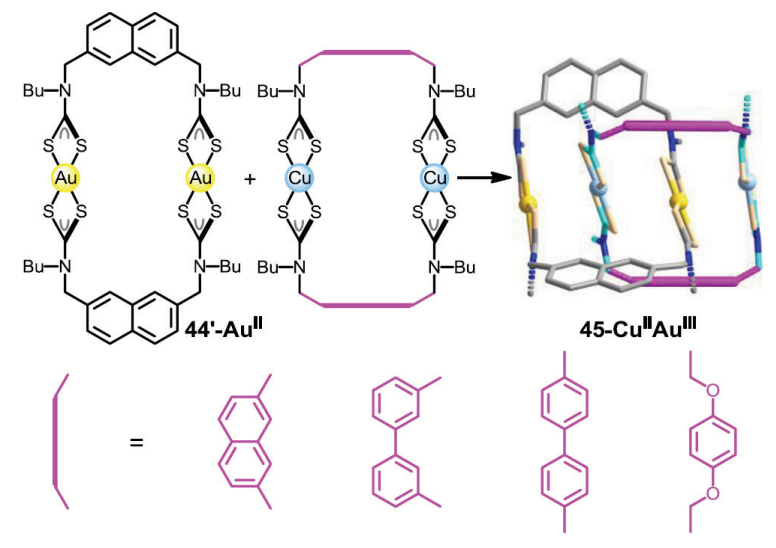

Fig. 21. Synthesis of [2]catenane 45-Cü ${ }^{\mathrm{II}} \mathbf{A} \mathbf{u}^{\mathrm{III}}$ [97].

\subsection{Hybrid Catenanes}


In contrast to purely metal-organic catenanes, hybrid catenanes can be constructed from both organic and inorganic macrocycles. Donor-acceptor interactions have become a favorable driving force to enforce the formation of mechanically interlocked systems, because of the syntheticallyconvenient nature of some well-known macrocycle-based host-guest chemistry. For example, due to the electron-rich nature of crown ether compounds, they can interact easily with electron-deficient pyridinium compounds. If metal-ligand coordination is utilized together with donor-acceptor interactions, hybrid catenanes can be produced with relative ease.

Cucurbituril (CB) has large internal cavity, high chemical stability and stable inclusion ability with protonated diaminoalkanes, making it a good candidate for hybrid catenane formation. By the combined use of CB-diaminoalkane interactions and metal-pyridine interactions, Kim and coworkers synthesized a series of hybrid [n]catenanes. For example, stirring the 1:1:1 mixture of CB, N,N'-bis(4-pyridylmethyl)-1,4-diaminobutane dihydronitrate $\left(\mathrm{L}_{28}\right)$ and $\operatorname{Pt}(\mathrm{en})\left(\mathrm{NO}_{3}\right)_{2}$ afforded the [4]catenane 46-Pt ${ }^{\mathrm{II}}$ in $90 \%$ yield (Fig. 22) [98]. Using a similar synthetic method with different building blocks, or changing the pre-organised pseudorotaxane linkers as the mixture of protonated diaminoalkanes and $\mathrm{CB}$ can also efficiently produce other [n]catenane complexes [99-101]. The simultaneous use of orthogonal $\mathrm{Cu}^{\mathrm{I}}$-phenanthroline and $\mathrm{CB}$-diaminoalkane interactions preorganising the precursors and the efficient azide-alkyne cycloaddition closing the ring, resulted in [7]catenane 47-C $\mathbf{u}^{\mathbf{I}}$ with high structural complexity [102].

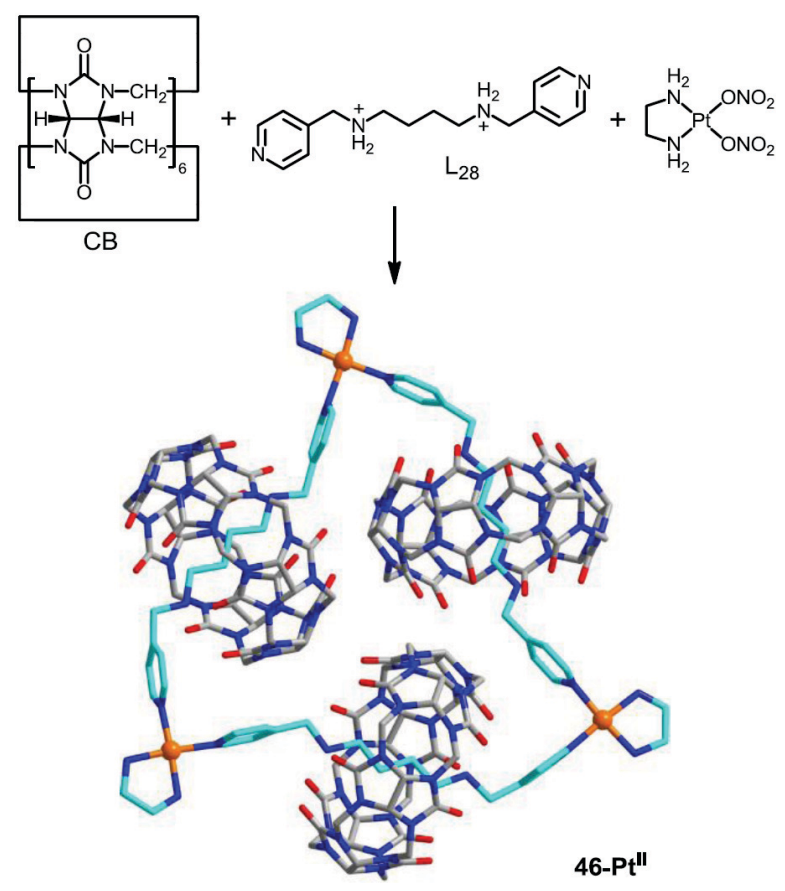

Fig. 22. Synthesis of hybrid [4]catenane $46-\mathbf{P t}^{\mathrm{II}}[98]$.

Among the crown-ether-based examples, $\mathrm{BPy}^{2+}$-based $\pi$-acceptors have been the electrondeficient units most frequently used to template the formation of donor-acceptor catenanes. Peinador and co-workers developed a hybrid [2]catenane system based on the $\pi$-donor/ $\pi$-acceptor 
interactions between electron-deficient pyridinium component and electron-rich crown ethers. The combination of these $\pi$-deficient ligands with $\mathrm{M}^{\mathrm{II}}(\mathrm{M}=\mathrm{Pd}$ or $\mathrm{Pt})$ takes advantage of thermodynamic control and ensures a superior $\pi$-deficient character of the resulting metallacycles. These can be efficiently threaded by the organic ring with $\pi$-donor properties, resulting in the efficient synthesis of [2]- and [3]catenanes. Mixing bipyridinium ligands $\mathrm{L}_{29}, \mathrm{Pd}(\mathrm{en})\left(\mathrm{NO}_{3}\right)_{2}$ and crown ether $\mathrm{L}_{30}$ in $\mathrm{D}_{2} \mathrm{O}$, and heating at $100{ }^{\circ} \mathrm{C}$ for $10 \mathrm{~h}$, the catenane 48-Pd ${ }^{\mathrm{II}}$ was observed as the sole product by ${ }^{1} \mathrm{H}$ NMR. Employing the same method, the analogous Pt-catenane 48-Pt ${ }^{\mathrm{II}}$ was isolated as its $\mathrm{PF}_{6}{ }^{-}$salt (Fig. 23a) [103]. However, the employment of higher-symmetry bipyridinium ligands $\mathrm{L}_{31}$ (or $\mathrm{L}_{32}$ ), trans- $\mathrm{PdCl}_{2}(\mathrm{MeCN})_{2}$ and excess crown ethers $\mathrm{L}_{30}$ led to self-assembly of the [3]catenane 49-Pd ${ }^{\text {II }}$ (or 50-Pd ${ }^{\mathbf{I I}}$ ), viz. a Pd-macrocycle interlocked by two $\pi$-complementary crown ethers (Fig. 23b). In $\mathrm{MeCN}$, the dicationic ligand $\mathrm{L}_{31}$ (or $\mathrm{L}_{32}$ ) and crown ether $\mathrm{L}_{30}$ are in a dissociated state. Following the formation of coordinative $\mathrm{Pd}^{\mathrm{II}}-\mathrm{N}$ bond, they can bond together and promote the catenation process, because the acceptor character of the ligand $\mathrm{L}_{31}$ (or $\mathrm{L}_{32}$ ) increases upon coordination [104]. The multi-component self-assembly of corner-ligand $\mathrm{L}_{33}, \mathrm{Pd}(\mathrm{en})\left(\mathrm{NO}_{3}\right)_{2}$ and polyether macrorings $\mathrm{L}_{30}$ afforded [3] catenanes 51-Pd ${ }^{\text {II }}$ (Fig. 23c). Single-crystal X-ray diffraction analysis and NMR studies indicated the [3] catenanes are stabilized by means of a combination of $\pi-\pi$ stacking, [C$\mathrm{H} \cdots \pi]$ interaction and $[\mathrm{C}-\mathrm{H} \cdots \mathrm{O}] \mathrm{H}$-bonds. Interestingly, the successive addition of $\mathrm{KPF}_{6}$ and 18 crown-6 reversibly tune the catenane process of 51-Pd ${ }^{\text {II }}$ [105-106]. The correct angles at the metal center, the length of the side arm, and its $\pi$-complementary character determine the binding ability of the metallacyclic acceptor with an organic donor. To probe the effect of the cavity size on guest inclusion and catenane formation, one non-symmetrical bipyridinium ligand $\left(\mathrm{L}_{34}\right)$ with elongated arms based on the bpe motif was used, leading to the isolation of [3]catenanes 52-Pd ${ }^{\text {II }}$ [107-109]. Nevertheless, if the organic ring was replaced by a similar metallacycle-containing crown ether group, the attempted self-assembly of the [2]catenane failed, by both multi-component one-pot reaction and reaction between preformed metallacycles. Finally, the expected [2]catenane 54-Pt ${ }^{\text {II }}$ was obtained through a stepwise method involving the threading of dioxoaryl ligand $\mathrm{L}_{35}$ and preformed $\mathrm{Pt}^{\mathrm{II}}$-macrocycle 53-Pt ${ }^{\mathrm{II}}$, and the subsequent cis-Pt-directed cyclization (Fig. 23d). In the presence of metal ions, the dioxoaryl ligand $\mathrm{L}_{35}$ preferred to form the coordinate species rather than donor-acceptor adducts. Upon combination with metal ions, the $\pi$-donor character of the dioxoaryl groups was decreased, making them unable to bind with the $\pi$-deficient site, so the self-assembly approach can not take effect [110]. 
(a)

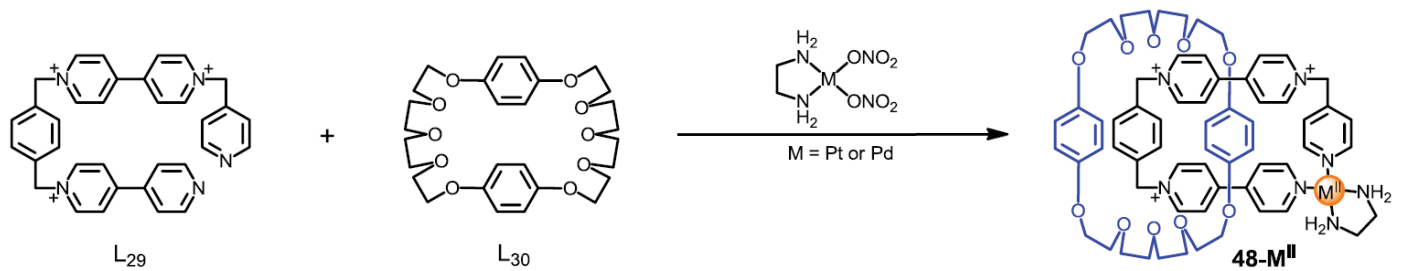

(b)

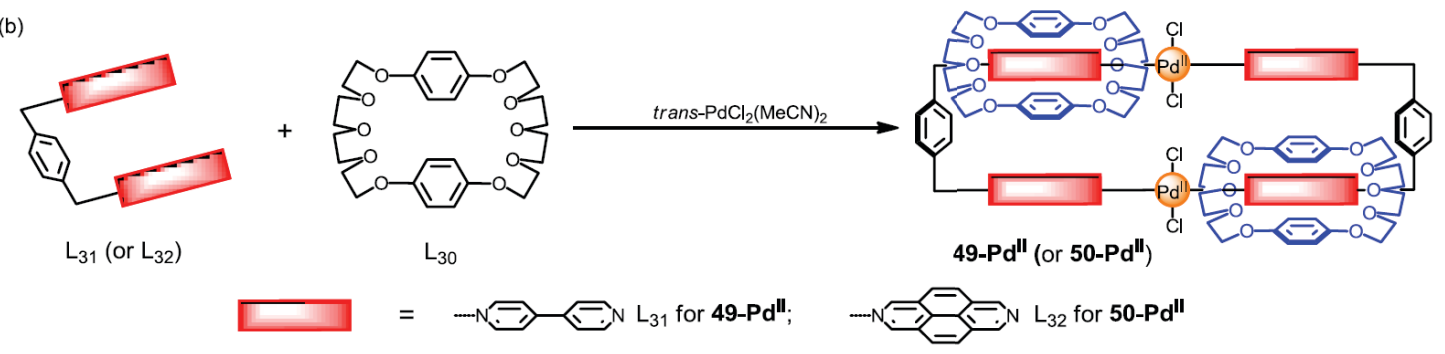

(c)
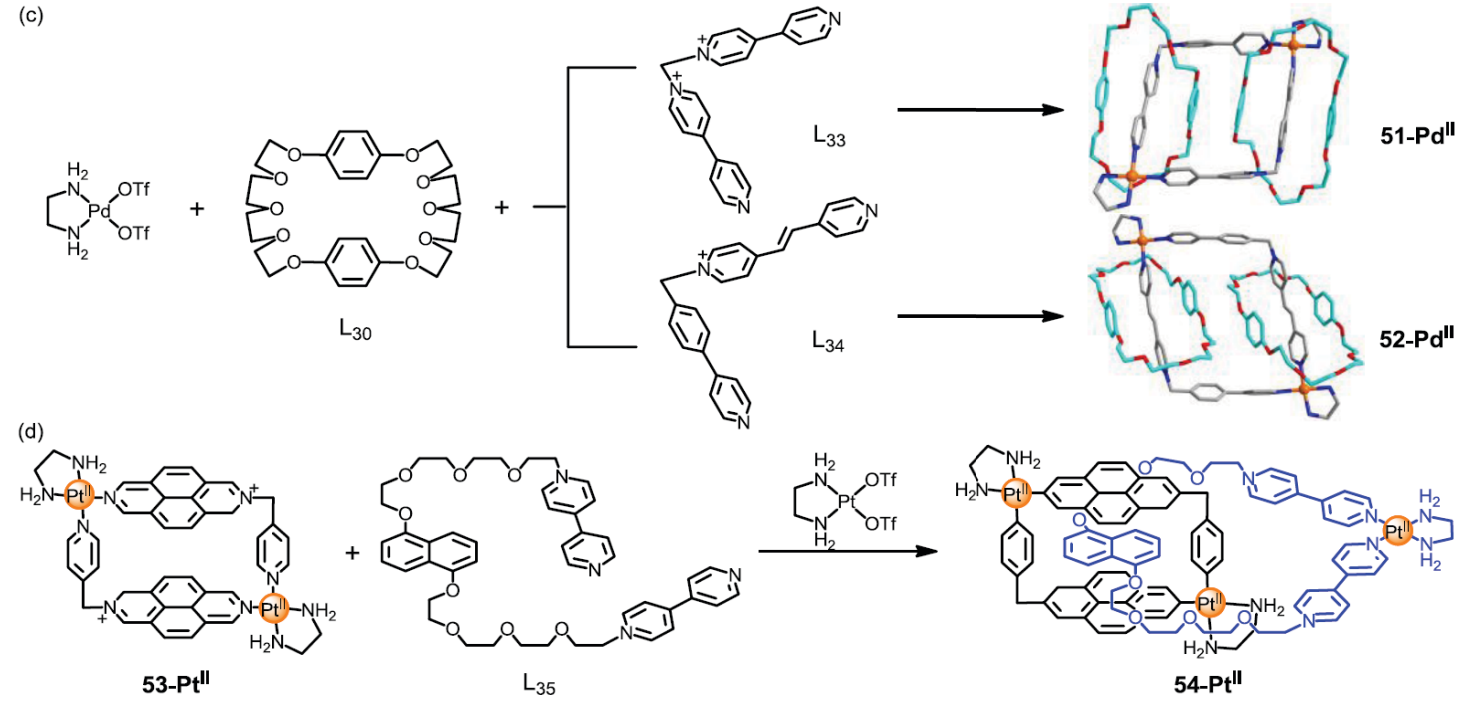

Fig. 23. The construction of different hybrid catenanes based on polyether donors [103-110].

The well-developed $\mathrm{DB}_{24} \mathrm{C}_{8}\left(\mathrm{~L}_{36}\right)$ recognition motif has been widely used in the synthesis of interlocked molecules. Stang et al. extended its application to the coordination-driven self-assembly of [n]catenanes. The [3]catenane 55-Pt ${ }^{\text {II }}$ were synthesized from the one-pot reaction of 1,2-bis(4,4'bipyridinium)-ethane $\left(\mathrm{L}_{37}\right)$, cis- $\mathrm{Pt}\left(\mathrm{PEt}_{3}\right)_{2}(\mathrm{OTf})_{2}$, ditopic carboxylate ligands $\left(\mathrm{L}_{38}\right)$ and $\mathrm{DB}_{24} \mathrm{C}_{8}$ (Fig. 24a) [111]. Using the initially formed [2]pseudorotaxane or addition of $\mathrm{DB}_{24} \mathrm{C}_{8}$ to the pre-organised metallacycles can also provide the target [3]catenanes 55-Pt ${ }^{\mathbf{I I}}$, suggesting that the system is under thermodynamic control with the catenane as the energetically preferred product. The NMR spectroscopy, ESI-MS and single-crystal X-ray diffraction data of the assembly confirmed the formation of [3]catenanes. $\mathrm{DB}_{24} \mathrm{C}_{8}$ has a stronger affinity for $\mathrm{K}^{\mathrm{I}}$ than for 1,2-bis(4,4'-bipyridinium)-

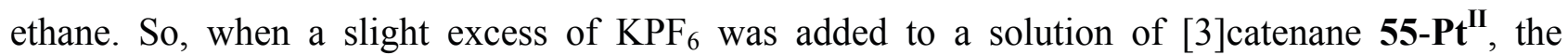
catenane dissociated to furnish metallacycles. The [3]catenanes could be re-formed by titration with 18-crown-6, which forms a stronger complex with $\mathrm{K}^{\mathrm{I}}$ than $\mathrm{DB}_{24} \mathrm{C}_{8}$. Taking a similar strategy, but without the participation of ditopic carboxylate ligands, the [4]catenanes and [7]catenanes were obtained from the respective use of $60^{\circ}$ or $90^{\circ} \mathrm{Pt}^{\mathrm{II}}$-corner units [112]. Similarly, the addition of crown ether $\mathrm{DB}_{24} \mathrm{C}_{8}$ rigidified flexible ligands, leading to the conversion of binuclear macrocycles 
into triangular molecular necklace 56-PtII . The three interlocked crown ether rings completely fill the centre of the triangle [113]. The dialkylammonium ions can also be used as recognition sites for $\mathrm{DB}_{24} \mathrm{C}_{8}$. Liu et al. reported the porphyrin-based [2]catenane 57-Sn ${ }^{\mathbf{I I}}$, and the ring closure was achieved from the axial ligation of Sn-porphyrin dihydroxide with two resorcinol moieties of the termini of the dialkylammonium spacer (Fig. 24b) [114].
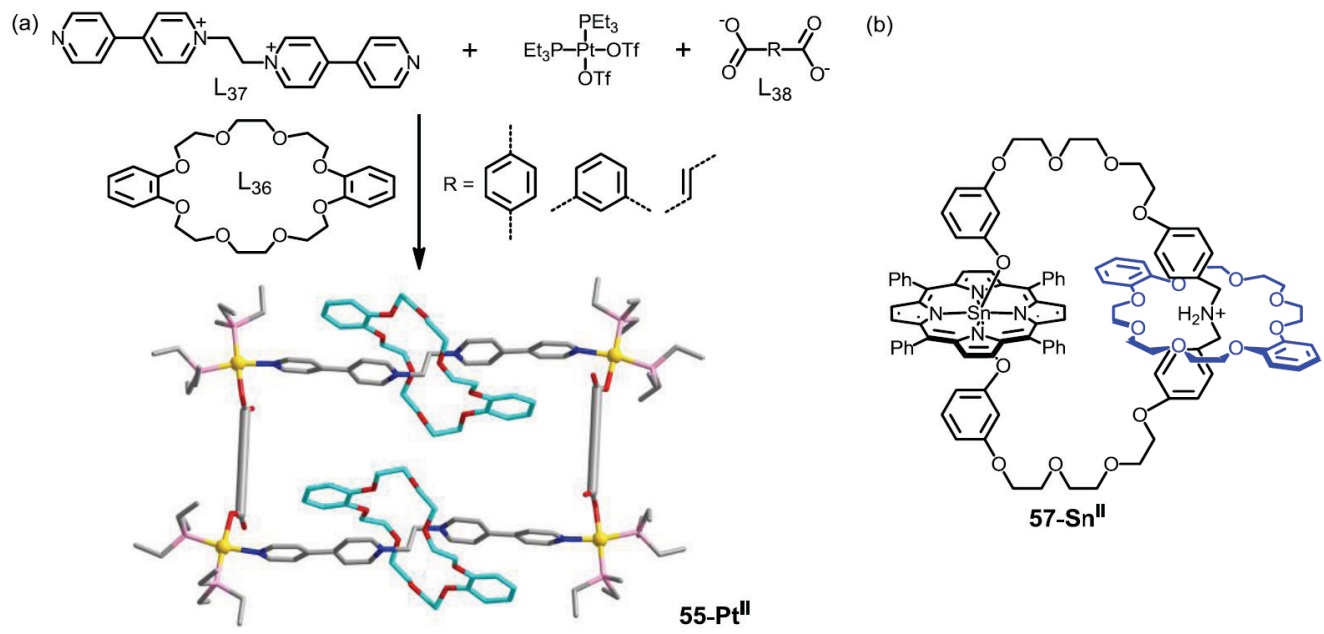

Fig. 24. The construction of $\mathrm{DB}_{24} \mathrm{C}_{8}$-based [3]catenanes $\mathbf{5 5 -}-\mathbf{P t}^{\mathrm{II}}$ (a) [111] and [2]catenane 57-Sn ${ }^{\mathrm{II}}$ (b) [114].

Similarly to $\mathrm{BPy}^{2+}$ derivatives, neutral diimide units are readily available electron-deficient $\pi$ acceptors that can in some cases also form inclusion complexes with $\pi$-electron-rich macrocyclic polyethers. However, the $\pi$-accepting ability of these ligands was much weaker. Despite this, the imide-based derivatives can effectively hold the crown ethers to give donor-acceptor catenanes. By utilising both crown ether-naphthalene diimide host-guest interactions and metallaporphyrin-pyridyl coordination, the [2]catenane 58-Rü ${ }^{\text {II }}$ was synthesized by Gunter and co-workers (Fig. 25a) [115]. Later, Liu and co-workers reported the high-yield assembly of the [2]catenanes 59-Pd ${ }^{\text {II }}$ from the multi-component system with a crown ether, a diimide-based ditopic ligand, a linking bipyridyl ligand and two cis-Pd ${ }^{\mathrm{II}}$ corner units (Fig. 25b). The $\pi$-stacking interactions arising from the filler groups of the $\pi$-accepting linkers can provide extra stabilization interactions and compensate the relatively weak donor-acceptor interactions [116].
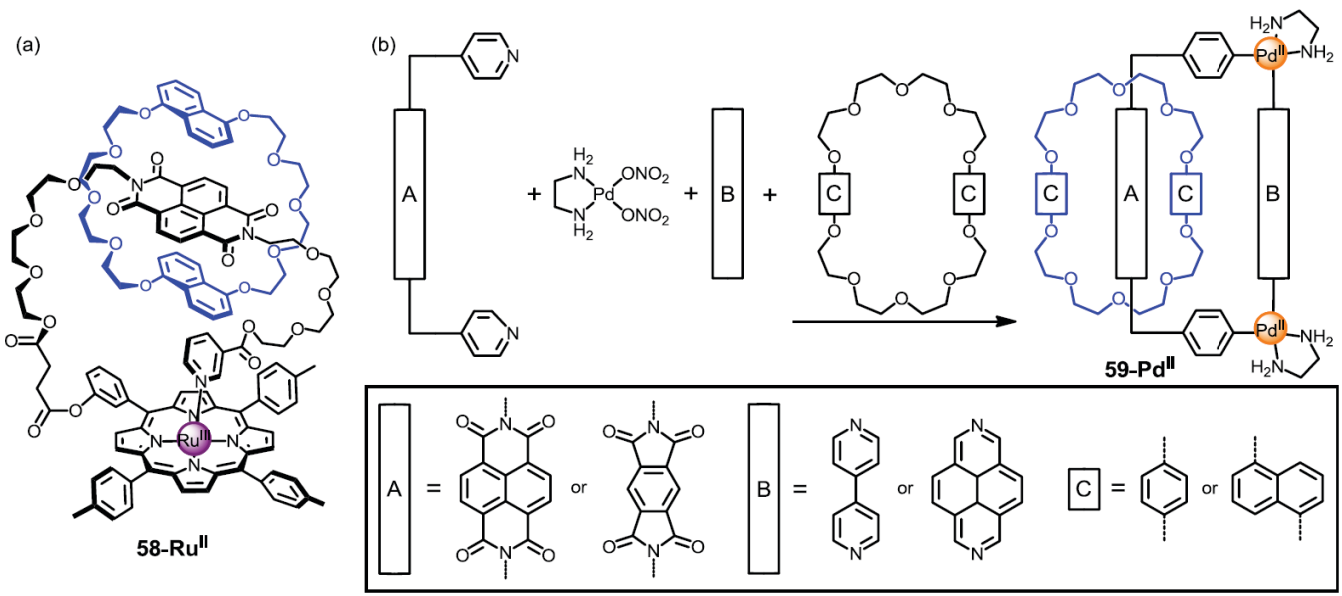
Fig. 25. The diimide-unit-induced formation of [2] catenane 58-Ru ${ }^{\text {II }}$ (a) [115] and [2]catenanes 59-Pd ${ }^{\text {II }}$ (b) [116].

The interactions applied in most catenanes formation reactions are limited to two kinds, and the harnessing of weaker interactions to generate complex structures is more difficult. Bampos et al. reported the construction of catenanes by the employment of three distinct non-covalent interactions, involving crown ether-diimide host-guest interactions, pyridine-metal porphyrin interactions and M-terpyridine interactions. In this one-pot reaction, both [2]catenane $\mathbf{6 0 a -} \mathbf{M}^{\mathbf{I I}}$ and [3]catenane 60b-M $\mathbf{M}^{\mathbf{I I}}$ were observed as the major products (Fig. 26) [117].
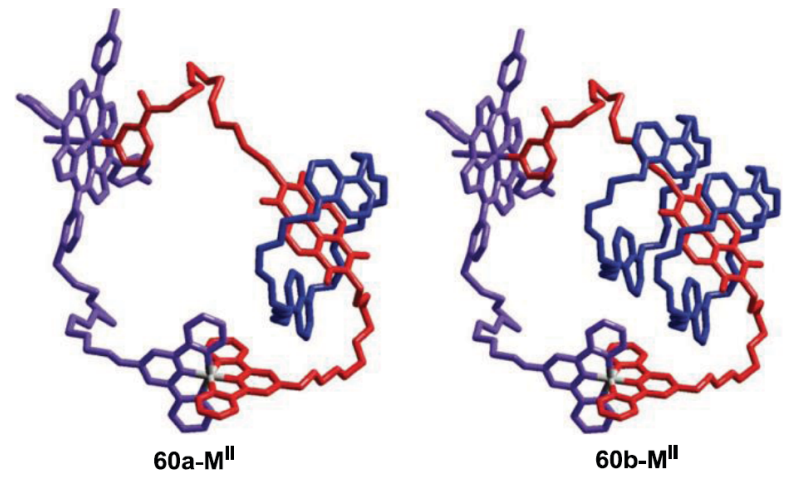

Fig. 26. Schematic representation of the [2]catenane $\mathbf{6 0 a}-\mathbf{M}^{\mathbf{I I}}$ and [3]catenane $\mathbf{6 0 b}-\mathbf{M}^{\mathbf{I I}}$. Adapted with permission from Ref. [117].

Sanders and co-workers reported a three-dimensional tetrahedral [7]catenane 61-Fe ${ }^{\text {II }}$ that was produced by a central cage threaded with six crown ethers $\left(\mathrm{L}_{39}\right)$. The tetrahedral cage comprises four $\mathrm{Fe}^{\mathrm{II}}$ ions and six ditopic $\mathrm{L}_{40}$ linkers incorporating an electron-poor aromatic naphthalene diimide group. Due to the dynamic nature of metal-pyridine bonds, the electron-rich crown ether can slip on an edge to bind the electron-deficient region, resulting in the [7]catenane formation (Fig. 27) [118].

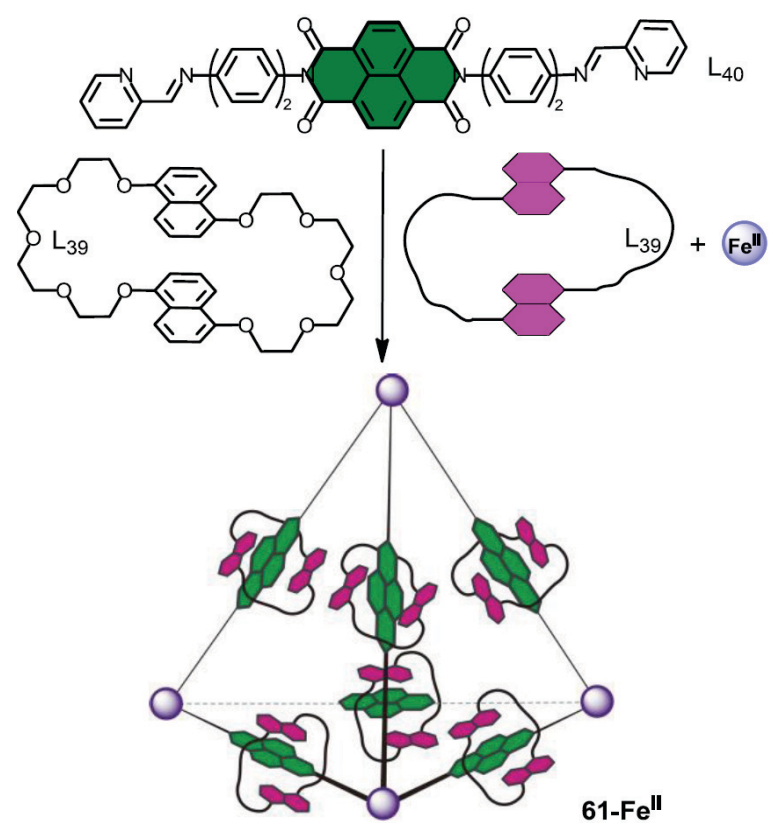

Fig. 27. Synthesis of tetrahedral cage-based [7]catenane 61-Fe ${ }^{\text {II }}$. Adapted with permission from Ref. [118]. 


\section{Solomon Links}

The Solomon link is a 421 link, as it comprises two components and four crossings. Such doubly-entwined [2]catenanes are still rare, and including a few metal-templated examples [119124] and examples with all-organic backbones [125].

A collaboration between Fujita and Sauvage's group combined $\mathrm{Cu}^{\mathrm{I}}$-templation and $\mathrm{Pd}^{\mathrm{II}}$-direction in the same assembly, resulting in the quantitative formation of Solomon link $62-\mathbf{C u}^{\mathbf{I}} \mathbf{P} \mathbf{d}^{\mathbf{I I}}$. This unexpected structure was obtained because the organic ligand $\mathrm{L}_{41}$, containing attached pyridine units, was too short to chelate a single Pd ${ }^{\mathrm{II}}$ and failed to form the [2]catenane (Fig. 28) [126].

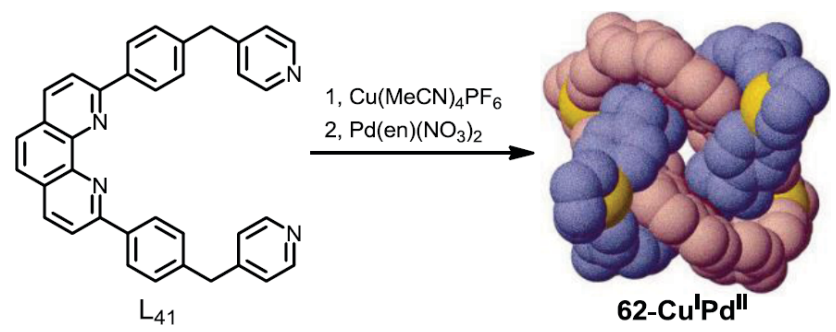

Fig. 28. Self-assembly of the Solomon link 62-Cu $\mathbf{u}^{\mathbf{I}} \mathbf{P} \mathbf{d}^{\mathbf{I I}}$. Adapted with permission from Ref. [126].

As mentioned above, in Puddephatt's digold-diacetylide-diphosphane [2]catenane system, a Solomon link complex 63-Au' ${ }^{\mathbf{I}}$ was surprisingly observed upon using the hinge group $\mathrm{C}_{6} \mathrm{H}_{10}$ and the $\mathrm{Ph}_{2} \mathrm{P}\left(\mathrm{CH}_{2}\right)_{4} \mathrm{PPh}_{2}$ linker (Fig. 29) [127]. In contrast to the mono-ring and the 2-interlocked ring, the Solomon link structure was constructed from doubly-braided 50-membered rings. Variable temperature ${ }^{1} \mathrm{H}$ and ${ }^{31} \mathrm{P}$ NMR studies of both the single ring and the [2]catenane show no significant differences, indicating the effective $C_{2 v}$ symmetry in each case. For Solomon link 63-A $\mathbf{u}^{\mathbf{I}}$, however, two chemically distinct types of phosphorus atoms coalesce to appear as one resonance as the sample is warmed up from $-90{ }^{\circ} \mathrm{C}$ to $20{ }^{\circ} \mathrm{C}$. The coalescence of inequivalent resonances was similarly observed in the ${ }^{1} \mathrm{H}$ NMR spectra, which further confirmed the fluxional behaviour and

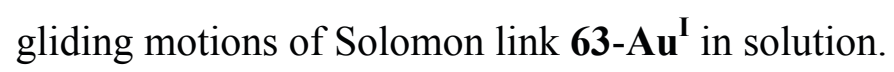

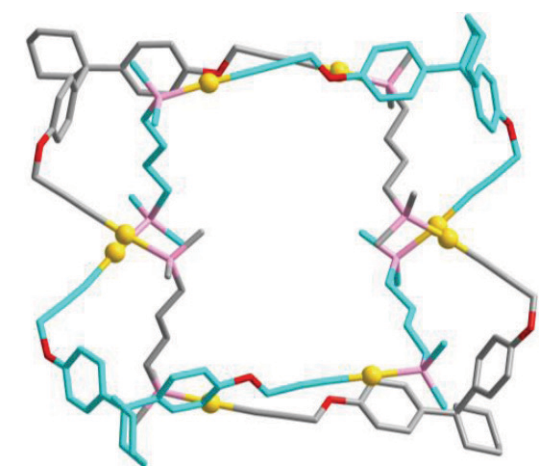

Fig. 29. X-ray structure of Solomon link 63-Au' (all Ph rings attached to $\mathrm{P}$ atoms are omitted for clarity) [127].

As mentioned above, Peinador and Quintela have synthesized many hybrid catenanes with the aid of donor-acceptor interactions and $\mathrm{Pd}^{\mathrm{II}}$-directed coordination assembly. When constructing 
catenanes, in addition to the participation of a pyridinium component $\left(\mathrm{L}_{42}\right)$ and a $\mathrm{Pd}^{\mathrm{II}}$-corner unit, a small crown ether containing only two ether chains was usually used. Nevertheless, a molecular Solomon link 64-Pd ${ }^{\text {II }}$ was observed when the crown ether was changed as a larger ring incorporating four ether chains $\left(\mathrm{L}_{43}\right)$ (Fig. 30). The extra ether chains not only provide a source of more donor atoms but also increase the flexibility of the crown ether ring, giving it the chance to become doubly interlocked with the metallacycles [128].

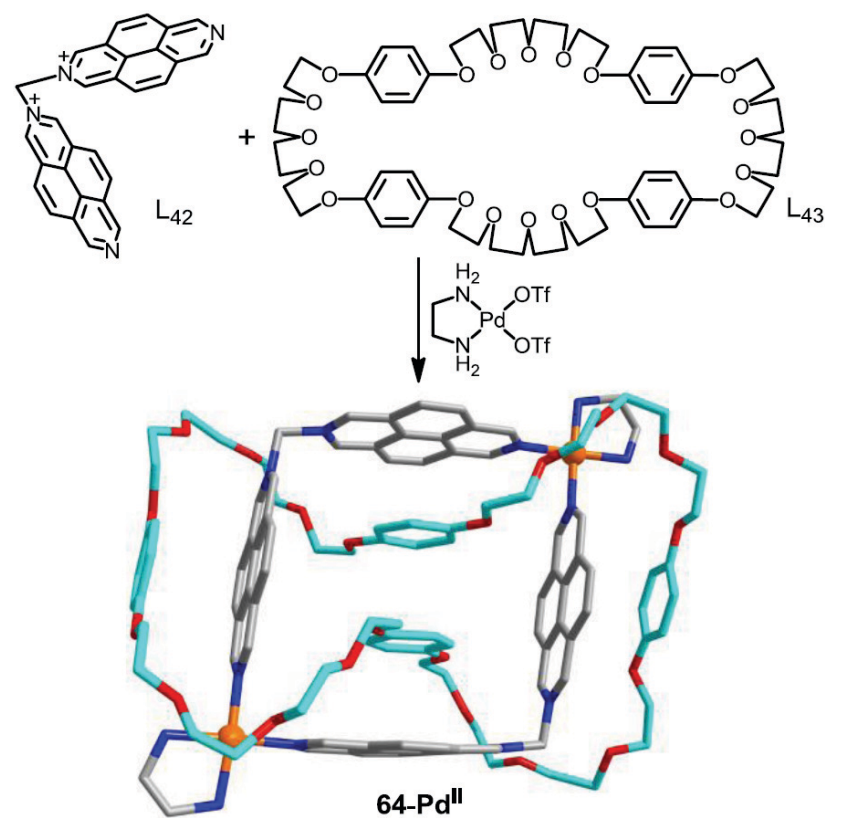

Fig. 30. The multicomponent assembly of Solomon link 64-Pd ${ }^{\text {II }}[128]$.

Hardie et al. designed the cyclotriveratrylene-based pyramidal ligand tris(3-(3pyridyl)phenylester)cyclotriguaiacylene $\mathrm{L}_{44}$. Reaction of $\mathrm{L}_{44}$ with $\operatorname{Pd}\left(\mathrm{NO}_{3}\right)_{2}$ in DMSO solution led to the production of complex 65-Pd ${ }^{\text {II }}$ (Fig. 31) [129]. The single-crystal X-ray structure of 65-Pd ${ }^{\text {II }}$ reveals that two rings interpenetrated each other with four crossover points, so tetramer $\mathbf{6 5}-\mathbf{P d} \mathbf{d}^{\text {II }}$ has

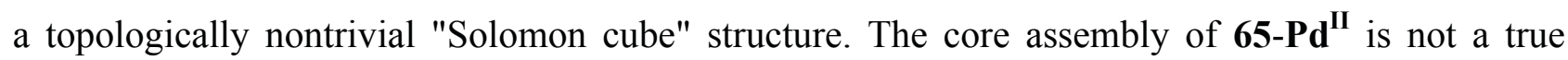
Solomon link because the two interlocking rings share the same $\mathrm{Pd}^{\mathrm{II}}$ cross center and are not independent.

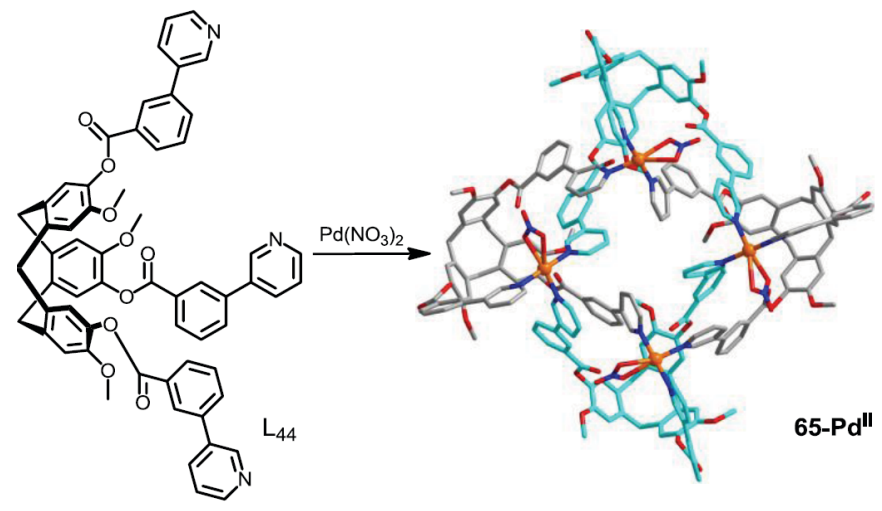

Fig. 31. Construction of the "Solomon cube" 65-Pd" [129]. 
In Leigh's group, the reaction of flexible ligand $\mathrm{L}_{45}$ with $\mathrm{n}$-hexylamine and $\mathrm{FeCl}_{2}$, and subsequent anion exchange with $\mathrm{KPF}_{6}$ solution, afforded the Solomon link 66-Fe ${ }^{\text {II }}$ (Fig. 32a). Using other $\mathrm{Fe}^{\mathrm{II}}$ salts, such as $\mathrm{Fe}\left(\mathrm{BF}_{4}\right)_{2}$ and $\mathrm{Fe}\left(\mathrm{ClO}_{4}\right)_{2}$, also produced $\mathbf{6 6}-\mathrm{Fe}^{\mathrm{II}}$ but in significantly lower yields. When $\mathrm{FeBr}_{2}$ was selected as the iron source, a linear triple helicate was the main product. Substituting n-hexylamine for 4-methylbenzylamine in the reaction of $\mathrm{L}_{45}$ and $\mathrm{FeCl}_{2}$, gave a mixture of both cyclic and linear species, and their distribution was significantly altered by the initial concentration of ligand $\mathrm{L}_{45}$. By using a similar synthetic method and replacing the monoamine with 2,2'-(ethylenedioxy)bis(ethylamine), the closed Solomon link 67-Fe ${ }^{\text {II }}$ was generated in $75 \%$ isolated yield (Fig. 32b). As single-crystal X-ray diffraction study showed that the two organic macrocycles doubly interlock, constituting the topology of a Solomon link [130]. Dialdehydes $\mathrm{L}_{45}$ and $\mathrm{L}_{46}$ have structural similarities and vary only by one oxygen atom; however, they react individually with the amine and $\mathrm{FeCl}_{2}$ to generate completely different complexes: the Solomon link 66-Fe ${ }^{\mathrm{II}}$ and the pentafoil knot 84-Fe ${ }^{\mathrm{II}}$ (Fig. 40b). These two dialdehydes were combined to investigate their potential self-sorting behaviour, as well as the dynamic or thermodynamic behaviour of any self-sorting processes. Besides open $66-\mathbf{F e}^{\text {II }}$ and pentamer $84-\mathbf{F e} \mathbf{e}^{\text {II }}$, no detectable mixed-ligand species formed upon using the monoamine. However, the behaviour of the closed circular systems upon using the diamine differ from that of the open analogues. Both the mixedligand Solomon link and pentafoil knot were observed by ESI-MS. In contrast, when the aldehydes were pre-reacted with diamine, viz. using the pre-organised cyclic precursors, no ligand exchange phenomena were found. The rationale for the differing behavior of the open and closed species is the relative ease of dissociation of their corresponding ligands. Compared with the easy dissociation of bidentate coordination sites, the quadridentate binding sites derived from diamine interact strongly with the $\mathrm{Fe}^{\mathrm{II}}$ center. Furthermore, in the closed system, only the imine bonds are destroyed, and the ligand exchange can take place. The energetic cost of this additional process is evidently too high to allow the rearrangement of pure-ligand complexes [131].
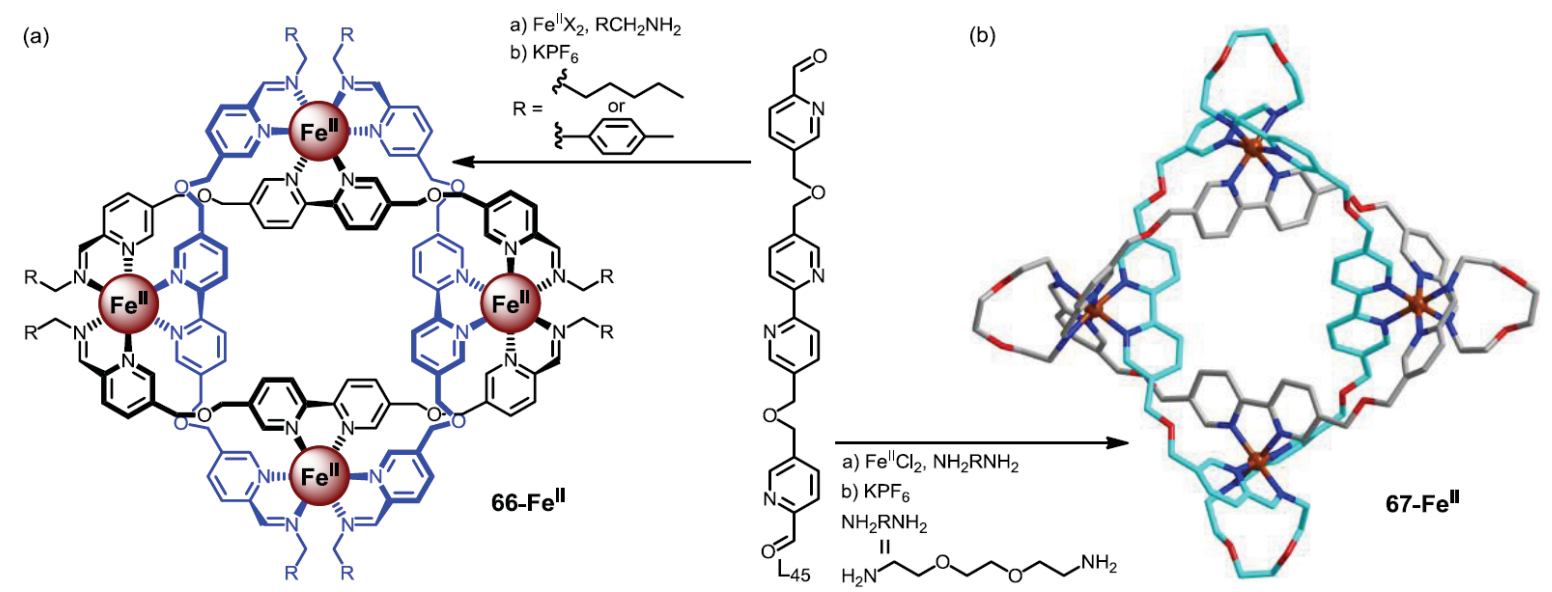

Fig. 32. Synthesis of the open Solomon link 66-Fe ${ }^{\text {II }}$ (a) [130] and closed Solomon link 67-Fe ${ }^{\text {II }}$ (b) [131]. 
In Severin's group, a bi-functional ligand $\mathrm{L}_{47}$ containing both mono-dentate terminal pyridine groups and a bi-dentate 2,2'-bipyridine (bpy) group was synthesized. Two methyl groups were intentionally introduced to increase the steric effect of the bpy groups, which can tune the recognition of bpy groups with different metal ions. Their reaction with the cis-blocked $\mathrm{Pt}^{\mathrm{II}}$ metalcorner successfully afforded the metallacyclic complex 68-Pt ${ }^{\text {II }}$ with uncoordinated bpy sites. The square-planar coordination mode of $\mathrm{Pt}^{\mathrm{II}}$ and repulsive interaction between methyl groups and dppp is presumably responsible for preventing the coordination of bpy and cis- $\mathrm{Pt}^{\mathrm{II}}$. However, in contrast to $\mathrm{Pt}^{\mathrm{II}}$, when tetrahedrally coordinated $\mathrm{Cu}^{\mathrm{I}}$ was used, two bpy groups easily bonded with the $\mathrm{Cu}^{\mathrm{I}}$ and form the well-known $\left[\mathrm{Cu}(\mathrm{bpy})_{2}\right]^{+}$motif. When the reaction was attempted with both $c i s-\mathrm{Pt}^{\mathrm{II}}$ and $\mathrm{Cu}^{\mathrm{I}}$ in the mixture, the Solomon link 69-Cu${ }^{\mathbf{I}} \mathbf{P t}^{\mathbf{I I}}$ formed in quantitative yield (Fig. 33). Both ${ }^{1} \mathrm{H}$ NMR and ESI-MS techniques confirmed the formation of $\mathbf{6 9}_{-\mathbf{C}} \mathbf{C u}^{\mathrm{I}} \mathbf{P t}^{\mathrm{II}}$. Single-crystal X-ray diffraction analysis indicated that two hexanuclear $\mathrm{Pt}_{6}(\mathrm{dppp})_{6}$ macrocycles were doubly interlocked to give the Solomon link 69-Cu' $\mathbf{P t}^{\mathbf{I}}[132]$.

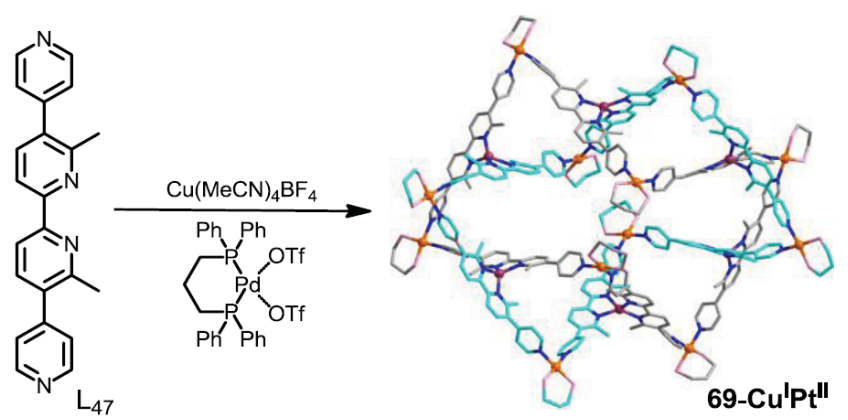

Fig. 33. Synthesis of Solomon link 69-Cu' $\mathbf{C u t}^{\mathrm{II}}$ (all $\mathrm{Ph}$ rings attached to $\mathrm{P}$ atom are omitted for clarity) [132].

The combination of bis-chelating unit bridged arene- $\mathrm{Ru}$ II acceptor and a bifunctional pyridine linker often generate the molecular rectangles. Using 3,6-di(pyridin-4-yl)carbazole $\mathrm{L}_{48}$ as pyridyl linker, the bent, rather than planar structures of the macrocycles were obtained. Due to the slim body of $\mathrm{L}_{48}$, the tetracene-based arene- $\mathrm{Ru}$ II acceptor $\left(\mathrm{L}_{20}\right)$ lead to the doubly-interlocked structure 70-Ru' ${ }^{\text {II }}$ in methanol solution (Fig. 34). Nevertheless, using other slightly different acceptors could just produce the non-interlocked macrocycles both in methanol and nitromethane solvents, and the $\mathrm{CH} \cdots \pi$ interactions and $\pi \cdots \pi$ interactions between different rings were proposed as the driving force for the formation of Borromean rings[133].
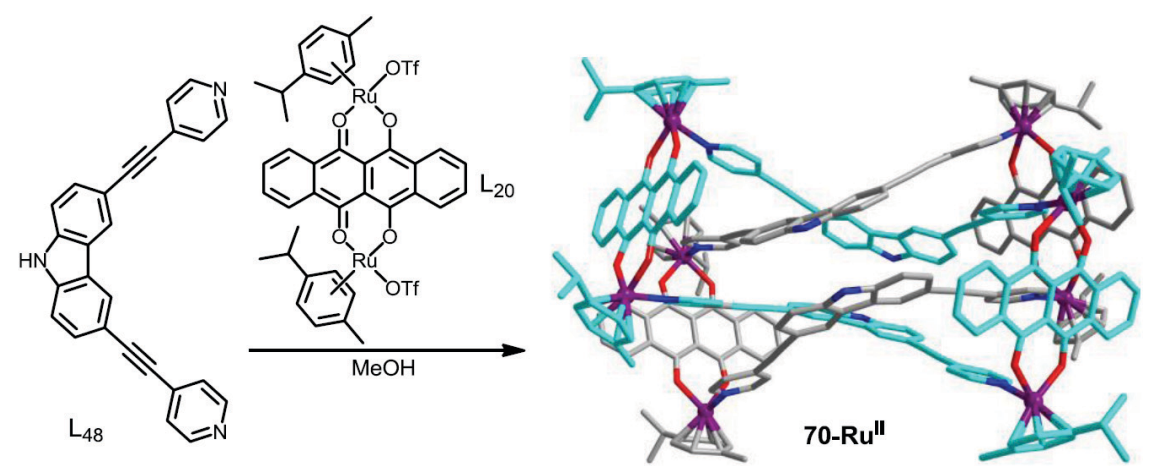


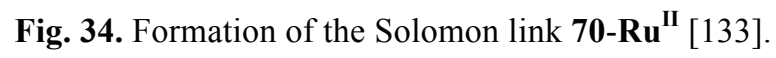

\section{Ring-in-ring complexes}

In sharp contrast with [2]catenanes, ring-in-ring complexes, while also interlocked, consist of one ring encapsulating another ring in a non-catenane fashion. Initially, ring-in-ring complexes were obtained as intermediate products during the step-wise construction of molecular Borromean rings [134-137]. Metal-template and donor-acceptor interactions have been used in the synthesis of fully organic backbones. Until now, only three coordination-directed ring-in-ring examples have been reported.

$\beta$-cyclodextrins ( $\beta$-CD) are nano-sized macrocycle that have been widely used as supramolecular hosts thanks to their ability to accommodate guest molecules. The self-assembly of flexible dipyridyl ligands $\left(\mathrm{L}_{49}\right.$ and $\left.\mathrm{L}_{50}\right)$ and cis- $\mathrm{M}^{\mathrm{II}}(\mathrm{M}=\mathrm{Pd}$ or $\mathrm{Pt})$ easily generate metallacycles, and these complexes can also be used as host frameworks. However, when these two species meet together, dinuclear metallacycles $M_{2}\left(L_{n}\right)_{2}(n=47$ or 48$)$ can be included in the cavity of $\beta-C D$ to give ringin-ring complexes 71-Pd ${ }^{\mathrm{II}}$ (Fig. 35). When the more rigid dipyridyl ligand $\mathrm{L}_{7}$ is used, ${ }^{1} \mathrm{H}$ NMR indicated co-existence of $\beta-\mathrm{CD}$ and $\mathrm{M}_{4}\left(\mathrm{~L}_{7}\right)_{4}$ macrocycles with no mutual recognition. Compared with $\mathrm{M}_{2} \mathrm{~L}_{2}$ macrocycles, the larger $\mathrm{M}_{4} \mathrm{~L}_{4}$ complexes are size-mismatched with the $\beta$-CD host [138].

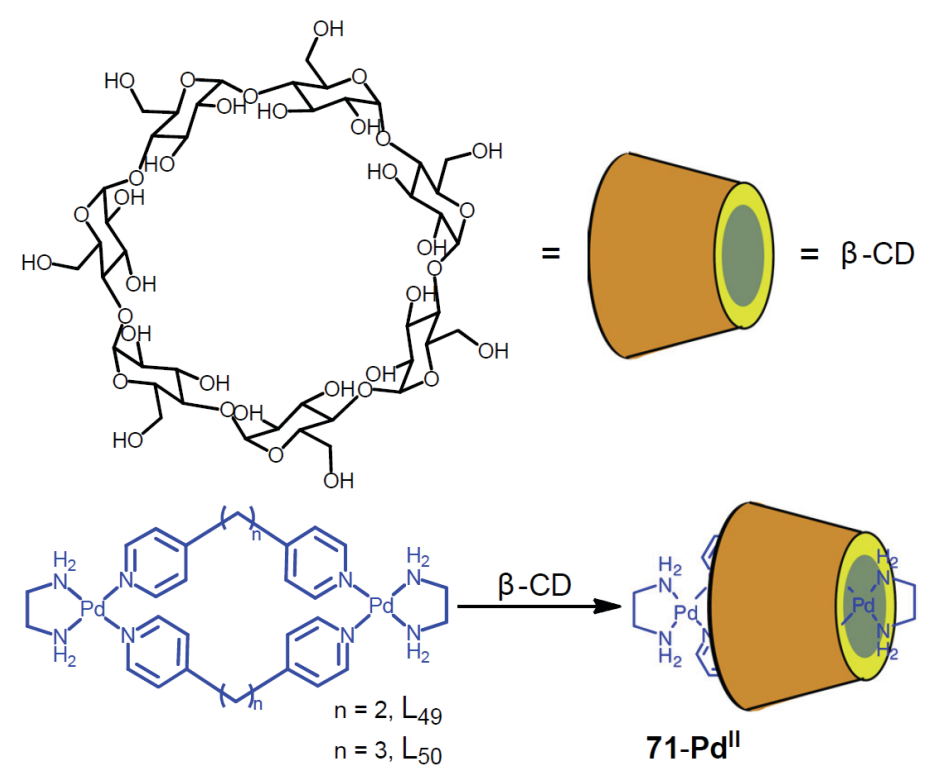

Fig. 35. Synthesis of $\beta$-CD-based ring-in-ring complexes 71-Pd ${ }^{\text {II }}$ [138]. Adapted with permission from Ref. [138]

As mentioned above, $\pi$-deficient metallacycles can often be threaded by $\pi$-donor polyether loops thanks to donor-acceptor interactions, resulting in the formation of hybrid catenanes. The meeting of metallacycles with en groups and $\mathrm{DN}_{50} \mathrm{C}_{14}\left(\mathrm{~L}_{51}\right)$ afforded the hybrid [3]catenanes 72-Pd ${ }^{\mathrm{II}}$. By replacing the $\mathrm{NH}_{2}$ groups with $\mathrm{NMe}_{2}$ groups, the formation of the ring-in-ring complex 73-Pd ${ }^{\mathbf{I I}}$ was the preferred outcome - a notably different architecture from subtle modification of a corner ligand (Fig. 36). From $\mathrm{NH}_{2}$ with $\mathrm{NMe}_{2}$ groups, the loss of $[\mathrm{N}-\mathrm{H} \cdots \mathrm{O}]$ hydrogen bonding between 
corner ligand and crown ether groups is presumably responsible for the resulting varied recognition coalition [139].

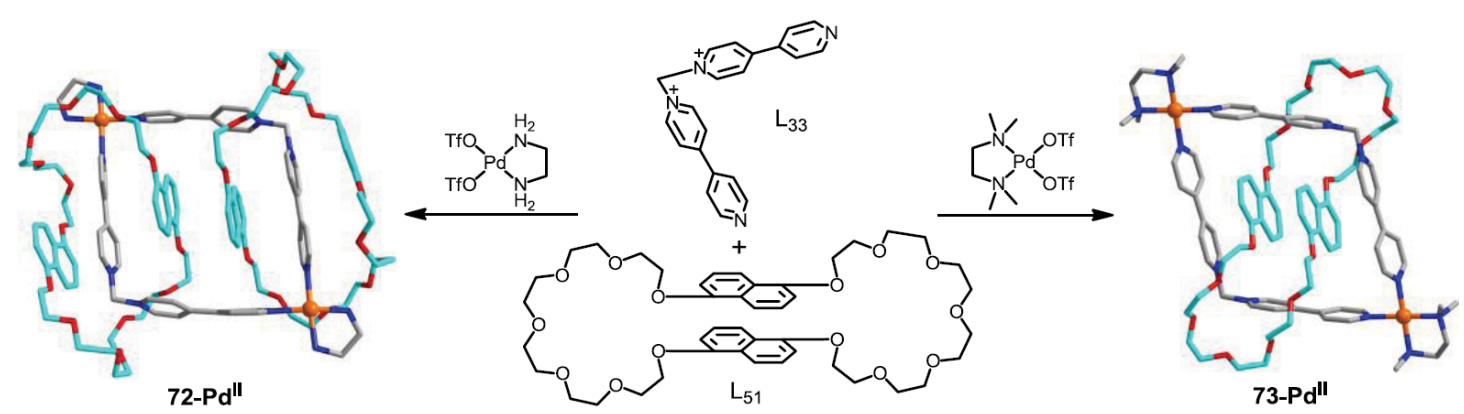

Fig. 36. Corner ligand-dependent [3]catenanes 72-Pd ${ }^{\text {II }}$ (a) and ring-in-ring complex 73-Pd ${ }^{\text {II }}$ (b) [139].

Stang and co-workers reported the construction of a self-assembled ring-in-ring complex 74-R $\mathbf{u}^{\text {II }}$ from two identical rectangles. Commonly, the combination of $c i s-\mathrm{Ru}$, bifunctional pyridine ligands and dhnd generates a mono-rectangular complex. Using the slimmer dbd ligand $\left(\mathrm{L}_{52}\right)$, the noncatenane 2-interlocked complex 74-Ru ${ }^{\text {II }}$ was obtained (Fig. 37). Interestingly, the addition of pyrene to the reaction system leads to the mono-rectangular complex $\mathbf{7 4}$ '-Ru' ${ }^{\mathbf{I I}}$. The additional interactions between the mono-ring and pyrene can destroy the interaction of two rectangles and prevent the formation of ring-in-ring complexes [140].

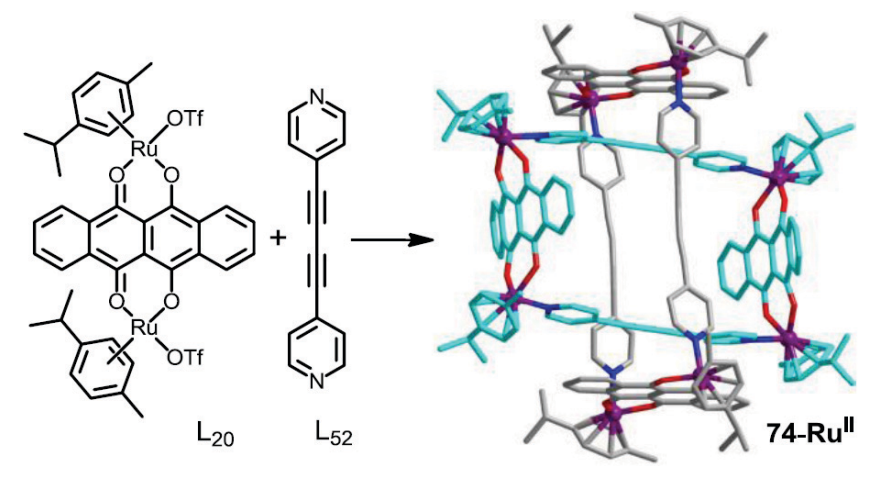

Fig. 37. Synthesis of ring-in-ring complexes $\mathbf{7 4 - R \mathbf { u } ^ { \mathrm { II } }}[140]$.

\section{Molecular Borromean Rings}

In contrast to ring-in-ring complexes, molecular Borromean rings comprise three non-catenane interlocked macrocycles, with each threaded through one of the other rings and threaded by the other one $(1 \rightarrow 2,2 \rightarrow 3,3 \rightarrow 1)$. Although no direct linkage exists, they collectively form an inseparable ensemble, and scission of one ring leads to the dissociation of the other two. Due to the topological complexity of molecular Borromean rings, this nontrivial link represents a formidable synthetic challenge to chemists. At present, only a few examples have been reported. In 1997, Seeman and co-workers synthesized the first artificial species from single-stranded DNA [141]. Two years later, a "ring-in-ring" strategy was proposed by Busch and co-workers [134]. Unfortunately, while there have been a number of reports of ring-in-ring complexes, no reports of 
further progress toward molecular Borromean Rings have been reported. Stoddart's group developed an all-in-one approach which facilitated the assembly of Borromeates 75-Zn ${ }^{\text {II }}$ [142] (Fig. 38) and upon demetalation led to the discrete Borromean rings 75 [143].

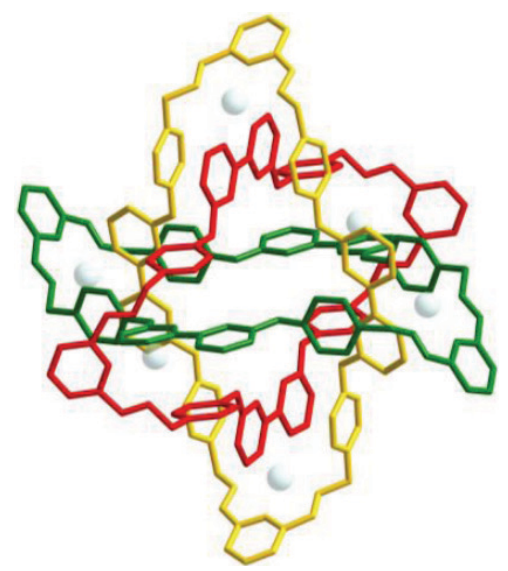

Fig. 38. X-ray structure of molecular Borromean Rings 75-Zn ${ }^{\text {II }}[142]$.

Using ligand 6,6'-bis(4-ethynylpyridine)-2,2'-bipyridine $\left(\mathrm{L}_{53}\right)$ and tetrahedral $\mathrm{Cu}^{\mathrm{I}}$ or $\mathrm{Ag}^{\mathrm{I}}$, Champness et. al discovered the first self-assembled architecture $\mathbf{7 6}-\mathbf{M}^{\mathbf{I}}$ with a Borromean ring-like topology with coordination interactions between sub-rings (Fig. 39a) [144]. Here, both the ligand $\left(\mathrm{L}_{53}\right)$ and $\mathrm{M}^{\mathrm{I}}$ have two different functionalities, with the ligand acting as both "blocking" and "bridging" unit, and the $\mathrm{M}^{\mathrm{I}}$ acting as both "templating" and "directing" agent. The $\mathrm{Cu}^{\mathrm{I}}$ complex is stable in both solid and solution phase, whereas the $\mathrm{Ag}^{\mathrm{I}}$ analogue could only be isolated in the solid state. A single counter anion was inseparably encapsulated in the cavity of the Borromean link, suggesting that the anion may template the assembly and stabilize the architecture. Using a similar phen-based ligand $\left(\mathrm{L}_{54}\right)$ and $\mathrm{Cu}^{\mathrm{I}}$, another Borromean ring-type structure 77-Cu $\mathbf{u}^{\mathrm{I}}$ was reported by Schmittel et al. (Fig. 39b) [145].

(a)
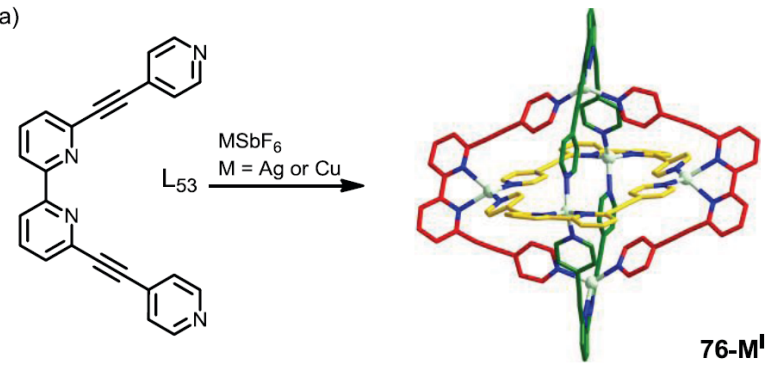

(b)

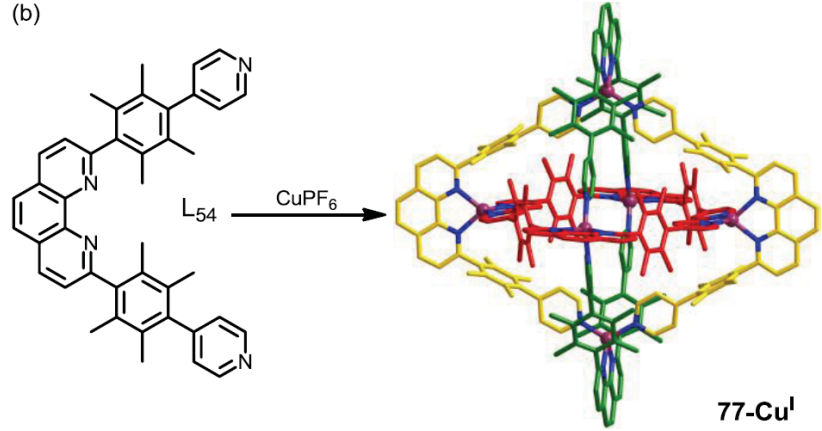


Fig. 39. Synthesis of metal-linked molecular Borromean Rings 76- $\mathbf{M}^{\mathbf{I}}$ (a) [144] and 77-C $\mathbf{u}^{\mathbf{I}}$ (b) [145].

Through Stoddart's metal-template method, a handful of molecular Borromean rings have been synthesized. Nevertheless, creating the molecular Borromean rings by a directed approach remains a challenging topic. Having extensive experience in the synthesis of $\mathrm{Cp} * \mathrm{Rh}-\mathrm{based}$ metallasupramolecules [146-155], Jin's group developed a directed synthetic approach from the assembly of coordination rectangles. Three components, a metal-corner unit [Cp*Rh], a coppercontaining bis(chelating) linker $\left(\mathrm{L}_{55}\right.$ and $\left.\mathrm{L}_{56}\right)$ and a bifunctional pyridine linker $\left(\mathrm{L}_{7}, \mathrm{~L}_{9}, \mathrm{~L}_{57}-\mathrm{L}_{61}\right)$, were employed for synthesizing the molecular rectangles. By tuning the length of the pyridine linkers, a series of size-dependent Borromean-link frameworks $\mathbf{n}-\mathbf{R} \mathbf{h}^{\mathbf{I I I}}(\mathrm{n}=78-81)$ were observed (Fig. 40). Only careful choice of the pyridine arms favored the formation of Borromean ring structures. Binding energy calculations were performed by DFT methods, indicating that the interactions between the different rings are the driving force to form n-interlocked rings. This group proposed three criteria for constructing molecular Borromean rings: 1) the short arms need to be long enough to accommodate the spatial requirements of the long arms; 2) the long arms need to be long enough to accommodate the entire length of the short arms; and 3 ) the ratio of the length of the long arm to that of the short arm should be appropriate for the production of ring-ring interactions [156-157]. They also proposed the application of a long-arm linker with a slim alkyne spacer could give surprising results, that was successfully achieved by Chi and co-workers. In sharp contrast to the mono-rectangle obtained from common linear pyridyl linker, the use of alkyne-based arm led to the formation of molecular Borromean rings $\mathbf{8 2}-\mathbf{R} \mathbf{u}^{\mathbf{I I}}$ [158].
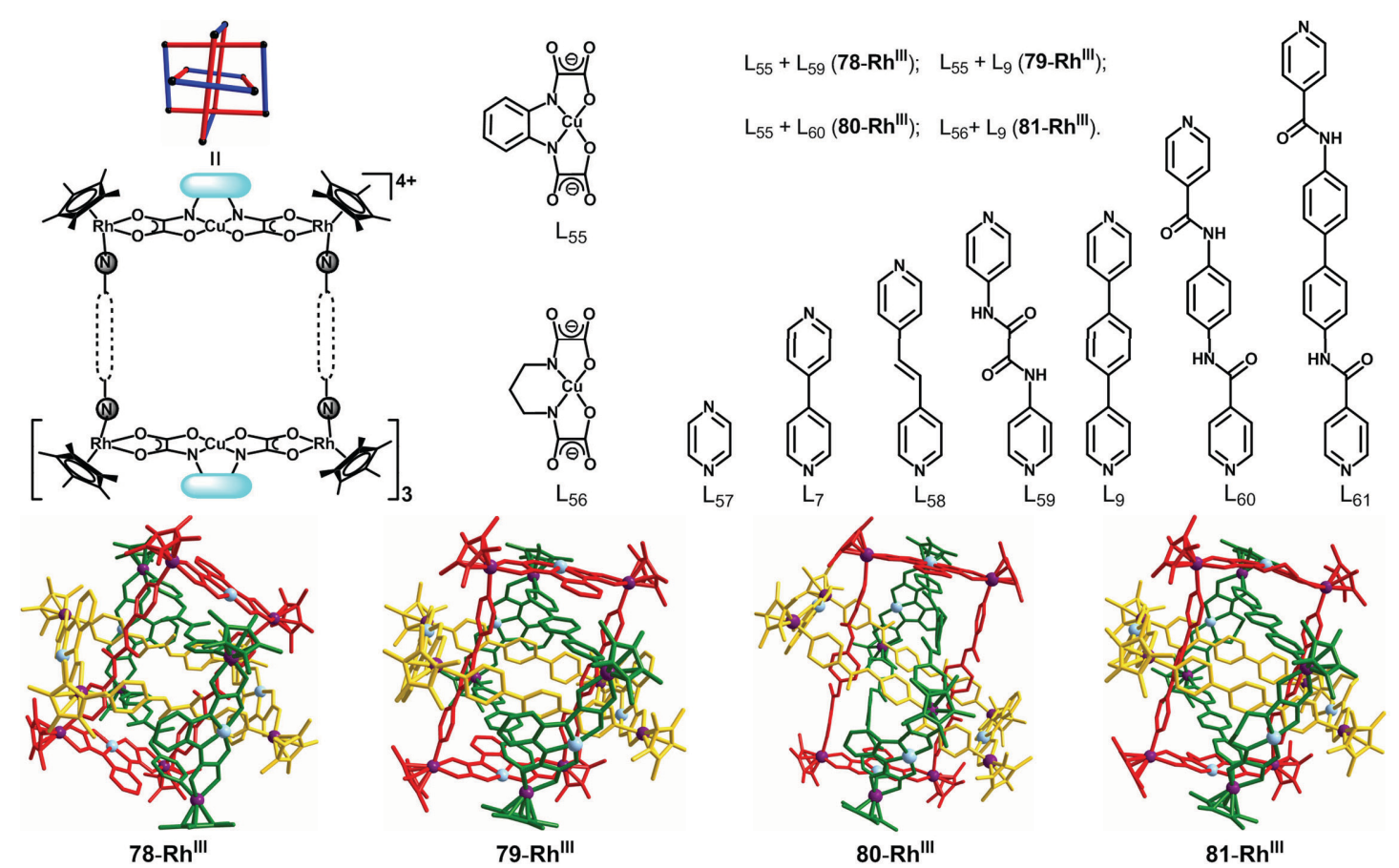

Fig. 40. The size-dependent molecular Borromean rings $\mathbf{n}-\mathbf{R h}^{\text {III }}$ [156-157]. 


\section{Molecular Knots}

Knots are fascinating non-trivial topological entities and are commonly found in many scientific fields, from mathematics to biology [159]. However, molecular knots have only been known for a few years. Since the first molecular knot was synthesized by Sauvage in 1989 [160], a number of different synthetic methods have been developed [161], but only a few of these are based on metallacyclic assemblies.

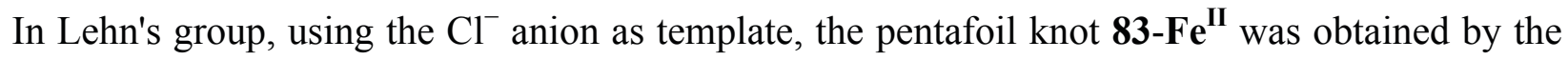
reaction of the tris-2,2'-bipyridine ligand $\mathrm{L}_{62}$ and $\mathrm{FeCl}_{2}$. Both variation in the features of the ligand, or in the counter-anion of the metal source, have great influence on the nature of the species generated. For example, the use of non-template $\mathrm{SO}_{4}{ }^{2-}$ led to hexapentafoil knot formation, while slight modification of the ligand generated a tetrafoil knot [162-163]. Leigh and co-workers developed Lehn's synthetic method further, by replacing two terminal bipyridine groups of $\mathrm{L}_{46}$ with formylpyridine groups. Their reversible reaction with amines was used to form imines and produce the pentafoil knot 84-Fe ${ }^{\text {II }}$ (Fig. 41).
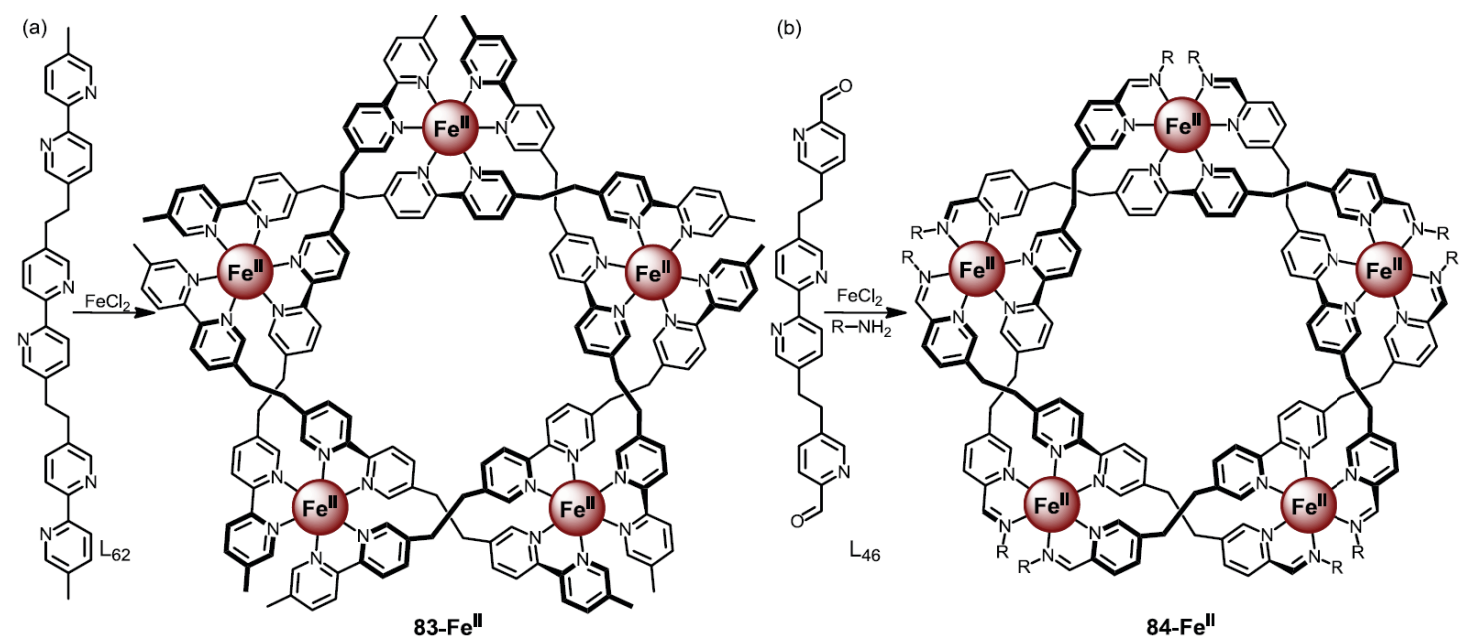

Fig. 41. Synthesis of open pentafoil knot 83-Fe $\mathbf{e}^{\text {II }}$ (a) and $84-\mathbf{F e}^{\text {II }}$ (b) [162-163].

The structure of the amine, reactant stoichiometry and reaction conditions can influence the assembly process. By using a diamine, the closed pentafoil knot $\mathbf{8 5 - F e}{ }^{\mathrm{II}}$ was successfully formed [164-165]. Using a similar ligand $\left(\mathrm{L}_{63}\right)$ and an octahedral $\mathrm{Fe}^{\mathrm{II}}$ cation, the open hexafoil knot 86-Fe ${ }^{\mathrm{II}}$ was obtained by the use of $\mathrm{SO}_{4}{ }^{2-}$ counteranions. Using ring-closing metathesis, the terminal alkene groups were linked together covalently, resulting in the formation of the interesting David catenane 87-Fe ${ }^{\text {II }}$ (Fig. 42) [166]. Leigh and co-workers also developed an active-template approach to synthesize the molecular knots $\mathbf{8 8 -} \mathbf{C u}^{\mathbf{I}}$, via loop creation, loop threading and covalent closure steps. Here, the utilization of ligands with reactive end groups is important. Another feature is that metal ions play a dual role, acting as a template to create a loop in the ligand while also actively catalyzing the covalent bond-forming reaction that links the end groups [167]. 

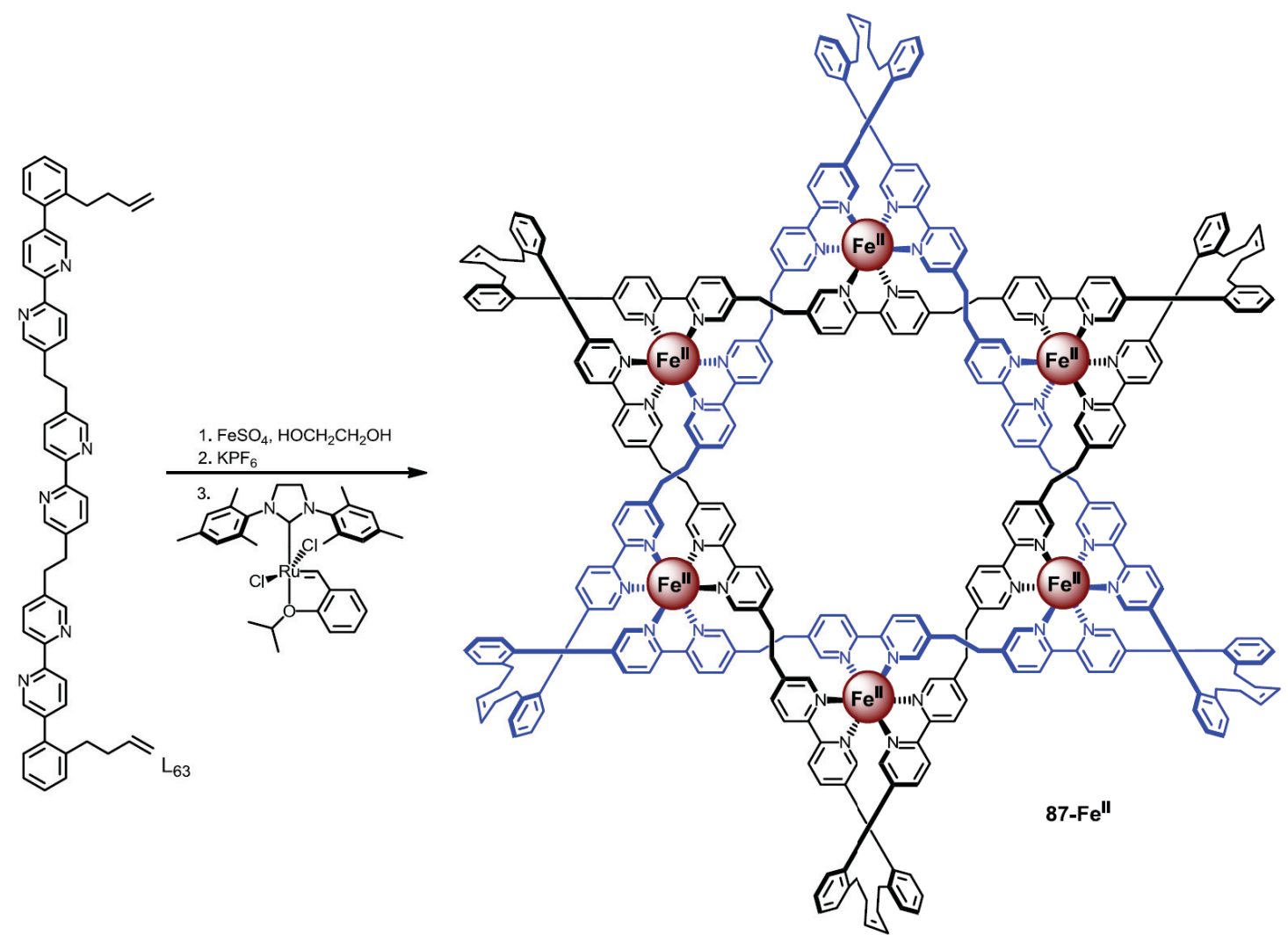

Fig. 42. Step-wise synthesis of the David catenane 87-Fe ${ }^{\text {II }}$ [166].

Lindoy et al. synthesized a bis- $\beta$-diketone derivative $\mathrm{L}_{64}$ incorporating two $\beta$-diketone termini groups and a flexible oxy-bisphenylene linkage. The reaction of $\mathrm{L}_{64}$ with $\mathrm{FeCl}_{3}$ in the presence of $\mathrm{NaHCO}_{3}$ afforded a red product. The recrystallization of this crude product from a dichloromethane/ethanol mixture gave the triple helicate complex $\mathrm{Fe}_{2}\left(\mathrm{~L}_{64}\right)_{3}$. Conversely, very slow diffusion of diethyl ether into the crude product solution led to the isolation of a different complex (89-Fe ${ }^{\text {III }}$, Fig. 43). A single-crystal X-ray structure determination showed that 89-Fe ${ }^{\text {III }}$ was an $\mathrm{Fe}_{8} \mathrm{~L}_{12}$ cluster containing a universal 3-ravel structure [168].
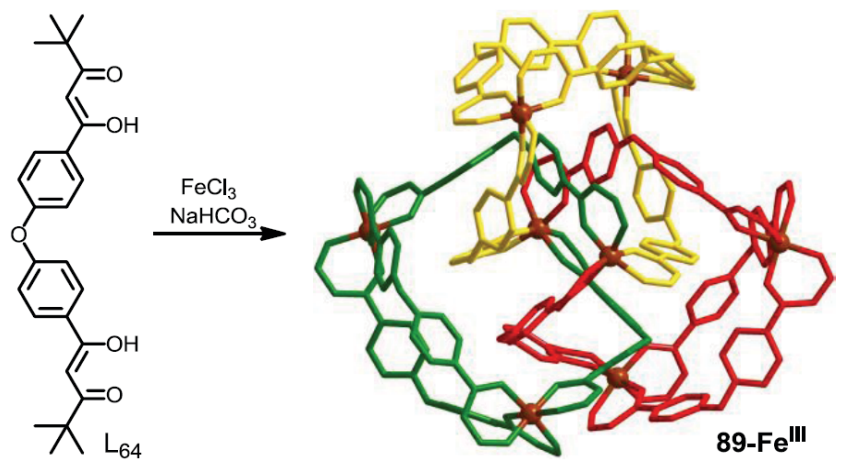

Fig. 43. Synthesis of a universal 3-ravel 89-Fe ${ }^{\mathrm{III}}$ [168].

The combination of the ribbon-like shape of $\mathrm{L}_{65}$ and $\left.\left[\mathrm{Pd}(\mathrm{MeCN})_{4}\right]\right]\left(\mathrm{BF}_{4}\right)_{2}$ has in a number of cases led to the formation of $\left[\mathrm{Pd}_{2}\left(\mathrm{~L}_{65}\right)_{4}\right]^{4+}$ cages. However, the subtle changes of the pyridyl groups resulted in the formation of a structurally complicated assembly of six ligands and three metal ions. 
The HRMS confirmed the formation of a cage of formula $\left[\mathrm{Pd}_{2}\left(\mathrm{~L}_{65}\right)_{4}\right]^{4+}$. Through NMR study, the authors proposed the cage $\mathbf{9 0 - P d ^ { I I }}$ to be a double-trefoil-knot (Fig. 44a) [169]. In contrast to the synthesis of discrete knot complexes, Advincula et al. reported the production of the trefoil knotted polymer 91-Sn ${ }^{\mathrm{II}}$ through a process involving $\mathrm{Cu}^{\mathrm{I}}$-templated knot initiator formation, ring expansion and removal of $\mathrm{Cu}^{\mathrm{I}}$ ions (Fig. 44b) [170].
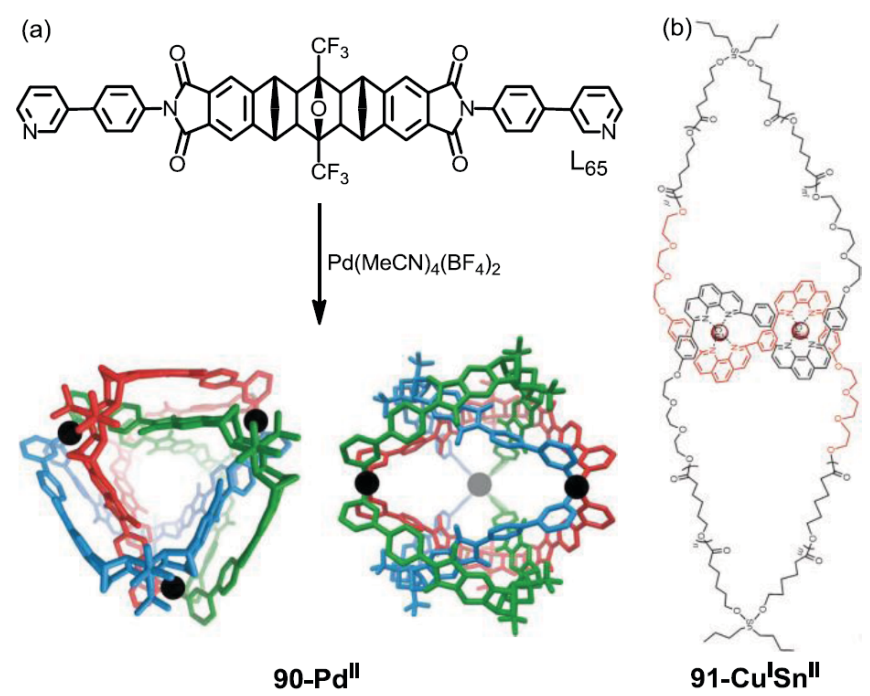

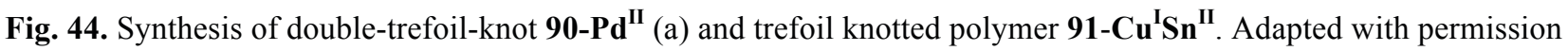
from Ref. [169] and [170], respectively.

\section{Interlocked Cages}

In sharp contrast to $2 \mathrm{D}$ catenanes, interlocked cages are $3 \mathrm{D}$ architectures with multiple crossing points [171]. Fujita and co-workers created the first interlocked metallacage by a one-pot reaction. The combination of cis- $\mathrm{Pd}^{\mathrm{II}}$ and two types of tridendate pyridyl ligands ( $\mathrm{L}_{66}$ and $\mathrm{L}_{67}$ ) led to the formation of the triply interlocked cage 92-Pd ${ }^{\text {II }}$ in 65\% yield (Fig. 45a) [172]. The independent use of two tridentate ligands afforded metallacages $\mathrm{Pd}_{6}\left(\mathrm{~L}_{66}\right)_{4}$ and $\mathrm{Pd}_{3}\left(\mathrm{~L}_{67}\right)_{2}$ in separate reactions. Mixing $\mathrm{Pd}_{6}\left(\mathrm{~L}_{66}\right)_{4}$ and $\mathrm{Pd}_{3}\left(\mathrm{~L}_{67}\right)_{2}$ in aqueous solution resulted in the formation of 92-Pd $\mathbf{d}^{\mathbf{I I}}$, which indicated that interlocked $\mathbf{9 2 -}-\mathbf{P d}^{\mathbf{I I}}$ is the most thermodynamically stable product. The efficient quadruple stacking of aromatic rings provides enough driving force for the interpenetrating process. However, upon replacing $\mathrm{L}_{67}$ with linear bipyridyl linker $\mathrm{L}_{58}$, the desired assembly of triangular prism complex was unsuccessful. The addition of aromatic guests can template the quantitative formation of interlocked cages $\mathbf{9 3 - P d ^ { I I }}$ with guest inclusion [173]. The donor-acceptor interaction between the electron-accepting triazine core of TPT and electron-donating guest is presumably responsible for the resulting structures. The elongation of the pillar linkers $\left(\mathrm{L}_{52}\right)$ also produced the interlocked cages 94-Pd ${ }^{\text {II }}$ including multiple guest templates. The utilization of the pillar linker $\left(\mathrm{L}_{68}\right)$ with functional long chains afforded the potentially liquid-crystalline materials 95-Pd ${ }^{\text {II }}$ (Fig. 45b) [174]. The reaction of TPT $\left(\mathrm{L}_{66}\right)$ with zinc halogenides commonly gave polymeric 
coordination frameworks, however the ligand $\mathrm{L}_{69}$, a minor variation of $\mathrm{TPT}$, produced the vastly different interlocking icosahedral cages 96-Zn ${ }^{\text {II }}$ (Fig. 45c) [175].
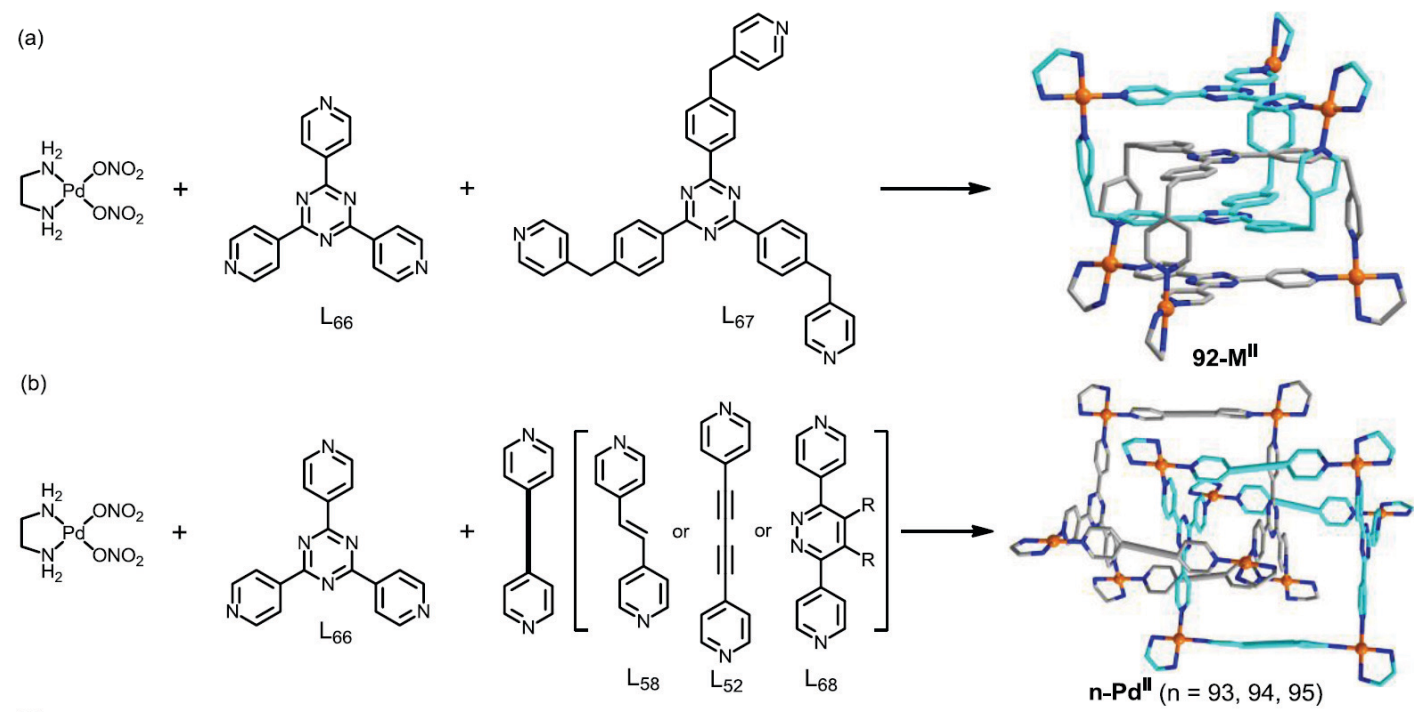

(c)

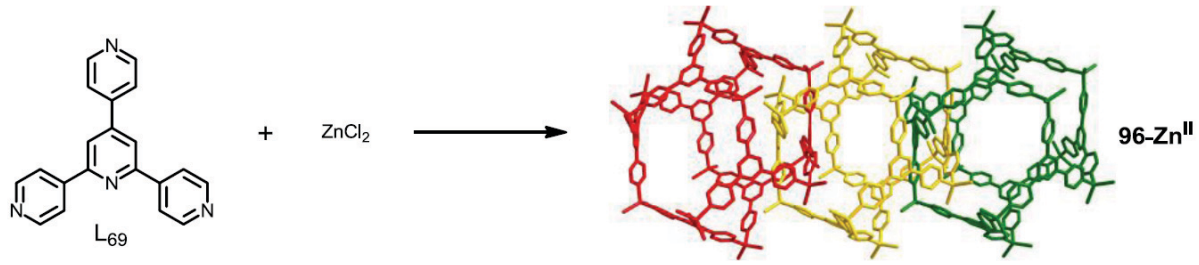

Fig. 45. Synthesis of a series of interlocked cages [172-175].

Cyclotriveratrylene has a relatively rigid bowl-shape, and a series of cyclotriveratrylene-related pyridyl ligands were synthesized in Hardie's group. Ligand $\mathrm{L}_{70}$ was appended with 2,2'-bipyridine moieties, and each ligand coordinated to three equivalent $\mathrm{M}^{\mathrm{II}}(\mathrm{M}=\mathrm{Zn}$ or $\mathrm{Co})$ centers creating a trigonal bipyramidal coordination cage, and two such cages formed the interlocked cage 97-M $\mathbf{M}^{\text {II }}$ (Fig. 46a) [176]. Similarly, the reaction of ligand tris(3-pyridylmethyl)cyclotriguaiacylene ( $\left.\mathrm{L}_{71}\right)$ with $\mathrm{Ag}^{\mathrm{I}}$ also produced the 2-interlocked cage $\mathbf{9 8 - \mathbf { A g } ^ { \mathrm { I } }}$ (Fig. 46b) [177].

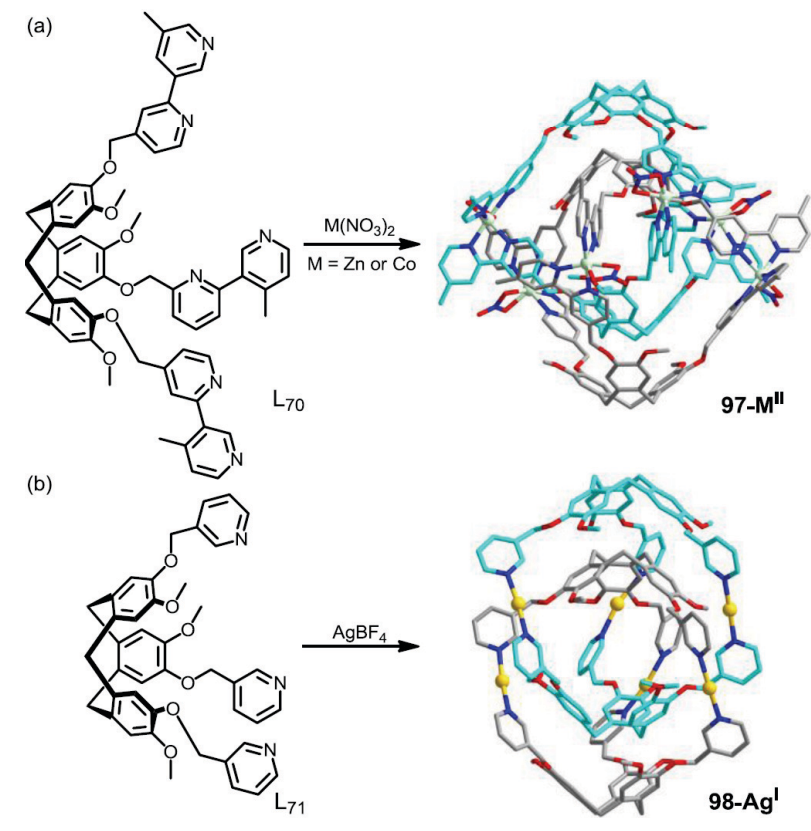


Fig. 46. Self-assembly of cyclotriveratrylene-based interlocked cages $\mathbf{9 7 - \mathbf { M } ^ { \text { II } } \text { (a) [176] and 98-Ag }}{ }^{\mathbf{I}}$ (b) [177].

In Kuroda's group, the 2-interlocked cage 99-Pd ${ }^{\text {II }}$ was synthesized from the reaction of $\mathrm{L}_{72}$ and square-planar coordinated $\mathrm{Pd}^{\mathrm{II}}$ ion (Fig. 47). An anion exchange study indicated that the dimerization was driven by the anion template effect, and that the stability of this double cage strongly depends on the size of the encapsulated anions. However, 2-naphthalenesulfonate $\left(\mathrm{ONs}^{-}\right)$ induces the monomerization of the double cage [178-179]. The solvent and anion-guest independently determined the formation, thermodynamic stability, and conversion of monomeric cage and dimeric interlocked cage [180].

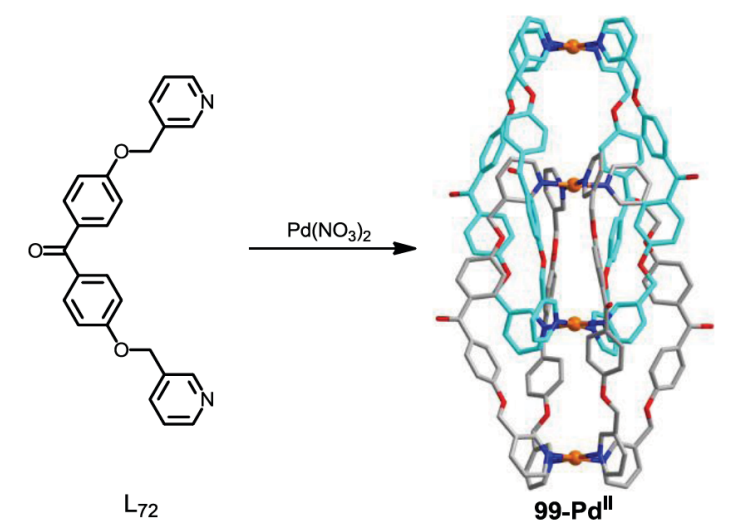

Fig. 47. Self-assembly of the 2-interlocked cage 99-Pd ${ }^{\text {II }}$ [178-179].

In Clever's lab, a series of structurally similar 2-interlocked coordination cages of the form $\left[\mathrm{Pd}_{4} \mathrm{~L}_{8}\right]^{8+}$ were synthesized from banana-shaped pyridyl ligands and square-planar $\mathrm{Pd}^{\mathrm{II}}$ ions, as well as their anion recognition were studied in great detail. Initially, the dibenzosuberone-based $\mathrm{L}_{73}$ and $\mathrm{L}_{74}$ were used to generate two topologically different architectures: monomeric cage $\mathbf{1 0 0}-\mathbf{P d}^{\mathbf{I I}}$ and 2-interlocked cage 101-Pd ${ }^{\text {II }}$ (Fig. 48) [181-182]. The shorter linker $\mathrm{L}_{73}$ resulted in the formation of small cage 100-Pd ${ }^{\text {II }}$, without enough space for interpenetration. Due to the separation of interpenetrating layers, there are two outer pockets and one inner pocket in the double-cage structure 101-Pd ${ }^{\text {II }}$, which were occupied by the counter-anions. The $\mathrm{BF}_{4}{ }^{-}$inside the outer pockets could be easily replaced by the addition of halide ions, with the binding order $\mathrm{Cl}^{-}>\mathrm{Br}^{-}>\mathrm{F}^{-}$; even the highly insoluble $\mathrm{AgCl}$ can be dissolved to deliver $\mathrm{Cl}^{-}$[183]. However, the addition of $\mathrm{I}^{-}$leads to the total decomposition of the coordination framework. In comparison to anion binding in the outer two pockets, the $\mathrm{BF}_{4}{ }^{-}$in the inner pocket is tightly surrounded by eight ligand arms, leaving no escape path for the imprisoned anion. It is noteworthy that, because of the high affinity of halide ions with $\mathrm{Pd}^{\mathrm{II}}$, the addition of excess halide ions destroyed the pyridine-Pd ${ }^{\mathrm{II}}$ bonds and finally the cage structures. In contrast to $\mathrm{L}_{74}$, the attached bulky aryl substituent $\left(\mathrm{L}_{75}\right)$ prevents the relatively large $\mathrm{BF}_{4}^{-}$anion from serving as an interpenetration template and gave the monomeric cage 102'Pd ${ }^{\text {II }}$. Introduction of the small $\mathrm{Cl}^{-}$template induced dimerization, yielding the 2-interlocked cage 
$\left\{\mathrm{Cl} @ \mathrm{Pd}_{4}\left[\mathrm{~L}_{75}\right]_{8}\right\}\left(\mathbf{1 0 2}-\mathbf{P d}^{\mathrm{II}}\right)$. The small size of the $\mathrm{Cl}^{-}$template in the central pocket led to enlarged outer pockets, which preferably bound to large anions, such as $\mathrm{ReO}_{4}{ }^{-}[184]$.
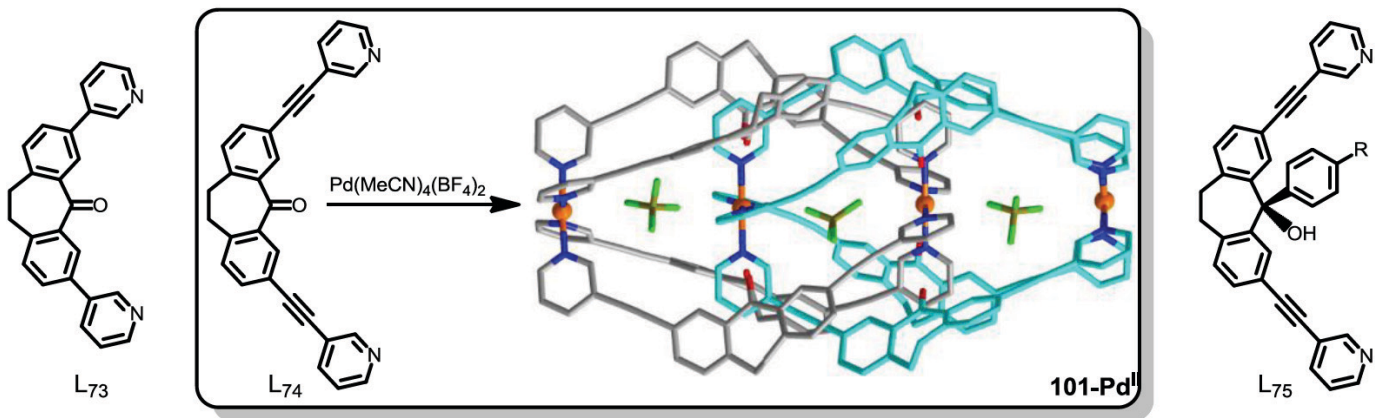

Fig. 48. Synthesis of interlocked cage 101-Pd ${ }^{\mathrm{II}}$ [181-184].

Following a similar method, the phenothiazine backbone-based double cages 103-Pd ${ }^{\text {II }}$ were synthesized from $\mathrm{L}_{76}$, and the oxygenated cage derivatives were accessible by both the oxidation of the ligands and direct oxidation of the parental cage 103-Pd ${ }^{\text {II }}$ (Fig. 49a) [185-187]. The investigation of halide anion recognition indicated that halide binding affinity decreased with increasing cage size. In this host system, although the central pocket is close to the halide anions, it is susceptible to the uptake of small neutral guest molecules [188]. Due to the smaller angles of the carbazole-based ligand $\mathrm{L}_{77}$, only monomeric cage $\mathbf{1 0 4}^{\prime}-\mathbf{P d}^{\mathrm{II}}$ was observed, and the small halide anions $\left(\mathrm{X}=\mathrm{Cl}^{-}, \mathrm{Br}^{-}\right)$templated the formation of the 2-interlocked cage $\left\{3 \mathrm{X} @ \mathrm{Pd}_{4}\left[\mathrm{~L}_{77}\right]_{8}\right\}$ 104-Pd . The subsequent addition of larger amounts of the halide anions destroyed the cage structures and produced the triply-catenated link structure 105-Pd ${ }^{\text {II }}$ (Fig. 49b) [189]. The mixed-ligand double cage 106-Pd ${ }^{\text {II }}$ which combines electron rich phenothiazine and electron deficient anthraquinone within one assembly, showing light-induced charge transfer in itself, as indicated by steady-state UV-vis and transient absorption spectroscopy [190].

(a)

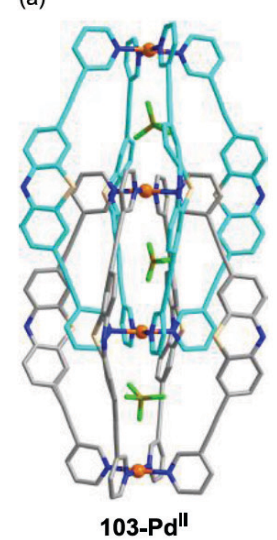

(b) 
Using the same $c$ is-Pd ${ }^{\mathrm{II}}$ acceptor and a neutral pyridyl-linear, but changing the neutral tritopic linker (TPT) as anionic species $\left(\mathrm{K}_{3} \mathrm{tma}\right)$, Mukherjee et al. synthesized a series of triangular prism complexes without any foreign templates, showing that subtle changes in the bulkiness of either the blocking amine or the pillar height can independently alter the final outcome [191-192]. Treatment of cis-[Pd(tmen) $\left.\left(\mathrm{NO}_{3}\right)_{2}\right]$ with $\mathrm{K}_{3}$ tma and linear pillar 4,4'-bipyridine $\left(\mathrm{L}_{7}\right)$ gave non-interlocked molecular prism 107-Pd ${ }^{\text {II }}$. Interestingly, the same reaction using the slightly less bulky complex cis$\left[\mathrm{Pd}(\mathrm{pn})\left(\mathrm{NO}_{3}\right)_{2}\right]$ instead of cis-[ $\left.\mathrm{Pd}(\mathrm{tmen})\left(\mathrm{NO}_{3}\right)_{2}\right]$ gave an equilibrium mixture of non-interlocked 108'-Pd $^{\text {II }}$ and triply interlocked prism cage 108-Pd ${ }^{\text {II }}$ (Fig. 50a). To further prove the steric effect of the blocking amine, the reaction was repeated using corner unit cis- $\left[\mathrm{Pd}(\mathrm{en})\left(\mathrm{NO}_{3}\right)_{2}\right]$, which led to the formation of interlocked analogous 109-Pd ${ }^{\text {II }}$ as the sole product. Accordingly, a sterically more crowded diamine (tmen) bound to $\mathrm{Pd}^{\mathrm{II}}$ favors the non-interpenetrating prism cage 107-Pd ${ }^{\mathrm{II}}$, whereas less crowded diamines (en or pn) favor interpenetrated molecular architectures. The length of pillar linker can decrease the steric effect of the blocking amine; this phenomenon was indicated by the fact that the reaction of $c i s-\left[\mathrm{Pd}(\mathrm{pn})\left(\mathrm{NO}_{3}\right)_{2}\right], \mathrm{K}_{3}$ tma and $\mathrm{pz}\left(\mathrm{L}_{57}\right)$ produced only the single interlocked complex 110-Pd ${ }^{\text {II }}$ instead of mixed complexes (Fig. 50b). Both NMR studies and single-crystal Xray analysis confirmed the formation of these structures.

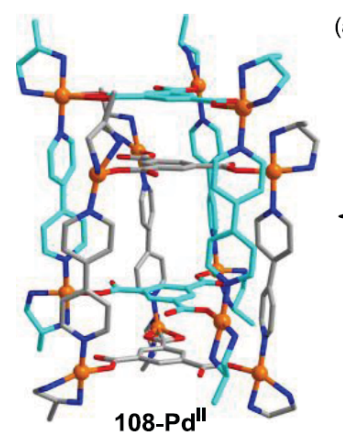

(a)

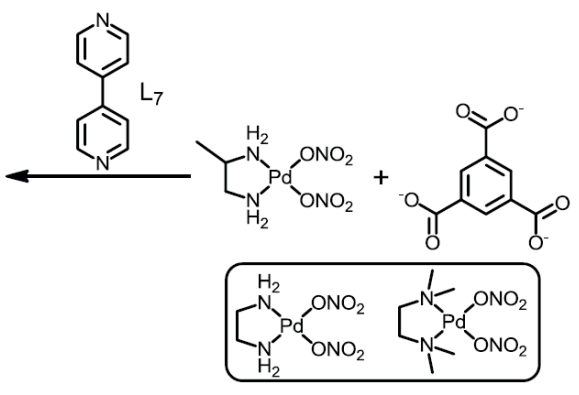

(b)

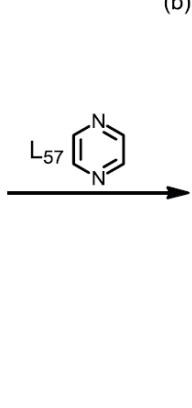

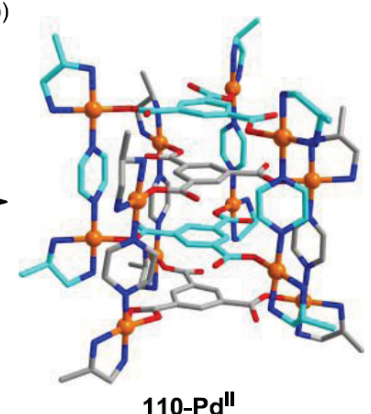

Fig. 50. Schematic representation of the formation of interlocked molecular prism 108-Pd ${ }^{\text {II }}$ (a) and 110-Pd ${ }^{\text {II }}$ (b) [191192].

Mukherjee and co-workers reported the synthesis of the triply-interlocked $\operatorname{Pd}_{6}$-cage $\left[\{(\text { tmen }) \mathrm{Pd}\}_{6}\left(\mathrm{~L}_{78}\right)_{3}\right]\left(\mathrm{NO}_{3}\right)_{12}\left(\mathbf{1 1 1}-\mathbf{P d}^{\mathbf{I I}}\right)$ by two-component self-assembly of cis-[Pd(tmen $\left.)\left(\mathrm{NO}_{3}\right)_{2}\right]$ and tritopic ligand $\mathrm{L}_{78}\left[\mathrm{~L}_{78}=\right.$ 1,3,5-tris((E)-2-(pyridin-3-yl)vinyl)benzene] (Fig. 51). The crystal structure of 111-Pd ${ }^{\text {II }}$ showed that a pair of olefin double bonds in the adjacent cages is juxtaposed parallel to each other with a distance of $3.66 \AA$. Upon UV irradiation or exposure to sunlight, [2+2] photoaddition between the adjacent cages took place via a SCSC reaction [193]. 


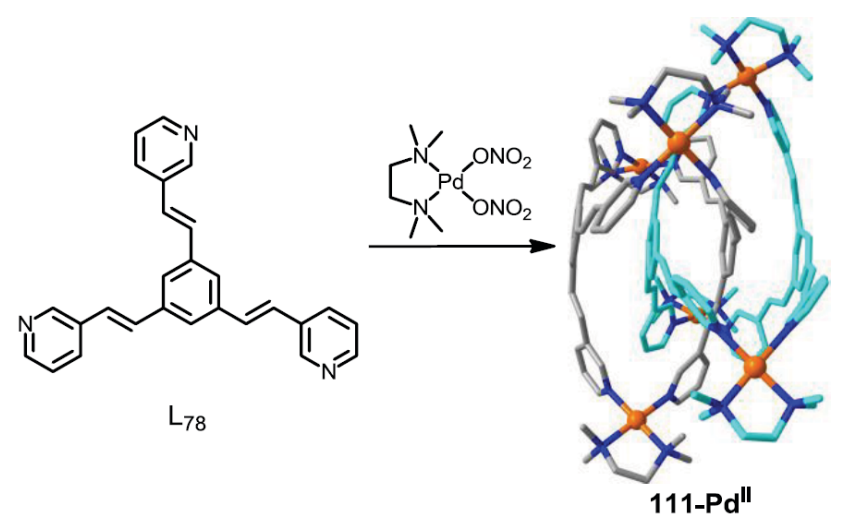

Fig. 51. Synthesis of interlocked cage 111-Pd ${ }^{\mathrm{II}}$ [193].

The reaction of $[(\mathrm{p} \text {-cymene }) \mathrm{RuCl}]_{2}$, bis-chelating linker and tridendate pyridyl ligand often produces prism cages. Interestingly, when 1,3,5-tris(3-(pyridin-4-yl)-1H-pyrazol-1-yl)benzene L $_{79}$ was used, the interlocked cage $\mathbf{1 1 2}-\mathbf{R} \mathbf{u}^{\text {II }}$ was selectively formed by using the sufficiently long bischelating arms (Fig. 52) [194].

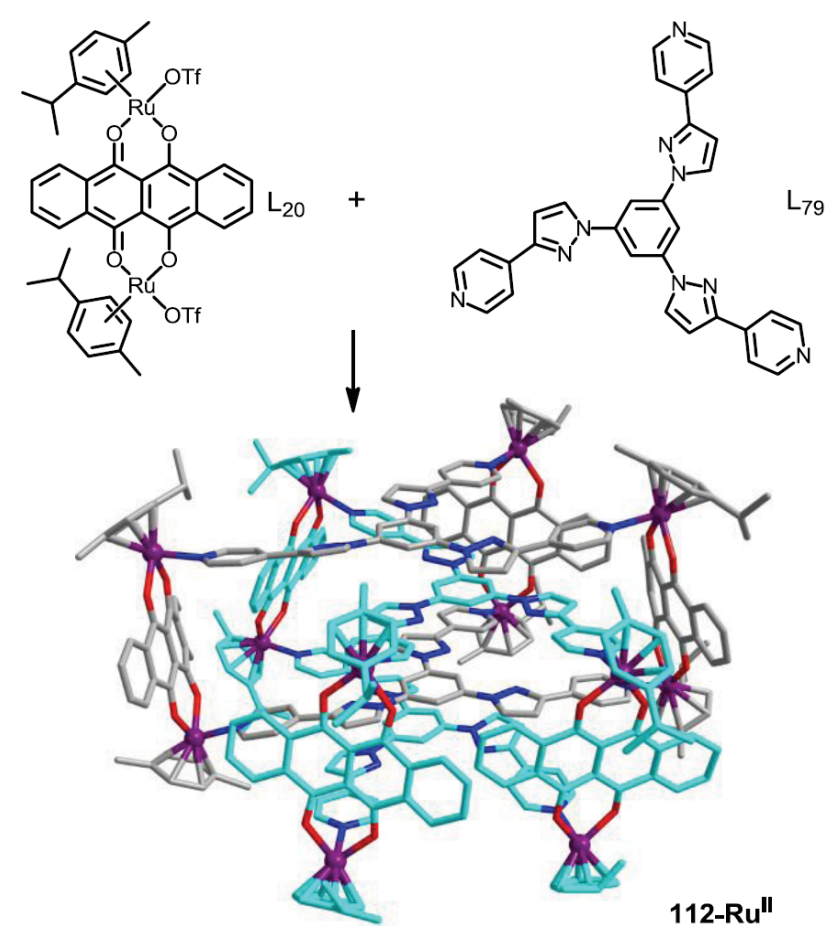

Fig. 52. Self-assembly of interlocked cage 112-Ru' ${ }^{\text {II }}$ [194].

\section{Conclusion and outlook}

The reversible nature of many coordination bonds enables the metallacyclic assembly of interlocked superstructures, but most of these limited examples are not initially designed and are merely unexpectedly observed in the synthesis of their non-interlocked isomers. An insufficient understanding of interlocked systems has limited the best use of the metallacyclic assembly methodology. A number of questions remain, for example, why can the same rings be spontaneously locked together and form a single entity? What is the formation mechanism and the 
driving force to power the assembly? More efforts need to be made to investigate the nature of interlocked systems and pave the way for the rational design of discrete interlocked species.

The Gibbs free energy $(\Delta \mathrm{G})$ value is an important parameter to evaluate whether a reaction can occur, and should be less than zero for a spontaneous reaction. Two important factors, $\Delta \mathrm{H}$ and $\Delta \mathrm{S}$ independently determine the value of $\Delta \mathrm{G}(\Delta \mathrm{G}=\Delta \mathrm{H}-\mathrm{T} \cdot \Delta \mathrm{S})$. The locking process from monomers to interlocked superstructures is an entropy-decreasing process, because of the distribution decrease and increase of symmetry of the whole system. Hence, in order to achieve the locking process, extra energy $(\Delta \mathrm{H})$ is required to overcome the entropy loss, and the binding energy between different monomers need to act as the main energy source. In template-directed interlocked systems, the binding energy arising from the template is clearly visible. However, in the absence of a template effect, interactions between different monomers are difficult to reliably design. Hence, in order to construct interlocked superstructures, the cavities of the monomers should be of suitable size to not only accommodate other copy of itself but also to bind strongly enough to produce sufficient binding energy. This presumption was successfully proved by Jin and co-workers in their study of molecular Borromean rings [156-157]. According to the Gibbs free energy equation, to form locking architectures, the $\Delta \mathrm{G}$ values for going from monomeric rings to a Borromean ring should be less than zero, which agrees well with the experimental results. In Fujita's interlocked system, although no binding energy calculations were applied, the interactions between the monomers are distinctly observed. So, to design interlocked superstructures, considerable attention must be paid to the shape and size control of the monomers.

The complex structures of interlocked molecular architectures are collections of simple monomeric components. They are regarded as good models for studying structure-property relationships due to the fact that both the monomeric and locked counterparts have the same ingredients but different topologies. The development of properties and reactivity originating from topology alone is a tantalising prospect, and has not been paid enough attention. Until now, only a few examples of such structure-based properties tuning have been reported. For example, Bäuerle and co-workers' study indicated that an additive contribution of both rings in an interlocked system led to a molar extinction coefficient of catenane that was twice that of the simple ring [79].

Although the last two decades have seen the successful use of metallacyclic assembly in the formation of interlocked systems, there are still unsolved problems - e. g. how to select suitable ligands and metal sources and how to exploit the novel architectures of interlocked structures for exciting applications. If our knowledge of the synthesis, design and application of interlocked superstructures can be advanced, we would expect interlocked molecules to run on many fields in tomorrow's world. 


\section{Abbreviations}

\begin{tabular}{|c|c|}
\hline $\mathrm{PhCN}$ & Benzonitrile \\
\hline DMSO & Dimethyl sulfoxide \\
\hline $\mathrm{MeCN}$ & Acetonitrile \\
\hline DMF & Dimethylformamide \\
\hline en & Ethylenediamine \\
\hline tmen & $N, N, N^{\prime}, N^{\prime}$-Tetramethylethylene diamine \\
\hline dppp & 1,3-Bis(diphenylphosphino)propane \\
\hline phen & 1,10-Phenanthroline \\
\hline terpy & Terpyridine \\
\hline dpp & Diphenylphenanthroline \\
\hline $\mathrm{PEt}_{3}$ & Triethylphosphine \\
\hline pn & Propane-1,2-diamine \\
\hline $\mathrm{Cp} *$ & 1,2,3,4,5-Pentamethylcyclopentadiene \\
\hline$p$-cymen & he $\quad$-Isopropyltoluene \\
\hline $\mathrm{K}_{3} \mathrm{tma}$ & Potassium 1,3,5-benzenetricarboxylate \\
\hline $\mathrm{CB}$ & Cucurbituril \\
\hline $\mathrm{BPy}^{2+}$ & Bipyridinium \\
\hline$\beta-C D$ & $\beta$-Cyclodextrin \\
\hline $\mathrm{ONs}^{-}$ & 2-Naphthalenesulfonate \\
\hline $\mathrm{DB}_{24} \mathrm{C}_{8}$ & Dibenzo-24-crown-8 \\
\hline $\mathrm{DN}_{50} \mathrm{C}_{14}$ & Bis-1,5-dinaphtho[50]crown-14 \\
\hline dtc & Dithiocarbamate \\
\hline $\mathrm{pz}$ & Pyrazine \\
\hline bpy & 2,2'-Bipyridine \\
\hline bpe & trans-1,2-bis(4-pyridyl)ethylene \\
\hline $\mathrm{H}_{2} \mathrm{dhnd}$ & 6,11-dihydroxy-5,12-naphthacenedione \\
\hline dbd & 1,4-di(pyridin-4-yl)buta-1,3-diyne \\
\hline TPT & 2,4,6-Tri(4-pyridyl)-1,3,5-triazine \\
\hline $2 \mathrm{D}$ & two-dimensional \\
\hline $3 \mathrm{D}$ & three-dimensional \\
\hline SCSC & Single-crystal-to-single-crystal transformation \\
\hline NMR & Nuclear magnetic resonance \\
\hline CSI-MS & Cold-Spray Ionization Mass Spectrometry \\
\hline ESI-MS & Electrospray Ionisation Mass Spectrometry \\
\hline HRMS & high resolution mass spectrometry \\
\hline
\end{tabular}

\section{Acknowledgements}

This work was supported by the National Science Foundation of China (91122017, 21374019), the Shanghai Science and Technology Committee (13JC1400600, 13DZ2275200), and the Program for Changjiang Scholars and Innovative Research Team in University (IRT1117).

\section{References}

[1] D.B. Amabilino and J.F. Stoddart, Chem. Rev. 95 (1995) 2725-2828.

[2] F.M. Roymo and J.F. Stoddart, Chem. Rev. 99 (1999) 1643-1664.

[3] R.S. Forgan, J.P. Sauvage and J.F. Stoddart, Chem. Rev. 111 (2011) 5434-5464.

[4] J.E. Beves, B.A. Blight, C.J. Campbell, D.A. Leigh and R.T. McBurney, Angew. Chem. Int. Ed. $50(2011) 9260-9327$. 
[5] G.G. Ramirez, D.A. Leigh and A.J. Stephens, Angew. Chem. Int. Ed. 54 (2015) 6110-6150.

[6] S.R. Batten and R. Robson, Angew. Chem. Int. Ed. 37 (1998)1460-1494.

[7] S.R. Batten, CrystEngComm, 3 (2001) 67-72.

[8] L. Carlucci, G. Ciani and D.M. Proserpio, Coord. Chem. Rev. 246 (2003) 247-289.

[9] A.R. Pease, J.O. Jeppesen, J.F. Stoddart, Y. Luo, C.P. Collier and J.R. Heath, Acc. Chem. Res. 34 (2001) 433-444.

[10] V. Balzani, A. Credi and M. Venturi, Chem. Soc. Rev. 38 (2009) 1542-1550.

[11] S.F.M.V. Donggen, S. Cantekin, J.A.A.W. Elmenans, A.E. Rowan and R.J.M. Nolte, Chem. Soc. Rev. 43 (2014) 99-122.

[12] M. Iyoda and H. Shimizu, Chem. Soc. Rev. 44 (2015) 6411-6424.

[13] R. Warmuth and J. Yoon, Acc. Chem. Res. 34 (2001) 95-105.

[14] Y.H. Jin, C. Yu, R.J. Denman and W. Zhang, Chem. Soc. Rev. 42 (2013) 6634-6654.

[15] D.C. Sherrington and K.A. Taskinen, Chem. Soc. Rev. 30 (2001) 83-93.

[16] H.L. Fu, Y. Liu and H.Q. Zeng, Chem. Commun. 49 (2013) 4127-4144.

[17] L. Adriaenssens and P. Ballester, Chem. Soc. Rev. 42 (2013) 3261-3277.

[18] S.J. Rowan, S.J. Cantrill, G.R.L. Cousins, J.K.M. Sanders and J.F. Stoddart, Angew. Chem. Int. Ed. 41 (2002) 898-952.

[19] N.E. Borisova, M.D. Reshetova and Y.A. Ustynyuk, Chem. Rev. 107 (2007) 46-79.

[20] F.B.L. Cougnon and J.K.M. Sanders, Acc. Chem. Res. 45 (2012) 2211-2221.

[21] M.E. Belowich and J.F. Stoddart, Chem. Soc. Rev. 41 (2012) 2003-2024.

[22] J.M. Lehn, Chem. Soc. Rev. 36 (2007) 151-160.

[23] S.L. Huang, G.X. Jin, H.K. Luo and T.S.A. Hor, Chem. Asian J. 10 (2015) 24-42.

[24] R.W. Saalfrank, H. Maid and A. Scheurer, Angew. Chem. Int. Ed. 47 (2008) 8794-8824.

[25] Y.F. Han. W.G. Jia, W.B. Yu and G.X. Jin, Chem. Soc. Rev. 38 (2009) 3419-3434.

[26] R. Chakrabarty, P.S. Mukherjee and P.J. Stang, Chem. Rev. 111 (2011) 6810-6918.

[27] Y.F. Han and G.X. Jin, Acc. Chem. Res. 47 (2014) 3571-3579.

[28] R.A. Bilbeisi, J.C. Olsen, L.J. Charbonnière and A. Trabolsi, Inorg. Chim. Acta. 417 (2014) 79-108.

[29] J. Wang, H.B. Liu, Z.F. Tong and C.S. Ha, Coord. Chem. Rev. 303 (2005) 139-184.

[30] T.R. Cook and P.J. Stang, Chem. Rev. 115 (2015) 7001-7045.

[31] C.O. Dietrich-Buchecker and J.P. Sauvage, Chem. Rev. 87 (1987) 795-810.

[32] J.D. Crowley, S.M. Goldup, A.L. Lee, D.A. Leigh and R.T. Mcburney, Chem. Soc. Rev. 38 (2009) 1530-1541.

[33] J.C. Chambron and J.P. Sauvage, New J. Chem. 37 (2013) 49-57.

[34] J.F. Ayme, J.E. Beves, C.J. Campbell and D.A. Leigh, Chem. Soc. Rev. 42 (2013) 1700-1712. 
[35] M. Fujita and K. Ogura, Coord. Chem. Rev. 148 (1996) 249-264.

[36] M. Fujita, Acc. Chem. Res. 32 (1999) 53-61.

[37] J.K. Klosterman, Y. Yamauchi and M. Fujita, Chem. Soc. Rev. 38 (2009) 1714-1725.

[38] A.G. Orpen, Acta. Cryst. Sec. B, 58 (2002) 398-406.

[39] M. Xue, Y. Yang, X.D. Chi, X.Z. Yan and F.H. Huang, Chem. Rev. 115 (2015) 7398-7501.

[40] K.S. Jeong, J.S. Choi, S.Y. Chang and H.Y. Chang, Angew. Chem. Int. Ed. 39 (2000) 16921695.

[41] S.Y. Chang, J.S. Choi and K.S. Jeong, Chem. Eur. J. 7 (2001) 2687-2697.

[42] S.Y. Chang, H.Y. Jang and K.S. Jeong, Chem. Eur. J. 9 (2003) 1535-1541.

[43] S.Y. Chang and K.S. Jeong, J. Org. Chem. 68 (2003) 4014-4019.

[44] C.A. Hunter, C.M.R. Low, M.J. Packer, S.E. Spey, J.G. Vinter, M.O. Vysotsky and C. Zonta, Angew. Chem. Int. Ed. 40 (2001) 2678-2682.

[45] Y. Suzaki, E. Chihara, A. Takagi and K. Osakada, Dalton Trans. (2009) 9881-9891.

[46] G.H. Clever and M. Shionoya, Chem. Eur. J. 16 (2010) 11792-11796.

[47] C.F. Lee, D.A. Leigh, R.G. Pritchard, D. Schultz, S.J. Teat, G.A. Timco and R.E.P. Winpenny, Nature 458 (2009) 314-318.

[48] E.K. Brechin and L. Cronin, Angew. Chem. Int. Ed. 48 (2009) 6948-6949.

[49] B. Ballesteros, T.B. Faust, C.F. Lee, D.A. Leigh, C.A. Muryn, R.G. Pritchard, D. Schultz, S.J. Teat, G.A. Timco and R.E.P. Winpenny, J. Am. Chem. Soc. 132 (2010) 15435-15444.

[50] N.H. Evans and P.D. Beer, Chem. Soc. Rev. 43 (2014) 4658-4683.

[51] G. Agam, D. Graiver and A. Zilkha, J. Am. Chem. Soc. 98 (1976) 5206-5214.

[52] K.E. Griffiths and J.F. Stoddart, Pure Appl. Chem. 80 (2008) 485-506.

[53] M.S. Vickers and P.D. Beer, Chem. Soc. Rev. 36 (2007) 211-225.

[54] G.J.M. Gruter, F.J.J. de Kanter, P.R. Markies, T. Nomoto, O.S. Akkerman and F. Bickelhaupt, J. Am. Chem. Soc. 115 (1993) 12179-12180.

[55] M. Fujita, F. Ibukuro, K. Yamaguchi and K. Ogura, J. Am. Chem. Soc. 117 (1995) 4175-4176.

[56] M. Fujita, F. Ibukuro, H. Seki, O. Kamo, M. Imanari and K. Ogura, J. Am. Chem. Soc. 118 (1996) 899-900.

[57] M. Fujita, M. Aoyagi, F. Ibukuro, K. Ogura and K. Yamaguchi, J. Am. Chem. Soc. 120 (1998) 611-612.

[58] S. Prusty, S. Krishnaswamy, S, Bandi, B. Chandrika, J. Luo, J.S. Mclndoe, G.S. Hanan, D.K. Chand, Chem. Eur. J. 21 (2015) 15174-15187.

[59] T. Sawada, M. Yamagami, K. Ohara, K. Yamaguchi, M. Fujita, Angew. Chem. Int. Ed. 55 (2016) 4519-4522. 
[60] A. Hori, A. Akasaka, K. Biradha, S. Sakamoto, K. Yamaguchi and M. Fujita, Angew. Chem. Int. Ed. 41 (2002) 3269-3272.

[61] A. Hori, K.I. Yamashita and M. Fujita, Angew. Chem. Int. Ed. 43 (2004) 5016-5019.

[62] A. Hori, T. Sawada, K.I.Yamashita and M. Fujita, Angew. Chem. Int. Ed. 44 (2005) 48964899.

[63] K.I. Yamashita, M. Kawano and M. Fujita. J. Am. Chem. Soc. 129 (2007) 1850-1851.

[64] D.M.P. Mingos, J. Yau, S. Menzer and D.J. Williams, Angew. Chem. Int. Ed. 34 (1995) 18941895.

[65] C.P. McArdle, M.J. Irwin, M.C. Jennings and R.J. Puddephatt, Angew. Chem. Int. Ed. 38 (1999) 3376-3378.

[66] C.P. McArdle, J.J. Vittal and R.J. Puddephatt, Angew. Chem. Int. Ed. 39 (2000) 3819-3822.

[67] C.P. McArdle, M.C. Jennings, J.J. Vittal and R.J. Puddephatt, Chem. Eur. J. 7 (2001) 35723583.

[68] C.P. McArdle, M.J. Irwin, M.C. Jennings, J.J. Vittal and R.J. Puddephatt, Chem. Eur. J. 8 (2002) 723-734.

[69] W.J. Hunks, J. Lapierre, H.A. Jenkins and R.J. Puddephatt, J. Chem. Soc., Dalton Trans. (2002) 2885-2889.

[70] F. Mohr, M.C. Jennings and R.J. Puddephatt, Eur, J. Inorg. Chem. 2003 (2003) 217-223.

[71] C.P. McArdle, S. Van, M.C. Jennings and R.J. Puddephatt, J. Am. Chem. Soc. 124 (2002) 3959-3965.

[72] F. Mohr, D.J. Eisler, C.P. McArdle, K. Atieh, M.C. Jennings and R.J. Puddephatt, J. Organomet. Chem. 670 (2003) 27-36.

[73] N.C. Habermehl, M.C. Jennings, C.P. McArdle, F. Mohr and R.J. Puddephatt, Organometallics 24 (2005) 5004-5014.

[74] N.C. Habermehl, D.J. Eisler, C.W. Kirby, N.L.S. Yue and R.J. Puddephatt, Organometallics 25 (2006) 2921-2928.

[75] N.C. Habermehl, F. Mohr, D.J. Eisler, M.C. Jennings and R.J. Puddephatt, Can. J. Chem. 84 (2006) 111-123.

[76] S.L. Castro, O. Just and W.S. Rees, Angew. Chem. Int. Ed. 39 (2000) 933-935.

[77] T.S.M. Abedin, L.K. Thompson and D.O. Miller, Chem. Commun. (2005) 5512-5514.

[78] M. Ammann, A. Rang, C.A. Schalley and P. Bäuerle, Eur. J. Org. Chem. 2006 (2006) 19401948.

[79] P. Bäuerle, M. Ammann, M. Wilde, G. Götz, E. Mena-Osteritz, A. Rang and C.A. Schalley, Angew. Chem. Int. Ed. 46 (2007) 363-368.

[80] B.A. Blight, J.A. Wisner and M.C. Jennings, Angew. Chem. Int. Ed. 46 (2007) 2835-2838. 
[81] J.Z. Lu, D.R. Turner, L.P. Harding, L.T. Byrne, M.V. Baker and S.R. Batten, J. Am. Chem. Soc. 131 (2009) 10372-10373.

[82] T.J. Burchell, D.J. Eisler and R.J. Puddephatt, Dalton Trans. (2005) 268-272.

[83] D.C.R. Hovorka, D.C.G. Meyer-Eppler, D.C.T. Piehler, S. Hytteballe, M. Engeser, F. Topić, K. Rissanen and A. Lützen, Chem. Eur. J. 20 (2014) 13253-13258.

[84] H. Lee, P. Elumalai, N. Singh, H. Kim, S.U. Lee and K.W. Chi, J. Am. Chem. Soc. 137 (2015) 4674-4677.

[85] P.D. Beer and A.S. Rothin, Polyhedron 8 (1989) 1251-1252.

[86] A. Hori, H. Kataoka, T. Okano, S. Sakamoto, K. Yamaguchi and M Fujita, Chem. Commun. (2003) 182-183.

[87] C. Piguet, G. Bernardinelli, A.F. Williams and B. Bocquet, Angew. Chem. Int. Ed. 34 (1995) 582-584.

[88] L. Aboshyan-Sorgho, M. Cantuel, G. Bernardinelli and C. Piguet, Dalton Trans. 41 (2012) 7218-7226.

[89] D.J. Cárdenas and J.P. Sauvage, Inorg. Chem. 36 (1997) 2777-2783.

[90] C. Dietrich-Buchecker, N. Geum, A. Hori, M. Fujita, S. Sakamoto, K. Yamaguchi and J.P. Sauvage, Chem. Commun. (2001) 1182-1183.

[91] C. Dietrich-Buchecker, B. Colasson, M. Fujita, A. Hori, N. Geum, S. Sakamoto, K. Yamaguchi and J.P. Sauvage, J. Am. Chem. Soc. 125 (2003) 5717-5725.

[92] B. X. Colasson and J. P. Sauvage, Inorg. Chem. 43 (2004) 1895-1901.

[93] M. Beyler, V. Heitz and J.P. Sauvage, J. Am. Chem. Soc. 132 (2010) 4409-4417.

[94] D.J. Cárdenas, P. Gaviña and J.P. Sauvage, J. Am. Chem. Soc. 119 (1997) 2656-2664.

[95] D.J. Cárdenas, J.P. Collin, P. Gaviña, J.P. Sauvage, A.D. Cian, J. Fischer, N. Armaroli, L. Flamigni, V. Vicinelli and V. Balzani, J. Am. Chem. Soc. 121 (1999) 5481-5488.

[96] M.E. Padilla-Tosta, O.D. Fox, M.G.B. Drew and P.D. Beer, Angew. Chem. Int. Ed. 40 (2001) 4235-4239.

[97] W.W.H. Wong, J. Cookson, E.A.L. Evans, E.J.L. McInnes, J. Wolowska, J.P. Maher, P. Bishop and P.D. Beer, Chem. Commun. (2005) 2214-2216.

[98] D. Whang, K.M. Park, J. Heo, P. Ashton and K. Kim, J. Am. Chem. Soc. 120 (1998) 48994900.

[99] S.G. Roh, K.M. Park, G.J. Park, S. Sakamoto, K. Yamaguchi and K. Kim, Angew. Chem. Int. Ed. 38 (1999) 637-641.

[100] K.M. Park, S.Y. Kim, J. Heo, D. Whang, S. Sakamoto, K. Yamaguchi and K. Kim, J. Am. Chem. Soc. 124 (2002) 2140-2147. 
[101] Y.H. Ko, K. Kim, J.K. Kang, H. Chun, J. Lee, S. Sakamoto, K. Yamaguchi, J.C. Fettinger and K. Kim, J. Am. Chem. Soc. 126 (2004) 1932-1933.

[102] K. Wang, C.C. Yee, H.Y. Au-Yeung, Chem. Sci. 7 (2016) 2787-2792.

[103] M. Chas, E. Pia, R. Toba, C. Peinado and J.M. Quintela, Inorg. Chem. 45 (2006) 6117-6119.

[104] M. Chas, V. Blanco, C. Peinador and J.M. Quintela, Org. Lett. 9 (2007) 675-678.

[105] V. Blanco, M. Chas, D. Abella, C. Peinador and J.M. Quintela, J. Am. Chem. Soc. 129 (2007) 13978-13986.

[106] V. Blanco, D. Abella, E. Pía, C. Platas-Iglesias, C. Peinador and J.M. Quintela, Inorg. Chem. 48 (2009) 4098-4107.

[107] V. Blanco, A. Gutiérrez, C. Platas-Iglesias, C. Peinador and J.M. Quintela, J. Org. Chem. 74 (2009) 6577-6583.

[108] V. Blanco, M.D. García, C. Peinador and J.M. Quintela, Chem. Sci. 2 (2011) 2407-2416.

[109] C. Alvariño, A. Terenzi, V. Blanco, M.D. García, G. Peinador and J.M. Quintela, Dalton Trans. 41 (2012) 11992-11998.

[110] E.M. López-Vidal, M.D. García, C. Peìnador and J.M. Quintela, Chem. Eur. J. 21 (2015) 2259-2267.

[111] S.J. Li, J.Y. Huang, T.R. Cook, J.B. Pollock, H. Kim, K.W. Chi and P.J. Stang, J. Am. Chem. Soc. 135 (2013) 2084-2087.

[112] S.J. Li, J.Y. Huang, F.Y. Zhou, T.R. Cook, X.Z. Yan, Y. Ye, B. Zhu, B. Zheng and P.J. Stang, J. Am. Chem. Soc.136 (2014) 5908-5911.

[113] E. Viljoen, K. Zhu, S.J. Loeb, Chem. Eur. J. 22 (2016) 7479-7484.

[114] M. Yan, H.Y. Zhang, L.X. Yang, Z.J. Ding, R.J. Zhuang and Y. Liu, Eur. J. Org. Chem. 2011 (2011) 7271-7277.

[115] K.D. Johnstone, K. Yamaguchi and M.J. Gunter, Org. Biomol. Chem. 3 (2005) 3008-3017.

[116] G. Koshkakaryan, K. Parimal, J.M. He, X.Y. Zhang, Z. Abliz, A.H. Flood and Y. Liu, Chem. Eur. J. 14 (2008) 10211-10218.

[117] M.Á.A. García and N. Bampos, Org. Biomol. Chem. 11 (2013) 27-30.

[118] S.P. Black, A.R. Stefankiewicz, M.M.J. Smulders, D. Sattler, C.A. Schalley, J.R. Nitschke and J.K.M. Sanders, Angew. Chem. Int. Ed. 52 (2013) 5749-5752.

[119] J.F. Nierengarten, C.O. Dietrich-Buchecker and J.P. Sauvage, J. Am. Chem. Soc. 116 (1994) 375-376.

[120] C. Dietrich-Buchecker and J.P. Sauvage, Chem. Commun. (1999) 615-616.

[121] C.D. Pentecost, K.S. Chichak, A.J. Peters, G.W.V. Cave, S.J. Cantrill and J.F. Stoddert, Angew. Chem. Int. Ed. 46 (2006) 218-222. 
[122] C.D. Meyer, R.S. Forgan, K.S. Chichak, A.J. Peters, N. Tangchaivang, G.W.V. Cave, S.I. Khan, S.J. Cantrill and J.F. Stoddart, Chem. Eur. J. 16 (2010) 12570-12581.

[123] T. Prakasam, M. Lusi, M. Elhabiri, C. Platas-Iglesias, J. Olsen, Z. Asfari, S. CianféraniSanglier, F. Debaene, L.J. Charbonniére and A. Trabolsi, Angew. Chem. Int. Ed. 52 (2013) 99569960.

[124] J.E. Beves, J.J. Danon, D.A. Leigh, J.F. Lemonnier and I.J. Vitorica-Yrezabal, Angew. Chem. Int. Ed. 54 (2015) 7555-7559.

[125] N. Ponnuswamy, F.B.L. Cougnon, G.D. Pantoş and J.K.M. Sanders, J. Am. Chem. Soc. 136 (2014) 8243-8251.

[126] F. Ibukuro, M. Fujita, K. Yamaguchi and J.P. Sauvage, J. Am. Chem. Soc. 121 (1999) 110141015.

[127] C.P. McArdle, J.J. Vittal and R.J. Puddephatt, Angew. Chem. Int. Ed. 39 (2000) 3819-3822.

[128] C. Peinador, V. Blanco and J.M. Quintela, J. Am. Chem. Soc. 131 (2009) 920-921.

[129] T.K. Ronson, J. Fisher, L.P. Harding, P.J. Rizkallah, J.E. Warren and M.J. Hardie, Nat. Chem. 1 (2009) 212-216.

[130] J.E. Beves, C.J. Campbell, D.A. Leigh and R.G. Pritchard, Angew. Chem. Int. Ed. 52 (2013) 6464-6467.

[131] J.F. Ayme, J.E. Beves, C.J. Campbell and D.A. Leigh, Angew. Chem. Int. Ed. 53 (2014) 7823-7827.

[132] C. Schouwey, J.J. Holstein, R. Scopelliti, K.O. Zhurov, K.O. Nagornov, Y.O. Tsybin, O.S. Smart, G. Bricogne and K. Severin, Angew. Chem. Int. Ed. 53 (2014) 11261-11265.

[133] Y.H. Song, N. Singh, J. Jung, H. Kim, E.H. Kim, H.K. Cheong, Y. Kim, K.W. Chi, Angew. Chem. Int. Ed. 55 (2016) 2007-2011.

[134] T.J. Hubin, A.G. Kolchinski, A.L. Vance and D.H. Busch, Adv. Supramol. Chem. 5 (1999) 237-257.

[135] M. Schmittel, A. Ganz and D. Fenske, Org. Lett. 4 (2002) 2289-2292.

[136] J.C. Loren, M. Yoshizawa, R.F. Haldimann, A. Linden and J.S. Siegel, Angew. Chem. Int. Ed. 42 (2003) 5702-5705.

[137] S.H. Chiu, A.R. Pease, J.F. Stoddart, A.J.P. White and D.J. Williams, Angew. Chem. Int. Ed. 41 (2002) 270-274.

[138] Y. Liu, Tetrahedron Lett. 48 (2007) 3871-3874.

[139] R.S. Forgan, D.C. Friedman, C.L. Stern, C.J. Bruns and J.F. Stoddart, Chem. Commun. 46 (2010) 5861-5863.

[140] V. Vajpayee, Y.H. Song, T.R. Cook, H. Kim, Y. Lee, P.J. Stang and K.W. Chi, J. Am. Chem. Soc. 133 (2011) 19646-19649. 
[141] C. Mao, W.Q. Sun and N.C. Seeman, Nature 386 (1997) 137-138.

[142] K.S. Chichak, S.J. Cantrill, A.R. Pease, S.H. Chiu, G.W.V. Cave, J.L. Atwood and J.F. Stoddart, Science 304 (2004) 1308-1312.

[143] A.J. Peters, K.S. Chichak, S.J. Cantrill and J.F. Stoddart, Chem. Commun. (2005) 3394-3396.

[144] O.V. Dolomanov, A.J. Blake, N.R. Champness, M. Shröder and C. Wilson, Chem. Commun. (2003) 682-683.

[145] M. Schmittel, B. He, J. Fan, H.W. Bats, M. Engeser, M. Schlosser and H.J. Deiseroth, Inorg. Chem. 48 (2009) 8192-8200.

[146] Y.F. Han, Y.J. Lin, W.G. Jia, G.L. Wang and G.X. Jin, Chem. Commun. (2008) 1807-1809.

[147] Y.F. Han, W.G. Jia, Y.J. Lin and G.X. Jin, Angew. Chem. Int. Ed. 48 (2009) 6234-6238.

[148] G.L. Wang, Y.J. Lin, H. Berke and G.X. Jin, Inorg. Chem. 49 (2010) 2193-2201.

[149] W.B. Yu, Y.F. Han, Y.J. Lin and G.X. Jin, Organometallics 29 (2010) 2827-2830.

[150] W.B. Yu, Y.F. Han, Y.J. Lin and G.X. Jin, Chem. Eur. J. 17 (2011) 1863-1871.

[151] G.L. Wang, Y.J. Lin and G.X. Jin, Chem. Eur. J. 17 (2011) 5578-5587.

[152] T. Wu, L.H. Weng and G.X. Jin, Chem. Commun. 48 (2012) 4435-4437.

[153] Z.J. Yao, W.B. Yu, Y.J. Lin, S.L. Huang, Z.H. Li and G.X. Jin, J. Am. Chem. Soc. 136 (2014) 2825-2832.

[154] H. Li, Y.F. Han, Y.J. Lin, Z.W. Guo and G.X. Jin, J. Am. Chem. Soc. 136 (2014) 2982-2985.

[155] Y.Y. Zhang, X.Y. Shen, L.H. Weng and G.X. Jin, J. Am. Chem. Soc. 136 (2014) 1552115524.

[156] S.L. Huang, Y.J. Lin, T.S.A. Hor and G.X. Jin, J. Am. Chem. Soc. 135 (2013) 8125-8128.

[157] S.L. Huang, Y.J. Lin, Z.H. Li and G.X. Jin, Angew. Chem. Int. Ed. 53 (2014) 11218-11222.

[158] T. Kim, N. Singh, J. Oh, E.H. Kim, J. Jung, H. Kim, K.W. Chi, J. Am. Chem. Soc. 138 (2016) 8368-8371.

[159] O. Lukin and F. Vögtle, Angew. Chem. Int. Ed. 44 (2005) 1456-1477.

[160] C.O. Dietrich-Buchecker and J.P. Sauvage, Angew. Chem. Int. Ed. 28 (1989) 189-192.

[161] J.F. Ayme, J.E. Beves, C.J. Campbell and D.A. Leigh, Chem. Soc. Rev. 42 (2013) 17001712.

[162] B. Hasenknoph, J.M. Lehn, B.O. Kneisel, G. Baum and D. Fenske, Angew. Chem. Int. Ed. 35 (1996) 1838-1840.

[163] B. Hasenknoph, J.M. Lehn, N. Boumediene, A. Gupontg-Gervais, A.V. Dorsselaer, B. Kneisel and D. Fenske, J. Am. Chem. Soc. 119 (1997) 10956-10962.

[164] J.F. Ayme, J.E. Beves, D.A. Leigh, R.T. McBurney, K. Rissanen and D. Schultz, J. Am. Chem. Soc. 134 (2012) 9488-9497. 
[165] J.F. Ayme, J.E. Beves, D.A. Leigh, R.T. McBurney, K. Rissanen and D. Schultz, Nat. Chem. 4 (2012) 15-20.

[166] D.A. Leigh, R.G. Pritchard and A.J. Stephens, Nat. Chem. 6 (2014) 978-982.

[167] P.E. Barran, H.L. Cole, S.M. Goldup, D.A. Leigh, P.R. McGonigal, M.D. Symes, J. Wu and M. Zengerle, Angew. Chem. Int. Ed. 50 (2011) 12280-12284.

[168] F. Li, J.K. Clegg, L.F. Lindoy, R.B. Macquart and G.V. Meehan, Nat. Commun. 2 (2011) 205-209.

[169] D.M. Engelhard, S. Freye, K. Grohe, M. John and G.H. Clever, Angew. Chem. Int. Ed. 51 (2012) 4747-4750.

[170] P.F. Cao, J. Mangadlao and R. Advincula, Angew. Chem. Int. Ed. 54 (2015) 5127-5131.

[171] M. Frank, M.D. Johnstone, G.H. Clever, Chem. Eur. J. 22 (2016) doi: 10.1002/chem.201601752.

[172] M. Fujita, N. Fujita, K. Ogura and K. Yamaguchi, Nature 400 (1999) 52-55.

[173] Y. Yamauchi, M. Yoshizawa and M. Fujita, J. Am. Chem. Soc. 130 (2008) 5832-5833.

[174] Y. Yamuchi, Y. Hanaoka, M. Yoshizawa, M. Alita, T. Ichikawa, M. Yoshio, T. Kato and M. Fujita, J. Am. Chem. Soc. 132 (2010) 9555-9557.

[175] J. Heine, J.S. Günne and S. Dehnen, J. Am. Chem. Soc. 133 (2011) 10018-10021.

[176] A. Westcott, J. Fisher, L.P. Harding, P. Rizkallah and M.J. Hardie, J. Am. Chem. Soc. 130 (2008) 2950-2951.

[177] J.J. Henkelis, T.K. Ronson, L.P. Harding and M.J. Hardie, Chem. Commun. 47 (2011) 65606562.

[178] M. Fukuda, R. Sekiya and R. Kuroda, Angew. Chem. Int. Ed. 47 (2008) 706-710.

[179] R. Sekiya, M. Fukuda and R. Kuroda, J. Am. Chem. Soc. 134 (2012) 10987-10997.

[180] Y.H. Li, J.J. Jiang, Y.Z. Fan, Z.W. Wei, C.X. Chen, H.J. Yu, S.P. Zheng, D. Fenske, C.Y. Su, M. Barboiu, Chem. Commun. 52 (2016) 8745-8748.

[181] S. Freye, J. Hey, A. Torras-Galán, D. Stalke, R. Herbst-Irmer, M. John, G.H. Clever, Angew. Chem. Int. Ed. 51 (2012) 2191-2194.

[182] J.M. Dieterich, G.H. Clever and R.A. Mata, Phys. Chem. Chem. Phys. 14 (2012) 1274612749.

[183] S. Freye, D.M. Engelhard, M. John and G.H. Clever, Chem. Eur. J. 19 (2013) 2114-2121.

[184] S. Freye, R. Michel, D. Stalke, M. Pawliczek, H. Frauendorf and G.H. Clever, J. Am. Chem. Soc. 135 (2013) 8476-8479.

[185] M. Frank, J. Hey, I Balcioglu, Y.S. Chen, D. Stalke, T. Suenobu, S. Fukuzumi, H. Frauendorf and G.H. Clever, Angew. Chem. Int. Ed. 52 (2013) 10102-10106. 
[186] M. Frank, J.M. Dieterich, S. Freye, R.A. Mata and G.H. Clever, Dalton Trans. 42 (2013) 15906-15910.

[187] M. Frank, L. Krause, R. Herbst-Irmer, D. Stalke and G.H. Clever, Dalton Trans. 43 (2014) 4587-4592.

[188] S. Löffler, J. Lübben, L. Krause, D. Stalke, B. Dittrich and G.H. Clever, J. Am. Chem. Soc. 137 (2015) 1060-1063.

[189] R.M. Zhu, J. Lübben, P. Doz, B. Dittrich and G.H. Clever, Angew. Chem. Int. Ed. 54 (2015) 2796-2800.

[190] M. Frank, J. Ahrens, I. Bejenke, M. Krick, D. Schwarzer, G.H. Clever, J. Am. Chem. Soc. 138 (2016) 8279-8287.

[191] A.K. Bar, G. Mostafa and P.S. Mukherjee, Inorg. Chem. 49 (2010) 7647-7649.

[192] A.K. Bar, S. Raghothama, D. Moon and P.S. Mukherjee, Chem. Eur. J. 18 (2012) 3199-3209.

[193] D. Samanta and P.S. Mukherjee, J. Am. Chem. Soc. 136 (2014) 17006-17009.

[194] A. Mishra. A. Dubey, J.W. Min, H. Kim, P.J. Stang and K.W. Chi, Chem. Commun. 50 (2014) $7542-7544$. 
(Graphic Abstract)

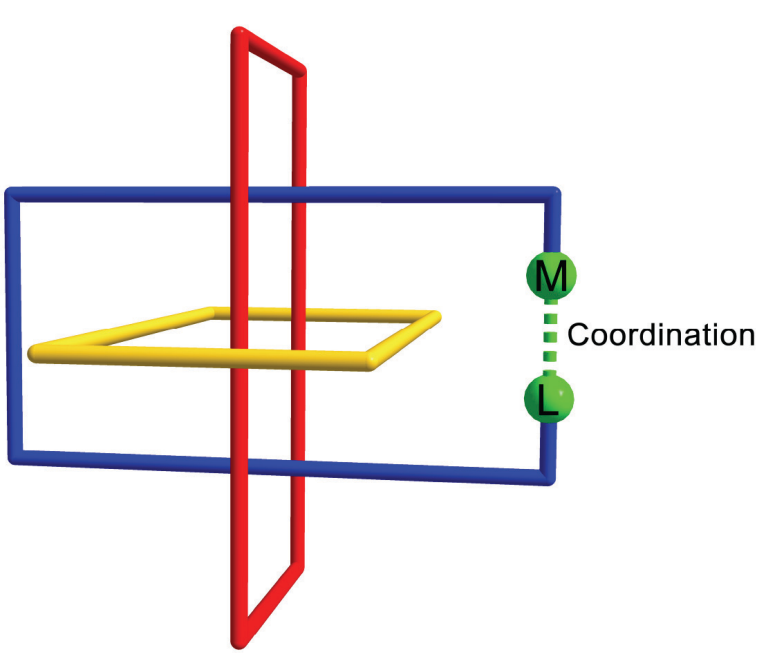

